\title{
LIGAND BRIDGING IN THE OXIDATION OF CHROMIUM(II) AT MERCURY ELECTRODES
}

\author{
Thesis by \\ Janet Gretchen Jones
}

In Partial Fulfillment of the Requirements

For the Degree of

Doctor of Philosophy

\author{
CaIffornia Institute of TechnoIogy \\ Pasadena, California \\ 1967
}

(Submitted June 30, 1966) 


\section{Copyright (C) by}

JAINET GRETCHEIN JONES

1367 
Dedicated to

Thomas Armstrong Peebles

$1882-1965$ 


\section{ACKNOWLEDGMENTS}

My advisor, Fred C. Anson, has contributed immeasurably to my education through his imperturbable even temper and his continuing enthusiasm for his work and mine.

Much of the work described in this thesis woulc have been impossible, and my graduate education would have been much poorer, without many helpful alscussions wilh and much maberlal assiblance from Juseplı Christie and George Lauer, to whom I owe a large debt.

I am also incebted to W1liam $P$. Schaefer, who has generously shorea with me his wide experience in chromium chemistry.

Financial support from the NSF, Woodrow Wilson Foundation, and the ARCS Foundation has been much appreciated.

Many people have contributed to my professional anà personal education. I can only name those who otherwise would be unknown or forgotten: John St.-Sure, Gilbert Haight, Peter Thompson, Carl Niemann, and finally, that small army of Caltech students who believed I could help them by listening to their troubles. 


\section{ABSTRACT}

Controlled potential electrolysis and electrochemical relaxation techniques have been used to investigate the mechanism of oxidation of chromium(II) at mercury electrodes in the presence of chloride, bromide, and ioaide. It is shown that the major path for the oxidation is through a bridged activated complex of the type $\mathrm{Hg}--\mathrm{X}--\mathrm{Cr}$.

Kinetic parameters have been determined for the bromide-dependent path and the halide-independent path. Equations have been derivea to predict from kinetic data the product distribution between two competing reactions.

It is suggested that the activated complex is formed with halide adsorbed on the electrode surface.

The limitations of chronopotentiometry at hanging mercury drop electrodes have been investigated and corrections are given for spherical diffusion effects at times greater than 0.1 sec. It is demonstrated that reverse current chronopotentiometry under these conditions is a qualitatively unreliable technique. 
PART I. GENERAI INTRODUCTION

Chapter

Page

1. INTRODUCTICN . . . . . . . . . . . . . 2

2. EXPERTMENTAL CONSIDERATIONS . . . . . . . . . . . 7

I. The Preparation of Chromium(II) Solutions . . . 7

II. Analysis of Chromium(II) Solutions . . . . . . . 13

III. Cxidation-Reduction Reactions of

Chromium(II) anä Chromium(III) . . . . . . 14

1. The Oxidation of $\operatorname{Cr}\left(\perp_{i}\right)$ and $\operatorname{Cr}($ III $)$

by Perchlorate........... 14

2. The Oxidation of $\mathrm{Cr}$ (II) by Nitrate... . 14

IV. The Rates of Aquation of Halide Complexes

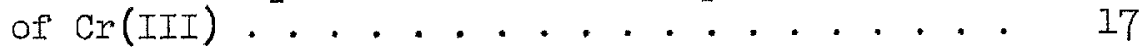

1. The Rate of Aquation of $\mathrm{CrCl}^{2^{+}}$...... 18

2. The Rate of Aquation of $\mathrm{CrBr}^{2}$...... 18

3. The Effect of $\operatorname{Cr}$ (II) on the Rate of Aquation of $\mathrm{CrBr}^{+}$........... . 20

4. Polarographic Determinatior of the Rate of Aquation of $\mathrm{CrBr}^{2^{+}}$......... . pp

5. Discussion............. . 23

PART II. EVIDENCE FOR THE LIGAND BRIDGING MECHANISN

Chaptier

Page

3. CONTROLIED POTENTIAL OXIDATION OF CIROMIUM(II) IN THE PRESENCE OF CHIORIDE . . . . . . . . . . . 26

4. CHRONOPOTENTIOMETRIC INVESTIGATION OF THE OXIDATION OF CHROMIUM(II) IN THE PRESENCE OF CHLORIDE . . . . . . 33

I. Chronopotentiometric Behavior of $\mathrm{Cr}$ (II)

In the Absence of Chloride......... . 38

1. The Variation of the Chronopotentiometric Constant with Current Density . . . 38

2. Reverse Current Chronopotentiometric Behavior ............ . . 38 
II. Chronopotentiometric Behavior of $\operatorname{Cr}$ (II)

in the Presence of Chloride ........ 40

1. Variation of the Cnronopotentiometric Constant with Current Density ..... 40

2. The Reverse Current Chronopotentiometric Behavior .......... 42

3. The Chronopotentiometric Behavior of $\mathrm{CrCl}^{2^{+}}$.............. 42

III. Experimental Details............. 44

IV. Discussion. . . . . . . . . . . . 52

5. THE OXIDATION OF CR(II) AT MERCURY ELECTRODES

IN BROMIDE SOLUTIONS.............. 54

I. Cironopotentiometric Behavior ........ . 56

1. Variation of the Chronopotentiometric Constant with Current Density;

Solutions Containing Excess Bromide * . . 56

2. Dependence of the oxidation of $\mathrm{Cr}$ (II) on Bromide Concentration ........ 56

3. Reverse Current Chronopotentiometric Behavior; Large Excess Bromide . . . . . . 66

4. Solutions with Low Bromide Concentration . . 68

5. Summary and Discussior. . . . . . . . 72

II. Double Potential Step Chronocoulometric

Behavior................ 73

1. The Reduction of $\mathrm{CrBr}^{2}$......... 73

2. The Inclusion of Bromide in $\mathrm{Cr}(I I)$ Oxication ............. . . 77

3. Discussion ............. . . 82

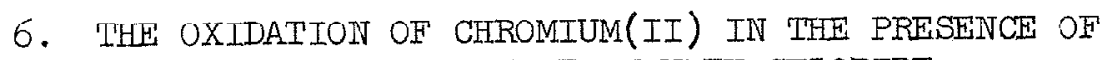
IODIDE: RATE COMPETITION WITH CHLORIDE . . . . . .

I. Cyclic Voltammetry of Chromium(II) in Iodide Solutions ............

II. Controlled Potential Elcctrolyois of $\mathrm{Cr}$ (II) Solutions: Oxidation in the Presence of Chloride-Iodide Mixtures . . . . . . . . 
Chapter

Page

7. THE RATE OF OXIDALION OF CHROMLUM(II) . . . . . . . . 97

I. Kinetic Parameters for the Couple $\operatorname{Cr}($ II)/ $\mathrm{Cr}^{+}$in Perchlorate Solutions ....... 98

1. The Rate of Recuction of $\mathrm{Cr}^{3^{+}}$. . . . . 98

2. The Rate of Oxidatior of $\operatorname{Cr}$ (II) ..... 100

3. Summary and Discussion......... 106

II. Kinetic Parameters for the Couplc $\mathrm{Cr}$ (II)/CrCl $2^{+}$. 109

III. Kinetic Parameters for the Couple $\mathrm{Cr}$ (II)/

$\operatorname{Cr}($ III) in Bromide Solution .......... 109

1. Caronopotentiometric Measurement of the Rate of Oxicition of Cr(TT) in Dilute

Bromide Solution . . . . . . . . . . 111

2. Polarographic Determination of the Bromide Dependence of the Rate of Cr(II) Oxidation . . . . . . . . . . 112

3. Polarographic Determination of the Rate of Reduction of $\mathrm{CrBr}^{+}$. . . . . . . 118

4. Discussion............. 118

IV. The Relation Between the Kinetic Parameters and Mechanism . . . . . . . . . . 122

APPEIDICES

I. CHRONOPOTENTIOMETRY AT HANGING MERCURY DROP ELECTRODES:

THE EFHECTS OF SPHERICAL DIFEUSION . . . . . . . . . 129

Correction of the Forward Transition Time . . 130

Chronopotentiometry with Current Reversal:

Correction of the Transition Time Ralio . . 138

II. PARALIEL REACTIONS . . . . . . . . . . . . I50

III. REVERSE CURRENI CHRONOPOTENTIOMETRY: REVERSAL AFTER

THE TRANSITION ITME . . . . . . . . . . . . 156 


\section{LIST OF FIGURES}

F1gure

Page

1. Electrolysis cell for preparing $\operatorname{Cr}($ II) solutions . . . . 8

2. Storage buret for $\operatorname{Cr}(I I)$ solutions........... 10

3. The absorbance of a solution formed by adding $10 \mathrm{mI}$. of $\mathrm{Cr}$ (II) stock solution to $190 \mathrm{ml}$. of $0.1 \mathrm{~F} \mathrm{HClO}_{4}$, $0.9 \mathrm{~F} \mathrm{NaClO}_{4}$ and $10 \mathrm{ml}$. $0.1 \mathrm{~F} \mathrm{NaNO}_{3}$. . . . . . . . . 16

4. The controlled potential oxidation of $\mathrm{Cr}$ (II) in chloride solutions. . . . . . . . . . . . . .

5. Cell used in controlled potential electrolysis of $\operatorname{Cr}$ (II) solutions.................. 30

6. Chronopotentiometric behavior of $\mathrm{Cr}$ (II) in the ahsence of complexing liganàs . . . . . . . . 36

7. Chronopotentiometric behavior of $\mathrm{Cr}$ (II) in the presence of chloride . . . . . . . . . . . . .

8. Constancy of the chronopotentiometric constant as a function of current for $\mathrm{Cr}$ (II) oxidation in the absence of complexing ligands . . . . . . . . .

9. Constancy of the chroropotentiometric constant as a function of current for $\mathrm{Cr}$ (II) oxication in the presence of chloride...............

10. Constancy of $\left(i T^{\frac{1}{2}}\right)^{\prime}$ with current for the reduction of $\mathrm{CrCl}^{+}$.................... . . . 43

11. Circuit used in chronopotentiometric experiments. . . . . 45

12. Cell used in chronopotentiometric experiments . . . . . 47

13. Cell inserts. See Figure 12............. 48

14. Chronopotentiometric wave wilh curreal reversal for $\operatorname{Cr}$ (II) in bromide solution... . . . . . . . 55

15. Conotancy of the chronopotentiometric constant as a function of current for $\mathrm{Cr}$ (II) oxidation in the presence of bromide . . . . . . . . . . . 
Figure

Page

16. Chronopotentiometric behavior of $\mathrm{Cr}$ (II) in solutions containing small amounts of bromide . . . . 58

17. Variation of $17^{\frac{1}{2}}$ with eurrent for the oxidation of mercury in bromide solution . . . . . . . . . .

18. Cell nsed for electrochemical studies on $\mathrm{Cr}$ (IT) solutions ..................

19. Reverse current chronopotentiometric behavior of $\mathrm{Cr}$ (II) in bromide solution . . . . . . . . .

20. Reverse current chronopotentiometric behavior for an ideal system, Fe(II) in pyrophosphate. . . . .

21. Typical double potential step chronocoulometric behavior....................

22. Potential step behavior for $\mathrm{CrBr}^{2+}$ reduction .......

23. Reduced time function plot of double potential step chronocoulometric behavior for Cr(II)

24. Cyclic voltammetry of $\mathrm{Cr}$ (II) in iodide solution . . . . 86

25. Cyclic voltammetry of $\mathrm{Cr}(\mathrm{II})$ in iodide solution . . . . 87

26. Cyclic yoltammetry of $\mathrm{Cr}(\mathrm{II})$ in iodidc colution . . . . 88

27. Cyclic voltammetry of $\mathrm{Cr}$ (II) in iodide solution . . . . 89

28. Cyclic voltammetry of $\mathrm{Cr}$ (II) in iodide solution . . . . 90

29. The effect of iodide on the inclusion of chloride in the controlled potential oxidation of $\operatorname{Cr}(I I) . . . .93$

30. Semi-logarithmic plot of $\lambda$ as a function of potential for the polarographic reduction

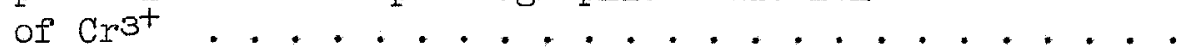

31. Semi-logarithmic plot of $\lambda t^{\frac{1}{2}}$ as a function of potential for the potential step chronocoulometric oxidation of $\mathrm{Cr}$ (II) . . . . . . . . . .

32. Semi-logarithmic plot of the potential dependence of the rate of the reaction $\mathrm{Cr}^{2^{+}} \rightarrow \mathrm{Cr}^{3^{+}}+e^{-}$ from the data of Aikens and Ross (6)......... 
33. Normalized polarogram for the kinetic parameters

$$
\begin{aligned}
& \mathrm{k}_{\mathrm{h}}{ }^{\circ}=10^{-5} \mathrm{~cm} / \mathrm{sec} \text {, and } \alpha=0.63 \text { with } \mathrm{n}=1, \mathrm{D}^{\frac{1}{2}}= \\
& 0.00254, \mathrm{~T}=27^{\circ} \mathrm{C} . . . . . . . . . . .108
\end{aligned}
$$

34. Semi-logarithmic plot of the potential dependence of the rate of the reaction $\mathrm{Cr}^{+}+\mathrm{Cl}^{-} \rightarrow \mathrm{CrCl}^{+}$ $+e^{-}$from the data of Aikens and Ross (6) . . . . . .

35. Chronopotentiometric determination of the rate of $\mathrm{Cr}$ (II) oxidation in dilute bromide solutions ......

36. The variation of the rate of $\mathrm{Cr}$ (II) oxidation with bromide concentration ...............

37. Semi-logarithmic plot of the potential dependence of the rate of the reaction $\mathrm{Cr}^{2+}+\mathrm{Br}^{-} \rightarrow \mathrm{CrBr}^{+}+e^{-}$.

38. Nermst plot for the polarographic reduction of $\mathrm{CrBr}^{2^{+}}$ in $0.91 \mathrm{~F} \mathrm{NaBr}, 0.066 \mathrm{~F} \mathrm{HClO}_{4}$ solution illustrating Kuryla's melhod or delermination of the reference potential . . . . . . . . . . . . . .

39. Semi-logarithmic plot of the potential dependence of the rate of reduction of $\mathrm{CrBr}^{+}$from polarographic measurements . . . . . . . . . . . . 120

40. The $\psi$ potential as a function of potential from the work of Gierst (42) ............. 124

I-1. The correction factor for spherical diffusion . . . . . 133

I-2. Hanging mercury drop electrode. . . . . . . . . . 134

I-3. Transition time dependence of the $i T^{\frac{1}{2}}$ product for

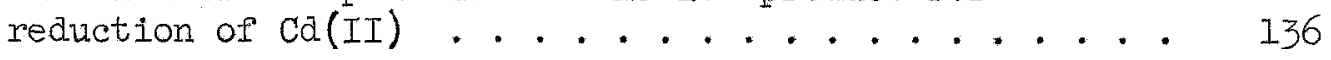

I-4. Variation of the transition time ratio with forward time for spherical diffusion . . . . . . . . 140

I-5. Working curve for the correction factor for transition time ratios.............. 141

I-6. Working curve for the correction factor for transition time ratios............. 142

I-7. Chronopotentiometric wave with current reversal for $30 \mathrm{mF} \mathrm{FeSO}_{4}$ in $0.5 \mathrm{~F} \mathrm{Na}_{4} \mathrm{P}_{2} \mathrm{O}_{7}$ at $\mathrm{pH} 2 \ldots . . . .144$ 
T-8. The effect of spherical diffusion on transition time ratios . . . . . . . . . . . . 145

I-9. Illustration of the pronounced current density dependence of the data shown in Figure I-8. . . . . . 146

I-10. Illustration of the pronounced deviation of the data of Figure I-8 from the predicted behavior for spherical diffusion . . . . . . . . . . 147

1-11. The dependence of the deviation of the data of Figure I-8 from ideal behavior on it . . . . . . . . 148

III-1. Qualitative belavior for reverse current chronupotentiometry with reversal after the transition time .................. 
$P A R T I$

GEIUERAL INTRODUCTION 
Chapter 1

INTRODUCTION

As early as 1947 Heyrovsky (1) suggested that the accelerating effect of jalide ions on the irreversible reduction of many metal ions at mercury electrodes is due to the ahility of adsoribed halide to act as an efficlent bridge for electron transfer. The vigor with which research is presently being carried on in the area of ligand bridging both in homogeneous solution ano electrode reactions is an appropriate comment on Heyrovsky's insight. This thesis is concerned with the study of the role of briaging ligands in the oxidation of $\mathrm{Cr}$ (II) at mercury electrodes.

The basic ideas of the bridging mechanism in homogeneous reactions are well known (2) and do not need further discussion here. The extension to heterogeneous reactions is less generally known and deserves some comment.

Halides with the exception of fluoride are strongly adsorbed or mercury electrodes at potentials anodic to the null charge potential. The basic idea of the extension of the concept of ligand bridging to electrode reactions is to consider the combination of electrode and adsorbed ligand as analogous to a metal lon-ligand complex, and then to draw the parallel between the homogeneous reaction

$$
\mathrm{MX}^{+\mathrm{L}}+{ }^{*} \mathrm{M}^{+\mathrm{E}} \longrightarrow\left(\mathrm{MX}^{*} \mathrm{M}\right)^{+\mathrm{n}+\mathrm{m}}
$$


and the heterogeneous reaction

$$
\mathrm{Hg}(\mathrm{X})_{\text {aãs }}+\mathrm{M}^{+n} \longrightarrow \mathrm{Hg}\left(\mathrm{XN}^{+n}\right)_{\text {ads }}
$$

where the products in (I) and (2) are the reactive intermediates or transition states for the electron transfer reactions.

If one wishes to study reactions of the type

$$
\mathrm{Hg}\left(\mathrm{X}^{-}\right)_{\mathrm{ads}}+\mathrm{M}^{+\mathrm{n}} \stackrel{-\mathrm{e}^{-}}{\longrightarrow} \mathrm{MX}^{+\mathrm{n}}
$$

the use of $\operatorname{Cr}(I I)$ as $\mathrm{M}^{\mathrm{n}}$ is particularly attractive. When $\mathrm{X}$ is chloride, the supposed product of the reaction, $\mathrm{CrCl}{ }^{+},{ }^{*}$ though thermodynamically unstable, is sufficiently substitution inert that solutions of $\mathrm{CrCl}^{2+}$ can be titrated with silver ion without appreciable decomposition of the complex. Tinis provides a substantial simplification of the problem of product analysis.

A second reason for the choice of Cr(II) for the study of ligand brlaglng in electrochemical reactions is that it is oxidized in the range 0 to $-0.5 \mathrm{v}$. Vs. $5 \mathrm{CE}$, the potential range of major interest for mechanisms involving halide adsorption.

An ancillary factor favorine the choice of $\mathrm{Cr}(I I)$ is the large amount of work that has been done on the role of ligand bridging in the homogeneous oxidation of $\operatorname{Cr}(\mathrm{II})(3)$; this work serves as a guide and comparison for electrochemical studies.

*For simplicity coordinated water molecules will not be included in complex ion formulas. The formula GrCl2t, for instance, is intended to imply the complex ion $\mathrm{Cr}\left(\mathrm{H}_{2} \mathrm{O}\right)_{5} \mathrm{Cl}^{+}$. 
It has been shown that many ligands dramatically affect the electrochemical oxidation of $\mathrm{Cr}(\mathrm{II})$. Pecsok and Iingane (4) have investigated the polarographic behavior of $\mathrm{Cr}(\mathrm{II})$ in the presence of $\mathrm{KCl}$, $\mathrm{KSCN}, \mathrm{CaCl}_{2}, \mathrm{Me}_{4} \mathrm{NBr}$, and several carboxylic acids. Large changes in apparent half-wave potential and in the degree of irreversibility of the oxidation were found by changing the nature of the supporting electrolyte solution.

Kemula and Rakowska (5), who studied the reduction of various $\operatorname{Cr}$ (III) species using cyclic voltammetry, present some interesting qualitative results. They found that when $\mathrm{Cr}^{3^{+}}$is reduced in chloride solutions, on the second cycle of cathodic polarization a second peak appears anodic to the peak initially observed for the reduction of $\mathrm{Cr}^{3^{+}}$. As the concentration of chloride in the supporting electrolyte solution is increased, this peak becomes larger and more clearly separated from the $\mathrm{Cr}^{3^{+}}$peak. The potential at which this peak occurs is the same as that for the reduction of $\mathrm{CrCl}^{+}$obtained from the calt $\mathrm{CrCl}_{3} \cdot \mathrm{l}_{\mathrm{H}} \mathrm{O}$. Aikens and Ross (6) have studied the rates of oxidation of Cr(II) at mercury electrodes in the presence of fluoride, chloride, and iodide. They found that the rate of $\mathrm{Cr}(\mathrm{TT})$ oxidation is proportional to the concentration of chloride over a fifty-fold change in chloride concentration, and that at a fixed potential, the accelerating effect of the halides decreases in the order $\left(\mathrm{I}^{-}\right)>\left(\mathrm{CI}^{-}\right) \gg\left(\mathrm{F}^{-}\right)$, the effect of fluoride being very small. They point out that the tendency for specific adsorption of halides also decreases in this order, while the stability of the $\operatorname{Cr}(I I)$ halides probably increases markedly in the same order. 
It has not been understood how halides increase the rate of oxidation of $\operatorname{cr}$ (II) at mercury electrodes. In the case of chloride we have a model system which gives us an opportunity to identify unambiguously gross features of the mechanism. $\operatorname{Cr}($ III) is sufficiently inert to chloride substitution that the reaction

$$
\mathrm{Cr}^{3^{+}}+\mathrm{CI}^{-} \longrightarrow \mathrm{CrCl}^{2+}
$$

may be ignored as a source of the complex $\mathrm{CrCl}^{2^{+}}$. Therefore if the product of electro-oxidation of $\mathrm{Cr}$ (II) in chloride solutions is $\mathrm{CrCl}^{2+}$ the transition state must contain chloride. But since the tendency for $\mathrm{CrCl}^{+}$formation is very small (7) this implies that the chloride in the transition state 1 intimately involved in the mechanism. The only way for this to be true is for the chloride to be bound to the chromium and also to interact strongly with the electrode surface. The only plausible coherent mechaniom with these characteriotico io that of halide bridged electron transfer. If the product of electro-oxidation of $\mathrm{Cr}$ (II) in chloride solutions is found to be $\mathrm{CrCl}^{+}$the bridge mechanism is established and any arguments about a more detafiled description of the mechanism do not change or challenge the validity of this conclusion. Chapters 3-6 of this thesis present experimental results which imply the bridge mechanism.

When it has been shown that the bridged transition state or intermediate is necessary to the mechanism, the question arises of how the bridged state is formed. The reaction may proceed primarily through the complex $\mathrm{CrCl}^{+}$; alternatively the key to the mechanism may be found in considering the analogy between halide adsorbed on a mercury surtace 
and halide in a complex oxidizing agent. From the latter viewpoint, the reaction can best be explained by electron transfer to the electrode from chromium via the chloride bridge. This proposed mechanism is quite general and may be used to explain a wide variety of electrochemical reactions.

The simplicity of this idea is not matched by its susceptibility to experimental verification. The difficulty lies in the large nonspecific effects which the halides have on irreversible reactions due to the effect of their adsorption on the structure of the electric double layer (8). A priort descriptions of the nature of the double layer in the presence of specifically adsorbed ions are not yet available, and very little data of adequate quality has been obtained to attack this problem. Also, the nature and extent of the adsorption itself is incompletely understood.

This means that any progress in understanding the details of the briage state formation must rest on the patient accumulation and comparison of data on the oxidation of $\mathrm{Cr}$ (II) under a variety of conditions. It seems unlikely that so complex a system can be made to yiela its secrets with a few cleverly designed experiments.

Chapter 7 of this thesis presents more detailed arguments about the nature of the bridging mechanism with supporting experimental evidence. 
Chapter 2

EXPERTMENTAL CONSIDERATIONS

During the course of this work the procedures and apparatus directly concemed with $\operatorname{Cr}($ II) solutions have been successively and somewhat successfully modified to give better results than did the original designs. As an aid to the interested experimenter this material is collected here together with some pertinent comments on chromium chemistry.

\section{The Preparation of Chromium(II) Solutions}

The most satisfactory general method of preparing $\mathrm{Cr}$ (II) solutions is by electrolysis of $\mathrm{Cr}$ (III) solutions at a mercury cathode. The $\operatorname{Cr}$ (III) solution for electrolysis is prepared by hydrogen peroxide reduction of a perchloric acid solution of sodium dichromate followed by heating in the presence of platinized platinum to decompose the excess peroxide. The resulting solution has the characterlstic violet color of $\mathrm{Cr}^{3^{+}}$.

Stock solutions $0.2 \mathrm{~F}$ In $\mathrm{Cr}$ (III) and $2 \mathrm{~F}$ in $\mathrm{HClO}_{4}$ were prepared In this manner. Solutions for electrolysis were $300 \mathrm{ml}$. of $\mathrm{Cr}$ (III) stock solution diluted 1:I with water. The resulting $\mathrm{Cr}$ (II) solutions typ1cally were $0.09 \mathrm{~F}$ in $\mathrm{Cr}(\mathrm{II}), 1.0 \mathrm{~F}$ in $\mathrm{HClO}_{4}(\mu=1.5)$.

The electrolysis is carried out in the three compartment cell shown in $\mathrm{F} 1$ gure 1 . A continuous flow of $1 \mathrm{~F} \mathrm{HClO} \mathrm{O}_{4}$ is maintained through the center compartment throughout the course of the electrolysis to complebly isulabe line cabiode cumparlmenl from line dnode comparbmenl. The 


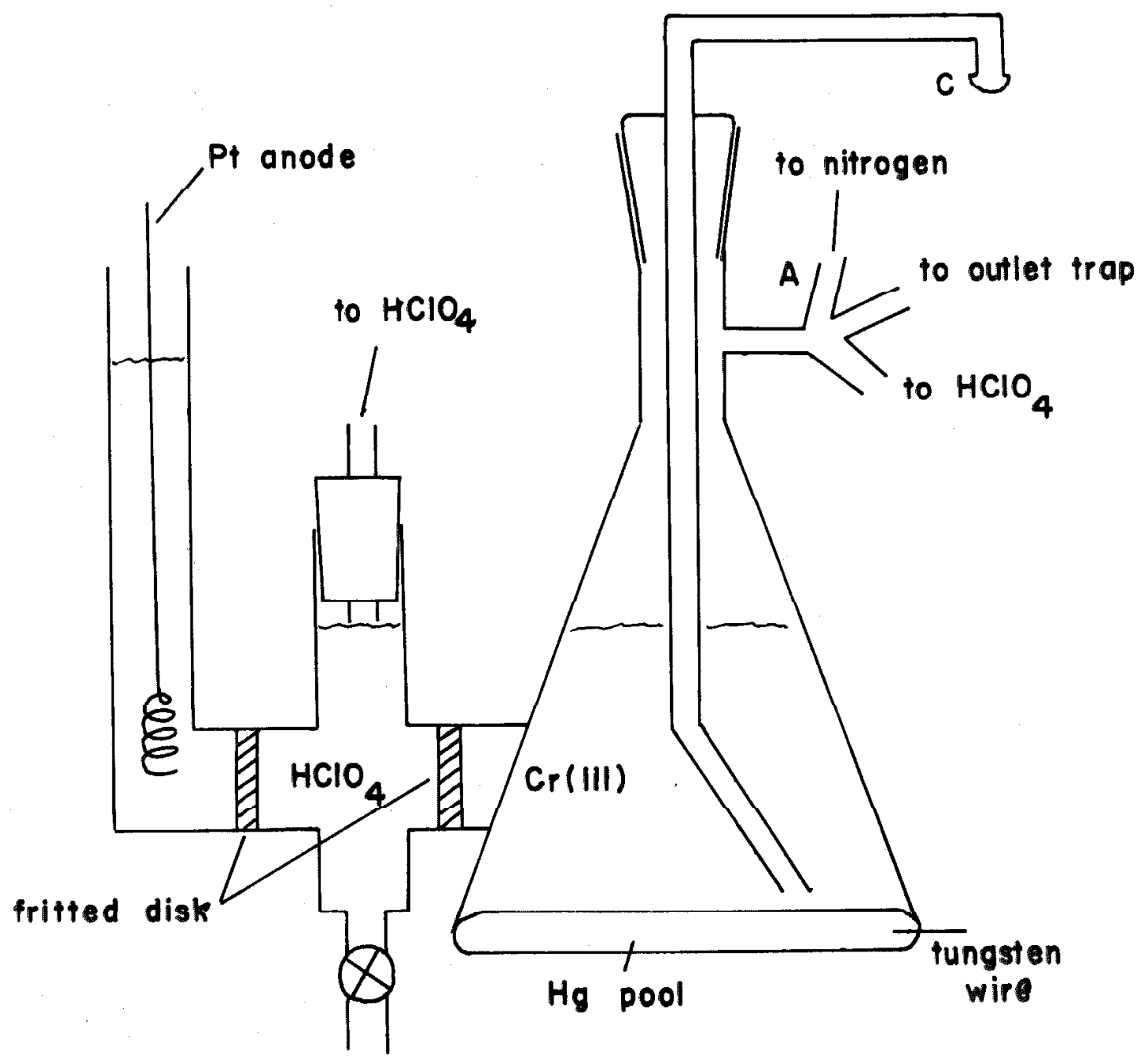

Figure 1. Electrolysis cell for preparing $\mathrm{Cr}$ (II) solutions. 
electrolysis is carried out by applying $12 \mathrm{v}$. between the platinum wire anode and the stirred mercury pool cathode. The back EMF of the cell is about $2 \mathrm{v}$. The current is $0.8-1.0 \mathrm{amp}$. The electrode area is about $135 \mathrm{~cm}{ }^{2}$ Under these conditions the reduction takes place with copious hydrogen evolution; the current efficiency is $50-70 \%$.

The flow of perchloric acid through the center compartment helps to maintain the hydrogen ion concentration in the cathode compartment and thus prevent precipitation of $\mathrm{Cr}(\mathrm{OH})_{2}$ which would ruin the preparation.

The electrolysis is carried out under positive nitrogen pressure as indicated by the difference in solution levels between the center and anode compartments. The pressure in the center and cathode compartments is equalized by connecting the $\mathrm{HClO}_{4}$ reservoir and the cathode compartment to the outlet trap. The perchloric acid flow is maintained by siphon.

The outlet trap consists of successive flasks containing V(II) in $1 \mathrm{FH}_{2} \mathrm{SO}_{4}$ and water, respectively. The $\mathrm{V}(\mathrm{II})$ is kept in the reduced state by zinc amalgam. The back-diffusion of oxygen into the system even with high nitrogen flow rates and very long outlet tubes is sufficlently large that a trap is an absolute necessity.

The nitrogen flow through the system is maintained by a nitrogen inlet at $\mathrm{D}$ to the $\mathrm{Cr}$ (II) reservoir (Figure 2), which is connected to the cell at $\mathrm{C}$. The reservoir is initially purged of oxygen by repeatedly evacuating and filling with nitrogen.

When the electrolysis appears to be finished, the $\operatorname{Cr}$ (II) solution Is transferred to the reservoir by closing off all the cell openings 


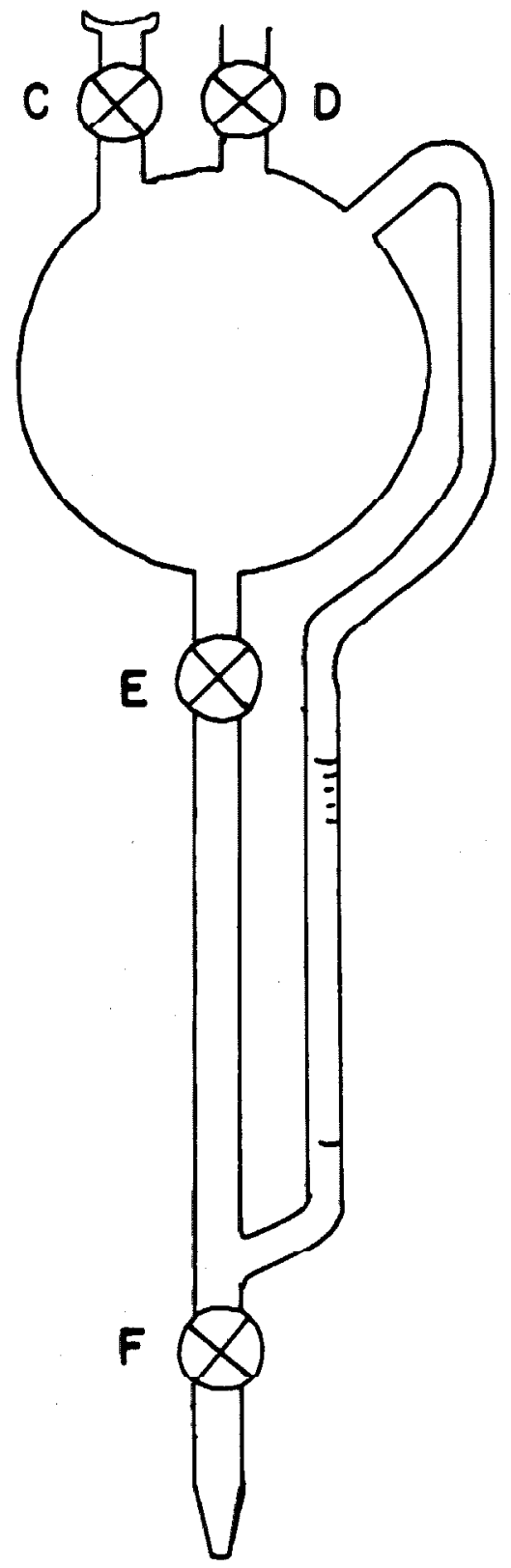

Figure 2. Storage buret for $\operatorname{Cr}$ (TT) solutions. 
(incluaing the center and anoce compartments), shunting the nitrogen I. Low from the reservoir (D) to the cell inlet at $A$, and forcing the solution over into the reserroir. Since it is most convenient to carry out this transfer with small pressure differences, during the transfer a Icals to vacuum is made through $F$ with $D$ and $E$ closed (Figure 2 ). When the transfer has been completed $C$ and $F$ are closed, and nitrogen is introduced at $D$ until the pressure in the reservoir is about two atmospheres absolute (the volume of the solution is about half the volume of the reservoir).

The standard taper joint below F (Figure 2) is fitted with an adapter for transfer of solution. The adapter is a $15 \mathrm{~cm}$. length of $1 \mathrm{~mm}$. capillary tubing with a matching standard taper folnt at the top and a $12 / 1$ ball joint at the bottom for flexibility. The dead space below the stopcock $F$ is filled with small glass beads to decrease the loss of $\mathrm{Cr}$ (II) by air oxidation in the interval while connection of the reservoli to the recelver is made.

The stopcocks in the reservoir may be Teflon ( $4 \mathrm{~mm}$. bore), which leak, or preclsion ground pressure stopcocks, which contaminate the solution with grease. Both are tolerable, neither is satisfactory. Chromium(II) solutions can also be prepared by oxidizing the metal with acid. "Spectrographically Standaraized Chromium Pellets" ava1lable from Johnson, Matthey, and Co., Ltd. (73/83, Hatton Garder, London E.C. 1) was found to be the most satisfactory source of chromium metal. This reaction is smooth and rapid in dilute $\mathrm{HCl}$, but will not start in $\mathrm{HClO}_{4}$ unless the metal is first activated by dipping in $\mathrm{HCl}$. If the metal is then washed anc placea in dilute (2 F) $\mathrm{HClO}_{4}$ solution 
the reaction proceeds at a lively pace for some time, but eventually the surface of the metal darkens and the rate of reaction decays to zero. This method of preparation is useful for making small amounts of dilute Cr(II) solutions, particularly if chloride is present, but seems not generally suitable for the preparation of stock solutions.

If the presence of zinc can be tolerated $\operatorname{Cr}(I I)$ solutions are also readily prepared by reduction of $\operatorname{Cr}(I I I)$ solutions in a Jones reductor. The zinc amalgam must be light and must be pretreated with warm acid to ensure quantitative reduction of the $\operatorname{Cr}$ (III) (9). The solution is best transferred directly into the oxygen-free reservoir and then put under nitrogen pressure, as described above. Nitrogen, free of oxidizing impurities, is most conveniently obtained by passing Matheson "prepurified" nitrogen over hot copper turnings. A Vycor tube filled with copper turnings and a tube fumace for this purpose are available from $\mathrm{E}$. H. Sargent and Co. The nitrogen is then cooled and presaturated by passing it through a washing tower filled with the appropriate solution.

The large oxygen leakage through Tygon or equivalent tubing makes it unsuitable for use. A thick wall synthetic rubber tubing, e.g., chlorinated butyl tubing, is recommended. Good rubber to glass seals can be made with Apiezon Q wax. 


\section{Analysis of Chromium(II) Solutions}

Chromium(II) stock solutions were analyzed for Cr(II) by adding $10 \mathrm{ml}$. of lhe sulution to $100 \mathrm{ml}$. of deaerated $\mathrm{Fe}$ (III) solution (pro pared by adding $58 \mathrm{~g}$. of $\mathrm{Fe}_{2}\left(\mathrm{SO}_{4}\right)_{3} \cdot\left(\mathrm{NH}_{4}\right)_{2} \mathrm{SO}_{4} \cdot 24 \mathrm{H}_{2} \mathrm{O}$ to $50 \mathrm{mI}$. of $18 \mathrm{~F}$ $\mathrm{H}_{2} \mathrm{SO}_{4}$ plus $80 \mathrm{ml}$. of $85 \% \mathrm{H}_{3} \mathrm{PO}_{4}$ and diluting to 2 ..). The resulting solution was then titrated with approximately $0.02 \mathrm{~N} \mathrm{Na} \mathrm{Nr}_{2} \mathrm{O}_{7}$ to a visual endpoint using 6 drops of sodium diphenylamine sulphonate indicator. The titration requires some practice because the bright green color of $\mathrm{Cr}$ (III) obscures the color change at the endpoint. The blank is negligible.

The $\operatorname{Cr}$ (II) solutions were analyzed for total chromium by adding $2 \mathrm{ml}$. of the solution to $14 \mathrm{ml}$. of $1 \mathrm{~F} \mathrm{NaOH}$ plus a few drops of $30 \%$ $\mathrm{H}_{2} \mathrm{O}_{2}$, boiling to decompose excess peroxide, diluting to $I$. and comparing the absorbance at $373 \mathrm{m \mu}$. with that of a standard solution differing in absorbance by less than 5\%. The molar absorptivity of chromate at $373 \mathrm{m \mu}$. is 4760 (10).

These procedures have the advantage that the same $\mathrm{Na}_{2} \mathrm{Cr}_{2} \mathrm{O}_{7}$ standard solution can be used for preparation and both analyses of the Cr(II) stock solution.

The solutions were analyzed for hydrogen ion by adding $2 \mathrm{ml}$. of the solution to $50 \mathrm{ml}$. of deaerated solution containing $0.2 \mathrm{~g}$. of ethylene diamine dihydrochloride and titrating potentiometrically with $0.1 \mathrm{~F}$ NaOH solution under air-free conditions using glass and NaCl-SCE electrodes. The pH at the endpoint is the same as that of the original ethylene diamine dihydrochloride solution. 
Carbonate-free O.I F NaOF solutions were prepared by diluting $6 \mathrm{wl}$. of saturated MaOH solution to 11 . With freshly bollea and cooled water and standardizing agairst potassium hydrogen phthalate using a potentiometric endpoint.

III. Oxidation-Reduction Reactions of $\mathrm{Cr}$ (II) and $\mathrm{Cr}$ (III)

1. The Oxidation of $\mathrm{Cr}$ (II) and $\mathrm{Cr}$ (III) by Perchlorate.

The quantitative oxidation of chromium to $\mathrm{Cr}$ (VI) hy botiting in concentrated $\mathrm{HClO}_{4}$ is part of a well known standard procedure for chromium determination. In $2 \mathrm{FHClO}_{4}$ this reaction occurs to a small extent even on mila heating. The practice of refluxing with excess silver ion to decompose $\mathrm{CrCl}^{2^{+}}$(II) should not be indiscriminately applied. Analysis of a $\mathrm{Cr}$ (II) stock solution at intervals of one or two weeks gave a ratio of the drop in titer to the chloride concentration of 6 to 7 corresponding roughly to the reduction of perchlorate to chloride by $\operatorname{Cr}(I I)$. The ciloride-free life of the solutions was found to be a month to six weeks.

2. The Oxidation of $\mathrm{Cr}$ (II) by Nitrate in Ac1d Solution.

In this work $\mathrm{NaClO}_{4}$ was used as the innocuous salt to maintain constant ionic strength. This introduces a deceptively simple problew which arises from the limited solubility of $\mathrm{KClO}_{4}$. A standard commercial SCE reference electrode cannot be used in a $\mathrm{NaClO}_{4}$ solution because $\mathrm{KClO}_{4}$ precipltates in the junction. One approach usea to aroid this problcm was to place the electrode in a salt briage containing $1 \mathrm{~F} \mathrm{NaNO}_{3}$ solution. The junction between the $\mathrm{NaNO}_{3}$ solution and the $\mathrm{NaClO}_{4}$ solution 
was a cracked glass bead. The $\mathrm{NaNO}_{3}$ solution isolates the cell from the chloride in the electrode and isolates the electrode from perchlorate in the cell.

The difficulty with this arrangement is that the leak rate of solution from the salt bridge into the cell, even with cracks having a resistance of $20 \mathrm{k} \Omega$ or larger, is great enough to introduce large amounts of nitrate into the cell in the course of an experiment. It was found. that in acid solution nitrate (or nitric acid) rapidly oxidizes $\mathrm{Cr}$ (II), probably to $\mathrm{CrNO}_{2}{ }^{+}$.

Higure 3 shows the spectrum of a solution of $\mathrm{Cr}$ (II) in $0.1 \mathrm{~F}$ $\mathrm{HClO}_{4}, 0.9 \mathrm{~F} \mathrm{NaClO}_{4}$ to which had been added sufficient $\mathrm{NaNO}_{3}$ to completely oxidize the $\operatorname{Cr}($ II) to $\operatorname{Cr}($ III). The spectrum labeled I was taken almost immediately after the addition of nitratc, the accond 3 houro later, and the third 20 hours later. The broad peak at $430 \mathrm{m \mu}$. In 1 is characteristic of $\mathrm{Cr}$ (III) but does not correspond to the species $\mathrm{Cr}^{3}$ which has peaks at 407 and $575 \mathrm{m \mu}$. (P). In $P$ and 3 this peak moves toward shorter wavelengths. At the same time sharp peaks appear at 358 , 370, and $387 \mathrm{m \mu}$. Bunton and stedman (12) report peaks for $\mathrm{HNO}_{2}$ at 356 , 369 , and $383 \mathrm{mu}$.

on standing for several days, the oxidation product solution, which initially was golden yellow, had changed to the characteristic violet color of $\mathrm{Cr}^{3^{+}}$.

These observations indicate that $\mathrm{HNO}_{3}$ oxidizes $\mathrm{Cr}$ (II) to $\mathrm{CrNO}_{2}{ }^{{ }^{+}}$ in acid, and that the product slowly dissociates to form $\mathrm{Cr}^{3^{+}}$and $\mathrm{HNO}_{2}$. When $\operatorname{Cr}$ (II) is oxidized by nitrate in the presence of bromide, the product solution apparently contains a mixture of $\mathrm{CrBr}^{2+}, \mathrm{CrNO}_{2} 2^{+}$, 


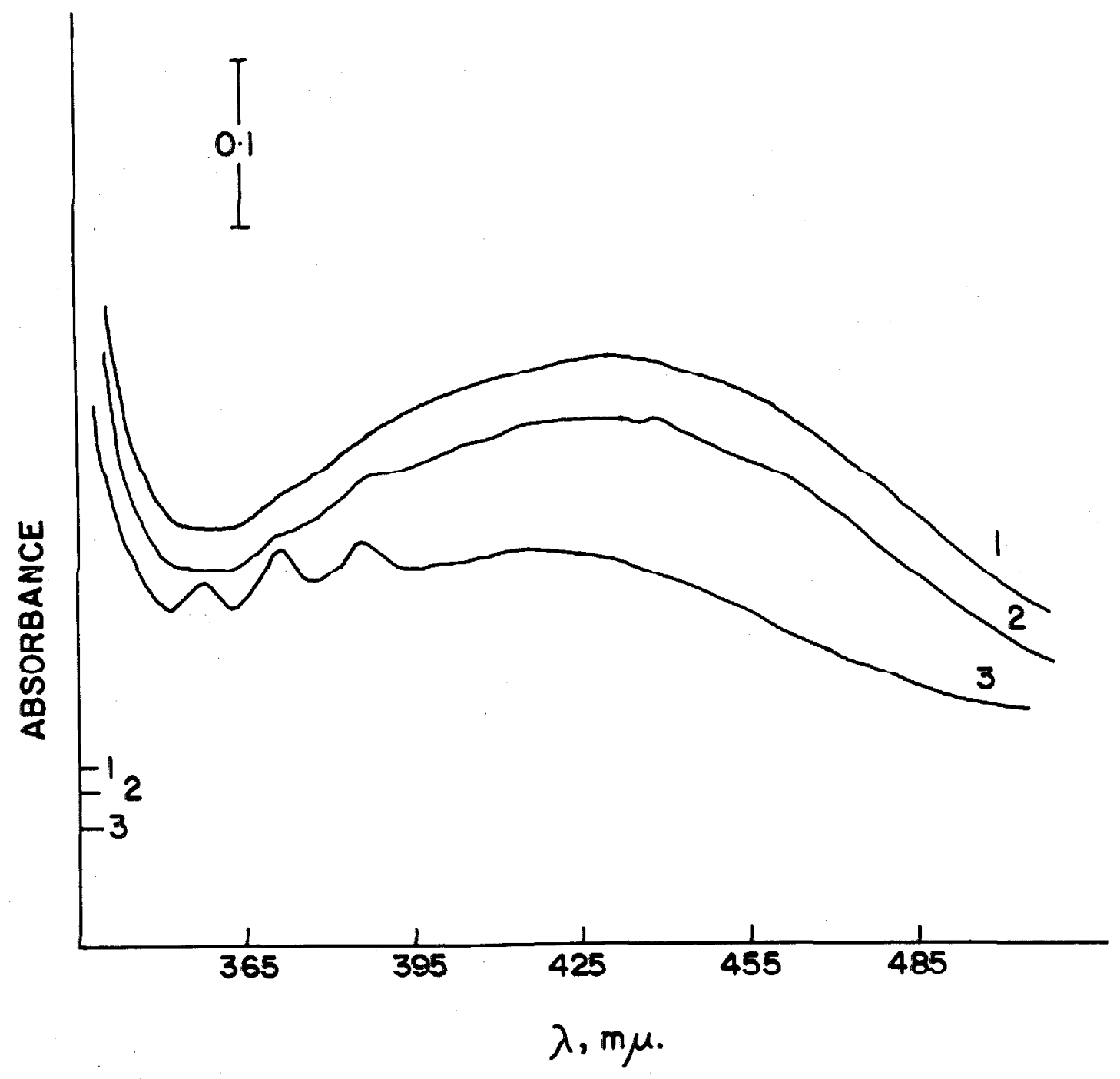

Figure 3. The absorbance of a solution formed by adding $10 \mathrm{ml}$. of $\mathrm{Cr}$ (II) stock solution to $140 \mathrm{ml}$. of $0.1 \mathrm{~F} \mathrm{HClO}_{4}, 0.9 \mathrm{~F} \mathrm{NaClO}_{4}$ and $10 \mathrm{ml}$. $0 . I \mathrm{~F} \mathrm{NaNO}_{3}$. Curve $1: t=20 \mathrm{~min}$; curve 2 : $t=3 \mathrm{hr} . ;$ curve $3: t=20 \mathrm{hrs}$. The ordinates $1,2,3$ are the absorbance zeros. 
$\mathrm{Cr}^{3^{+}}$, and possibly some dimerte $\mathrm{Cr}$ (III) species. $3.6 \mathrm{mF} \mathrm{Cr}$ (II) in $0.908 \mathrm{w}$ NaBr, $0.066 \mathrm{~F} \mathrm{HClO}_{4}$ with just suffic1ent $\mathrm{NaNO}_{3}$ sululiun present to cause complete oxidation gave a yellowish-green solution. This solution had a spectrum with peais at 422 and $575 \mathrm{m \mu}$. in contrast with the values of 407 and $575 \mathrm{m \mu}$. for $\mathrm{Cr}^{3^{+}}$and 132 ana $622 \mathrm{m \mu}$. for $\mathrm{CrBr}^{2}$ (2). Cathodic polarography in this solution gave a double wave with the first half-wave potential at about $-0.510 \mathrm{v}$. vs. SCE and the second at about $-0.850 \mathrm{v}$. vs. SCE. The yellowish color indicates that $\mathrm{CrNO}_{2}{ }^{2+}$ is a major product of the oxidation, while the two half-wave potentials correspond to the reduction of $\mathrm{CrBr}^{2^{+}}$and $\mathrm{Cr}^{3^{+}}$, respectively. It is suspectea that the reduction potential for $\mathrm{CrNO}_{2}{ }^{2+}$ is very near to that of the bromide complex.

It is quite clear that in any work with $\mathrm{Cr}$ (II) solutions, nitrate must be rigorously excluded. This point is worth strong emphasis because of the ubiquitous use of $\mathrm{NaNO}_{3}$ solutions as innocuous or inert sall solulions.

IV. The Rates of Aquation of Hollic Complcxco of $\mathrm{Cx}$ (III)

The cholce of technique for the study of the products of the electrochemical oxidation of $\mathrm{Cr}$ (II) in the presence of various ligands depends on the lifetime of those products in the solution. Guthrie and King (13) and Swaddle and King (14) have made a thorough study of the rates of aquation of the halicie complexes $\mathrm{CrX}^{2}{ }^{+}$as a function of hyörogen ion concentration. Some of their results are presented in Table 1 along with the time required for $1 \%$ of the complex to dissociate.

All of these rates are based on spectrophotometric measurements. 
TABIF 1

\begin{tabular}{lcccc}
\hline Complex & $\left(\mathrm{H}^{+}\right), \mathrm{M}$ & $\mathrm{T},{ }^{\circ} \mathrm{C}$ & $\mathrm{k}, \mathrm{sec} .^{-1}$ & $\mathrm{t}_{0.01}$ \\
\hline $\mathrm{CrF}^{2}$ & 0.01 & 25 & $7.6 \times 10^{-10}$ & 5.1 months \\
$\mathrm{CrCl}^{2^{+}}$ & 2.0 & 25 & $2.9 \times 10^{-7}$ & 9.6 hours \\
$\mathrm{CrBr}^{2}$ & 1.0 & 30 & $1.0 \times 10^{-5}$ & 16 minutes \\
$\mathrm{CrI}^{2}$ & 2.0 & 25 & $8.6 \times 10^{-5}$ & 1.9 minutes \\
\hline
\end{tabular}

1. I'he Rate of Aquation of $\operatorname{Crcl}^{2^{+}}$.

We have measured the rate of aquation of the complex $\mathrm{CrCl}^{2+}$ by determining the chloride concentration of a solution of $\mathrm{CrCl}^{2}$ as a function of time. Chloride concentration was deterwined in a sululiun Initially $20 \mathrm{mF}$ in $\mathrm{CrCl}^{2^{+}}$and $2 \mathrm{~F}$ in $\mathrm{HClO}_{4}$ by titrating aliquots of the solution with standard $\mathrm{AgClO}_{4}$ solution using a potentiometric endpoint with glass and silver wire electrodes.

The pseudo first order rate constant for the dissociation was found to be $3.2 \times 10^{-5} \mathrm{~min} .^{-1}$, or the $1 \%$ life is 5.2 hours. The temperature was not controllea but was $27.0 \pm 0.2{ }^{\circ} \mathrm{C}$.

\section{The Rate of Aquation of $\mathrm{CrBr}^{2+}$.}

We have determined the rate of aquation of the complex $\mathrm{Cr} \mathrm{Br}^{2}$ spectrophotometrically. The nolar absorptivities of $\mathrm{Cr}^{3^{+}}$and $\mathrm{CrBr}^{{ }^{+}}$in the visible region of the spectrum are known from the work of King (15) and Taube and Myers (2), respectively. It has been observed by many workers (16) in chromium chemistry that the range 380-500 $\mathrm{m \mu}$. does not give reliable spectra for concentration measurements because of the high absorptivity of several other chromium species which are likely to be in 
the solution in more than trace amounts. Accordingly the concentrations of life two major species in the solution worc calculated from the molar absomptivities at two points outside this region, namely 580 and $650 \mathrm{m \mu}$. at which the molar absorptivities of $\mathrm{Cr}^{3^{+}}$are 13.5 and 3.78 and those of $\mathrm{CrBr}^{2}+11.0$ and 17.1 , respectively.

The results are presented in Table 2 . The value of $k$, the pseudo first order rate constant for the dissociation, was found to be $1.79 \times 10^{-4} \min .^{-1}$, or the complex has a $1 \%$ life of 56 minutes.

TABIE 2

\begin{tabular}{ccccc}
\hline$t-t_{0}, \min$. & $A_{650}$ & $A_{580}$ & $\left(\mathrm{CrBr}^{2}\right), \mathrm{mM}$ & (Cr(III)), mM \\
\hline 152 & 0.379 & 0.350 & 21.4 & 25.1 \\
223 & 0.370 & 0.350 & 20.7 & 25.1 \\
338 & 0.370 & 0.347 & 20.7 & 25.1 \\
1367 & 0.331 & 0.345 & 17.8 & 25.0 \\
2530 & 0.276 & 0.343 & 13.7 & 24.9 \\
3998 & 0.234 & 0.336 & 10.6 & 24.6 \\
\hline
\end{tabular}

Txperimental dctailo. Onc $\mathrm{ml}$. of bromine was added to $50 \mathrm{ml}$, of deaerated $1 \mathrm{~F} \mathrm{HClO}_{4}$ solution, and $17 \mathrm{ml}$. of $0.1024 \mathrm{~F} \mathrm{Cr}$ (II) stock solution was added to the mixture. Under these conditions the reaction

$$
\mathrm{Cr}^{2^{+}}+\mathrm{Br}_{2} \longrightarrow \mathrm{CrBr}^{2^{+}}+\mathrm{Br}^{-}
$$

is quantitative. The reaction mixture was purged of excess bromine by vigorously bubbling nitrogen through the mixture. The composition of the resulting solution was $25.6 \mathrm{mF} \mathrm{Cr}$ (III), $1.01 \mathrm{~F} \mathrm{HClO}_{4}(\mu=1.12)$. 
The spectrum of this solution was determined as a function of lime using a Cary Modol 15 recording spectrophotomet.er.

3. The Effect of $\mathrm{Cr}$ (II) on the Rate of Aquation of $\mathrm{CrBr}^{2^{+}}$

The rate of aquation of $\mathrm{CrBr}^{2^{+}}$was also measured in the presence of excess $\mathrm{Cr}(\mathrm{TT})$ to see if $\mathrm{Cr}(\mathrm{II})$ catalyzes the aquation reaction.

A seven point equation was used to calculate the concentrations of $\mathrm{Cr}(\mathrm{II}), \mathrm{CrBr}^{2^{+}}$, and $\mathrm{Cr}^{3^{+}}$at each time using the measured absorbance at each wave length and the molar absorptivities given in Table 3 .

\section{TABIE 3}

\begin{tabular}{|c|c|c|c|}
\hline \multirow[b]{2}{*}{$\lambda, m \mu}$. & \multicolumn{3}{|c|}{ Molar Absorptivity } \\
\hline & $\mathrm{CrBr}^{2+}$ (15) & $\mathrm{Cr}^{3^{+}}(2)$ & $\operatorname{Cr}(\mathrm{II})$ \\
\hline 380 & 5.7 & 10.01 & 0.036 \\
\hline 450 & 19.4 & 6.64 & 0.25 \\
\hline 540 & 6.0 & 9.78 & 0.93 \\
\hline 575 & 13.0 & 13.9 & 0.16 \\
\hline 580 & 14.0 & 13.5 & 0.19 \\
\hline 590 & 16.1 & 12.6 & 2.26 \\
\hline 650 & 17.1 & 3.78 & 4.34 \\
\hline
\end{tabular}

The method of calculablun was at simple least squares treatment with the constraint that the total chromium concentration be $30.73 \mathrm{mF}$, The pseudo first order rate constant for the dissociation of $\mathrm{CrBr}^{+}$in the presence of $\mathrm{Cr}$ (II) wad found to be $\mathrm{k}=2.20 \times 10^{-4} \mathrm{~min} .^{-1}$, or the $1 \%$ life is 46 minutes. 
In view of the quality of the data and the known pitfalls in the calculation of $\mathrm{Cr}$ (III) complex concentrations in chromium solutiond from absorbance data, this result indicates that $\mathrm{Cr}$ (II) does not catalyze the rate of dissociation of $\mathrm{CrBr}^{2+}$.

Experimental details. The cell used was specifically designed for mixing and transferring air sensitive solutions to spectrophotometer cells by W. P. Schaefer and has been described by him (17).

A chlorine-free saturated aqueous bromine solution was prepared by adding a large excess of bromine to triply distilled water and bubbling nitrogen through the solution for several days. The solubility of bromine in water at $25^{\circ} \mathrm{C}$. is $0.210 \mathrm{M}(18)$.

To $50 \mathrm{ml}$. of oxygen-free $1 \mathrm{~F} \mathrm{HClO}_{4}$ was added under oxygen-free conditions $20 \mathrm{ml}$. of a $\mathrm{Cr}$ (II) stock solution whose composition was $0.0970 \mathrm{M} \mathrm{Cr}($ II $), 0.0095 \mathrm{M} \mathrm{Cr}$ (III), and $1.093 \mathrm{M} \mathrm{HClO}_{4}(\mu=1.55) . \mathrm{A}$ sample was taken from the cell and the visible spectrum of the solution obtained to find the molar absorptivities of $\mathrm{Cr}$ (II). Over the range of Interest, $380.650 \mathrm{m \mu} .$, the maxtmum aboorbanec for $\mathrm{Cr}$ (II) occurs at $650 \mathrm{m \mu}$. $(\epsilon=4.34)$. A maximum is found at $410 \mathrm{m \mu}$. $(\epsilon=0.93)$.

To the remaining solution in the cell was added $3 \mathrm{ml}$. of the saturated bromine solution. These conditions provide approximately a. two-fold excess of $\mathrm{Cr}$ (II). An aliquot of the resulting solution was analyzed for total chromium by oxidation to chromate as described above (p. 13). The total chromium concentration was found to be $30.7 \mathrm{amF}$. The solution also had $\mathrm{HClO}_{4}=1.00 \mathrm{M}(\mu=1,12)$. 
4. Polarographic Determination of the Rate of Aquation of $\mathrm{CrBr}^{2+}$.

The diffusion current of a solution containing $\mathrm{CrBr}^{2^{+}}$was measured at -0.610 v. vs. SCE for a period of five hours. Semi-logarithmic plots of diffusion current as a function of time were made for data obtained over intervals of $30 \mathrm{~min}$. at times 100, 220, and 260 minutes. The values of the pseudo IIrst order rate constant for the dissociation of the complex obtained from the slopes were $1.78,1.21$, and $1.65 \times 10^{-3}$ min. ${ }^{-1}$, respectively. The average value $i s 1.55 \pm 0.22 \times 10^{-3} \mathrm{~min},{ }^{-1}$ or the $1 \%$ life is 6.5 minutes.

Experimental detaild. The experiment was done in the cell shown in Figure 18. Sufficient mercury was added to the cell to cover the bottom, and then sufficient saturated $\mathrm{NaBr}$ solution to cover the mercury to a depth of about $1 \mathrm{~cm}$. A smal1 amount of solid Na.Br was added to insure saturation during the course of the experiment. $140 \mathrm{ml}$. of deaerated $1 \mathrm{~F} \mathrm{HClO}_{4}$ was carefully floated on top of the saturated $\mathrm{NaBr}$ solution, and the cell closed. To this was added $10 \mathrm{ml}$. of a $\mathrm{Cr}$ (II) stock solution $0.095 \mathrm{~F}$ in $\mathrm{Cr}(\mathrm{II}), 1.09 \mathrm{~F}$ in $\mathrm{HClO}_{4}(\mu=1.55)$. Finally $0.9 \mathrm{ml}$. of bromine was added.

The design of the experiment accomplishes several purposes. First, it provides a large and stable combination reference and auxiliary electrode of known potential ( $-0.160 \mathrm{v}$. Vs. S(H) making possible the use of a conventional commercial polarograph. This would not be possible even in the presence of bromide if the mercury of the pool were not isolated from the Cr(II) solution. Second, it 1solated the solution 
under investigation from lihe posslule catalytic effect of mercury. The density of the saturated NaBr solution is sufficiently high (1.54 gm./mI.) that there is very little mixing of the two solutions (18).

The diffusion current constant for the reduction of $\mathrm{CrBr}^{2+}$ in $1 \mathrm{~F} \mathrm{HClO}_{4}$ was assumed to be 1.54 (19). The drop time was 3.64 seconds and the drop weight $2.52 \mathrm{mg}$, giving $\mathrm{m}^{2 / 3_{\mathrm{t}} / \mathrm{s}}=2.24$. No correction was madc for the backeround current since the measured current was always greater than $12 \mu \mathrm{a}$, and any correction would be small.

The same experiment was repeated in the absence of $\mathrm{Cr}$ (II). The composition of the solution was $0.147 \mathrm{FHCTO}_{4}$ and $0.843 \mathrm{~F} \mathrm{NaBr}(\mu=$ 1.02). The initial concentration of $\mathrm{CrBr}^{2^{+}}$was $6.7 \mathrm{mF}$. The current was recorded over a period of four hours. The rate was found to decrease slowly with time. The initial rate constant was found to be $8.21 \times 10^{-3}$ min. ${ }^{-1}$.

5. Discussion.

The work of King and co-workers on the aquation of the monohalide complexes of $\mathrm{Cr}$ (III) was carefully done for the purpose of obtaining thermodynamic quantities. The rate determinations we have carried out were done before $\mathrm{KIng}^{\prime} \mathrm{S}$ values were published and were done to obtain order of magnitude upper limits for the rate constants under conditions comparable to those of our electrochemical experiments. Under the circumstances the agreement with the results of king is good,

However, it should be pointed out the rates measured by spectrophotometric techniques are closer to the values of King than the rates measured by other techniques. In particular, the abnormally high value 
for the rate of aquation of $\mathrm{CrBr}^{2}$ determined polarographically seems to be outside the limits of expected error, especially since all sources of error would tend to make the apparent rate of decomposition smaller rather than greater.

Resolution of tils ditt'erence in rate constant might prove to be of fundamental interest. At worst it could lay valuable groundwork for the application of electrochemical techniques to the measurement of bulk concentrations of $\mathrm{Cr}$ (II) and $\mathrm{Cr}$ (III) species for use in the study of homogeneous reactions of chromium.

The general unreliability of the spectrophotometric techniques now universally usen for that purpose should provide a powerfin stimulus for development of adequate electrockemical techniques. 
$P A R T I I$

EVIDENCE FOR THE LIGAND BRIDGING MECHANISM 


\section{Chapter 3 \\ CONTROLIED POTENTIAL OXIDATION OF CHROMIUM(II)}

IN THE PRESENCE OF CHLORIDE

Large scale controlled potential electrolyses of Cr(II) solutions were carried out at a stirred mercury pool electrode at $-0.012 \mathrm{v}$. vs. SCE in the presence of chloride. Current-voltage eurves showed that the oxidation of $\operatorname{lr}(1 \perp)$ in the absence of chloride 1 d difusion limited at that potential. The amount of $\operatorname{Cr}($ II) oxidized to $\operatorname{Cr}$ (III) was determined by integration of the current. The amount of free chloride present in the solution at the conclusion of the electrolysis was determined by titration with silver. The difference between chloride found and chloride initially present gives the amount of $\mathrm{CrCl}^{2+}$ in the product. According to our prediction that the ligand bridging mechanism obtains under the conditions of these experiments the expected result is that when the inftial chloride to $\mathrm{Cr}$ (II) ratio is less than or equal to one no free chloride will be found in the product solution and when the initial chloride to $\mathrm{Cr}$ (II) ratio is greater than one the amount of chloride found will be equal to the initial excess of chloride over Cr(II). This behavior is illustrated by the solid line in Figure 4. The experimental results are presented in the same figure. The prediction that the oxidation proceeds via ligand bridging is clearly contirmed.

Experimental procedures. Keagent grade chemicals and tap distilled water were used unless otherwise specified. 


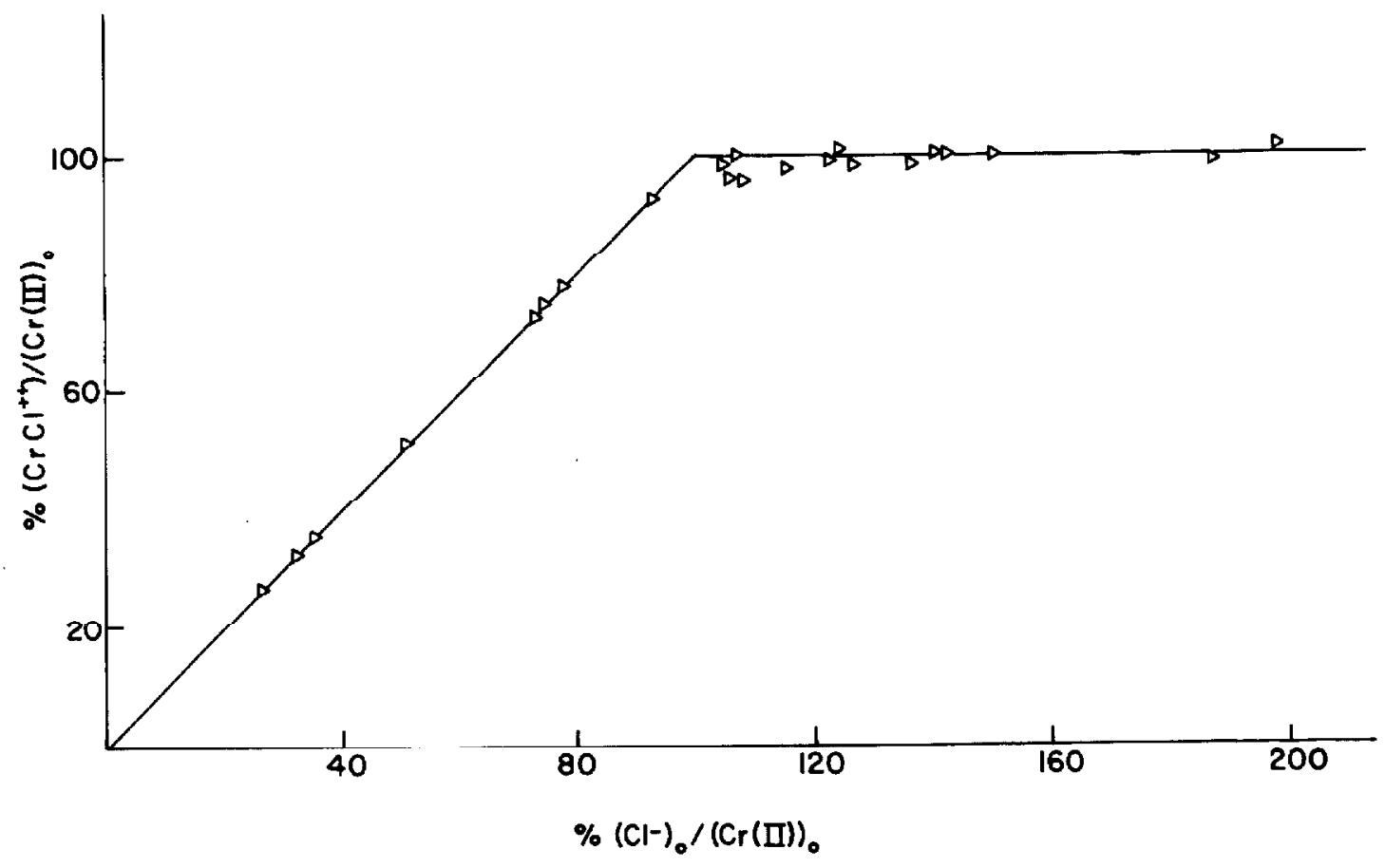

Figure 4. The controlled potential oxidation of $\operatorname{Cr}(\perp \perp)$ in chlorice solutions. $(\mathrm{Cr}(\mathrm{II}))_{0}$ and $\left(\mathrm{Cl}^{-}\right)_{0}$ are initial concentrations and $\left(\mathrm{CrCl}^{2+}\right)$ the final concentration of that species. The solia line shows the expected behavion. 
Sodium chloride was purlfied by precipitation from NaCl solution with HCl gas liberated from $12 \mathrm{~F}$ HCl by slowly aading $18 \mathrm{~F} \mathrm{H}_{2} \mathrm{SO}_{4}$.

Silver perchlorate solutions were prepared by dissolving G. F. Sith Silver Perchlorate in $2 \mathrm{FHClO}_{4}$ and filtering cff the precipitate. They were standardized by titrating samples of a standard. NaCl solution potentiometrically using glass and silver wire electrodes. Satisfactory potential response was obtained if the silver wire indicator electrode was cleaned with $12 \mathrm{FH}_{\mathrm{H}}$ s containing a pinch of $\mathrm{NaNO}_{2}$ just before the titration.

Mercury was Mallinckrodt distilled quality. After use in an electrolysis it was repurtfied by filtering, vigorously bubbling air through the mercury under $10 \% \mathrm{HNO}_{3}$ with glass wool present, and refiltering. It was then used again.

CIT nitroger was purfified by passing through successive gas washing towers containing $0.1 \mathrm{FV}(\mathrm{II})$ in $1 \mathrm{~F} \mathrm{H}_{2} \mathrm{SO}_{4}, 0.1 \mathrm{~F} \mathrm{Cr}$ (II) in $1 \mathrm{~F}$ $\mathrm{H}_{2} \mathrm{SO}_{4}$, and water. The $\mathrm{V}(\mathrm{II})$ and $\mathrm{Cr}$ (II) solutions were maintained in the reduced state by zinc amalgam.

Chromium(II) stock solutions approximately $0.1 \mathrm{~F}$ in $\mathrm{Cr}$ (II) and $2 \mathrm{~F}$ in $\mathrm{HClO}_{4}$ were prepared by reduction of $\mathrm{Cr}$ (III) perchlorate solutions in a Jones reductor and were dispensed from a storage buret as described in Chapter 2.

The stock sululions were analyzed for $\mathrm{Cr}$ (II) as described in Chapter 2 with the exception that the titration was done with $\mathrm{KMnO}_{4}$ rather than with $\mathrm{Na}_{2} \mathrm{Cr}_{2} \mathrm{O}_{7}$ solution. The former gives an obscure but satiofactory vicual endpoint due to the color of exeedo permanganatc. The endpoint fades rapidly. The point at which the color persists for 
one minute is taken to be the end point. The blank correction is typi$\operatorname{cally} 0.3 \%$.

The cell in which the electrolyses were carried out is shown in Figure 5 .

The oxidations were carried out at $-0.012 \mathrm{v}$. vs. SCE using an Analytical Instruments, Inc. potentiostat. The number of equivalents of $\operatorname{Cr}$ (II) oxidized was determined by an Analytical Instruments, Inc. current integrator in series with the cell.

The electrolysis was carrled out in the following manner. Forty $\mathrm{ml}$. of a solution of $\mathrm{NaCl}$ of the desired concentration in $2 \mathrm{~F} \mathrm{HClO}_{4}$ was added to the center compartment of the cell and the same solution with $\operatorname{Cr}$ (II) addea to prevent diffusion of oxygen into the center compartment through the fritted glass a1sk connechions was auded lo the Ieference and auxiliary electrode compartments. The main compartment was then thoroughly purgec of oxygen with purified nitrogen before adding $10 \mathrm{ml}$. of $0.1 \mathrm{~F} \operatorname{Cr}(\mathrm{II})$ solution from the storage buret. The electrolysis was then begun. The reference electrode was a NaCl-SCE and the auxiltary electrode platinum.

Chloride analyses were done by potentiometric titration with $\mathrm{AgClO}_{4}$ solution $2 \mathrm{~F}$ in $\mathrm{HClO}_{4}$ using glass and silver wire electrodes. The titrations were done at room temperature in dim light. Titrations done at $0^{\circ} \mathrm{C}$. With exclusion of oxygen gave no more reliable endpoints. The total amount of $\operatorname{Cr}$ (II) oxidized as measured by tie current integrator was typically $4-10 \%$ less than the amount adaed to the cell. It was felt that this was probably due to afr oxidation of the Cr(II). To check this the cell was filled as for an electrolysis and aliquots 


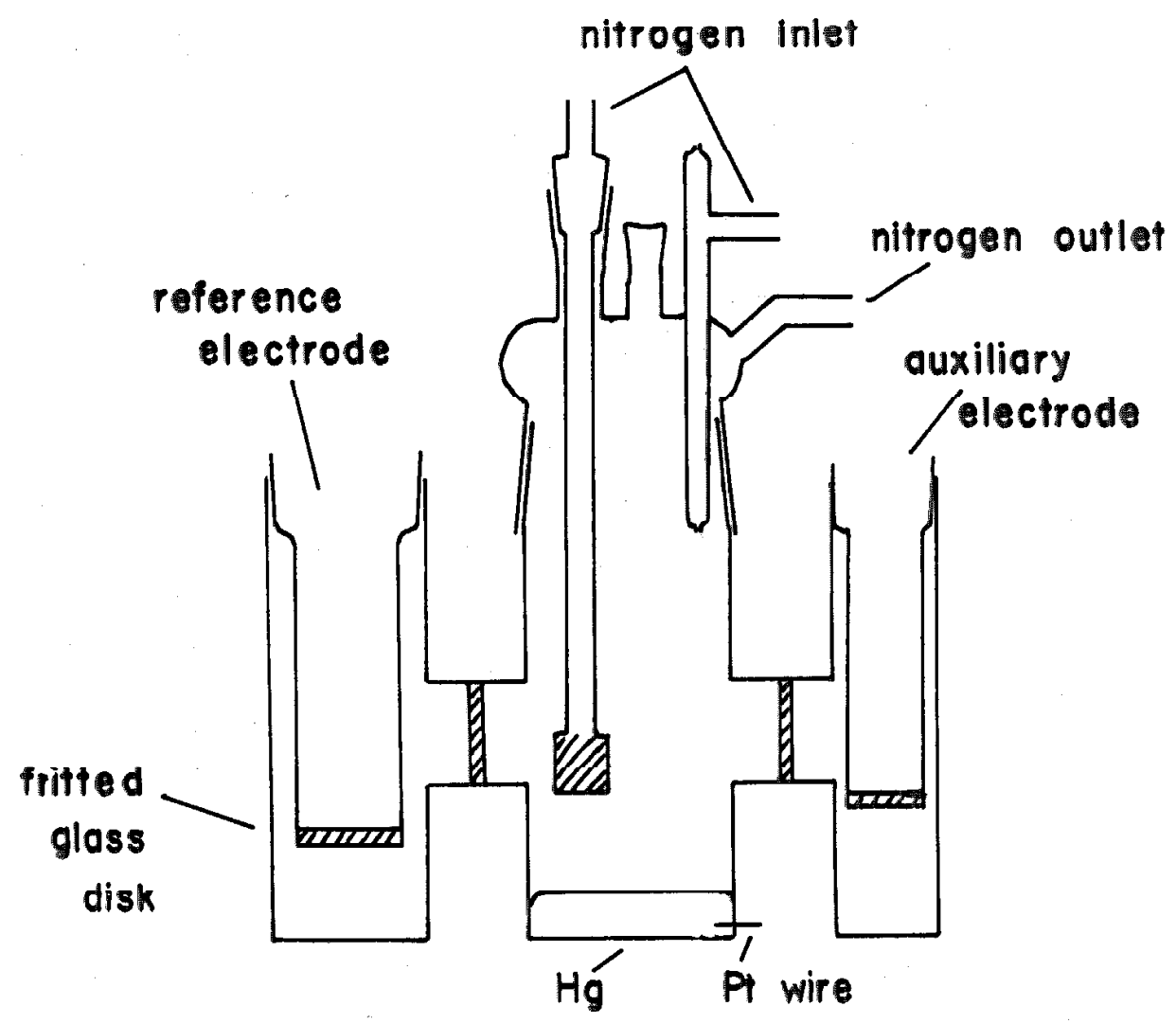

Figure 5. Cell used in controlled potential electrolysis of Cr(II) solutions. 
of the solution were analyzed for $\mathrm{Cr}$ (II) at intervals of $1 / 2$ to $\mathrm{I} \mathrm{hr}$. The rate of decay of the $\operatorname{Cr}$ (II) concentration was found to be between 1 and $2 \times 10^{-3} \mathrm{meq} \cdot / \mathrm{min}$. which accounts roughly for the observed discrepancy. The inclusion of chloride by $\operatorname{Cr}$ (II) on air oxidation is negligible (20).

Discussion. Proof that $\operatorname{Cr}($ II) is electrochemically oxidized in the presence of chloride via a chloride bridge raises more specific questions about the mechanism. The inclusion of chloride by Cr(II) specifies the transition state but does not tell us how the transition state is formed. In order to understand the reaction we need to know if $\mathrm{CrCl}^{+}$complex formation prior to the electron transfer step is important. We also need to know more about the relationship between the absorption of chloride and the formation of the transition state. These questions are discussed further in Chapter 4.

The prominent characteristics of chloride in this context are:

a) chloride increases the rate of oxidation of $\operatorname{Cr}$ (II) at mercury electrodes (6);

b) chloride is adsorbed on mercury at those potentials where $\operatorname{Cr}(I I)$ is oxidized (8);

c) chloride acts as a bridge for electron transfer in the homogeneous oxidation of $\operatorname{Cr}(\mathrm{II})(2)$;

and, as we have shuwn,

d) chloride acts as a bridge for electron transfer in the oxidation of $\operatorname{Cr}$ (II) at mereury electrodes. All ligands having a-c in common with chloride might aloo have d in 
common. This certainly must be true of at least bromide and iodide. The effects of bromide and iodide on the electrochemical oxidation of Cr(II) are discussed in Chapter 5 and Chapter 6 . 


\section{Chapter 4 \\ CHRONOPOTENTIOMETRIC INVESTIGATION OF THE OXIDATION OF \\ CHROMIUM(II) IN THE PRESENCE OF CHLORIDE}

Chronopotentiometry was used to investigate the effect of chloride on the oxidation of $\mathrm{Cr}$ (II) at mercury electrodes in more detail. The technique of chronopotentiometry has been throughly discussed by Delahay (21).

There are three purposes for investigating the reaction by chronopotentiometry. The first is to see if $\mathrm{CrCl}^{+}$is the species which reacts at the electrode. The second is to see if there is reactant adsorption. The third purpose is to show that the formation of $\mathrm{CrCl}^{2+}$ in the oxidation of $\mathrm{Cr}$ (II) is quantitative when microcoulombs of $\mathrm{Cr}$ (II) are oxidized as well as in mass electrolysis.

By observing the variation of the chronopotentiometric constant with current density one can determine the presence of a chemical reaction preceding the electron transfer step or detect the oxidation of material adsorbed on the electrode. In the former case the chronopotentiometric constant decreases with increasing current density. This occurs when the rate of electron transfer demanded by the controlled. current becomes comparable to the rate of the prior chemical reaction. The upper limit for detection of rate constants is approximately 500 sec..$^{-\frac{1}{2}}$ for the product $k_{f}\left(k_{f}+k_{b}\right)^{\frac{1}{2}} / k_{b}$ where the rate constants apply to the reaction scheme 


$$
\mathrm{I} \underset{\mathrm{k}_{\mathrm{b}}}{\stackrel{\mathrm{k}_{\mathrm{f}}}{\longrightarrow}} \mathrm{ine} \stackrel{+n \mathrm{e}^{\cdots}}{\longrightarrow} \mathrm{R}
$$

The preceding reaction of interest to us is

$$
\mathrm{Cr}^{\mathrm{e}^{+}}+\mathrm{CL}^{-}=\mathrm{CrCl} 1^{+}
$$

The complex formation constant for $\mathrm{CrCl}^{+}$is less than $5 \times 10^{-4} \mathrm{l} . / \mathrm{mole}$ (7) so the upper limit for detection of $\left(\mathrm{k}_{\mathrm{f}}+\mathrm{k}_{\mathrm{b}}\right)$ is about $10^{12} \mathrm{sec}^{-1}$. This limit is high enough that absence of kinetic effects rules out Reaction 2 as an important step in the oxidation mechanism.

In the case of adsorption, the chronopotentiometric constant increases with increasing current density. In the absence of any complications this product should be constant. That means that the higher the current density the smaller the number of equivalents of diffusing material oxidized, as that is proportional to $1 \mathrm{~T}$, not $1 \tau^{\frac{1}{2}}$. If a $5 \Gamma$ equivalents of adsorbed material are on the electrode, current must go to the oxtdation of the adsorbed material, thus decreasing the current going to diffusing matcrial and hence increasing the transition time. This effect can be seen when $n \Im \Gamma$ is as large as $10 \%$ of $i \tau$ for the diffusing material. Since chloride is adsorbed on the electrode, it is possible that the chloride hridged oxidation of $\operatorname{Cr}(\mathrm{TT})$ should show reactant adsorption.

A third and qualitatively different use of chronopotentiometry to study the reaction is the use of chronopotentiometry with current reversal to study the reaction product. For such a study to be possible the reduction of $\mathrm{CrCl}^{+}$must occur at potentials anodic to $\mathrm{Cr}^{3^{+}}$and the two waves must be clearly separable. If there is no adsorption of $\mathrm{CrCl}^{2}$ and if $\mathrm{CrCl}^{2^{+}}$is formed quantitatively during the oxidation time, 
the reverse wave for reduction of $\mathrm{CrCl}^{2^{+}}$should be $1 / 3$ as long as the forward time during which $\mathrm{CrCl}^{+}$is formed. Failure to form $\mathrm{CrCl}^{+}$ quantitatively during the forward time should shorten the reverse time or Increase the ratio of the forward to the reverse time.

Chronopotentiograms for $\mathrm{Cr}$ (II) in the presence and ahsence of chloride are shown in Figures 7 and 6, respectively. The current density for these waves is about $10 \mathrm{ma} . / \mathrm{cm} .^{2}$ It is necessary to use large current densities in order to obtain a distinct transition for the reverse wave. The large potential separation between the forward and reverse waves in Figure 6 indicates that the $\mathrm{Cr}$ (II)/Cr ${ }^{3^{+}}$couple is highly irreversible. The standard potential for the couple is $-0.647 \mathrm{v}$. Vs. SCE (22). The anodic and cathodic background reactions are $\mathrm{Hg} \rightarrow \mathrm{Hg}^{+}+2 \mathrm{e}^{-}$ and $\mathrm{H}^{+} \rightarrow \frac{1}{2} \mathrm{H}_{2}+\mathrm{e}^{-}$, respectively.

In Figure 7 we see that the oxidation of $\mathrm{Cr}$ (II) occurs at a much more negative potential in the presence of chloride. On current reversal a wave for the reduction of $\mathrm{CrCl}^{2}$ is obtuined us expected. The couple $\mathrm{Cr}(\mathrm{II}) / \mathrm{CrCl}^{2^{+}}$is quasi-reversible. An indistinct wave for the reduction of $\mathrm{Cr}^{3^{+}}$precedes $\mathrm{H}^{+}$reduction. The anodic background reaction in this case is calomel formation. The appearance of several waves is characteristic of mercury oxidation at high chloride concentram tions with high current densities. 

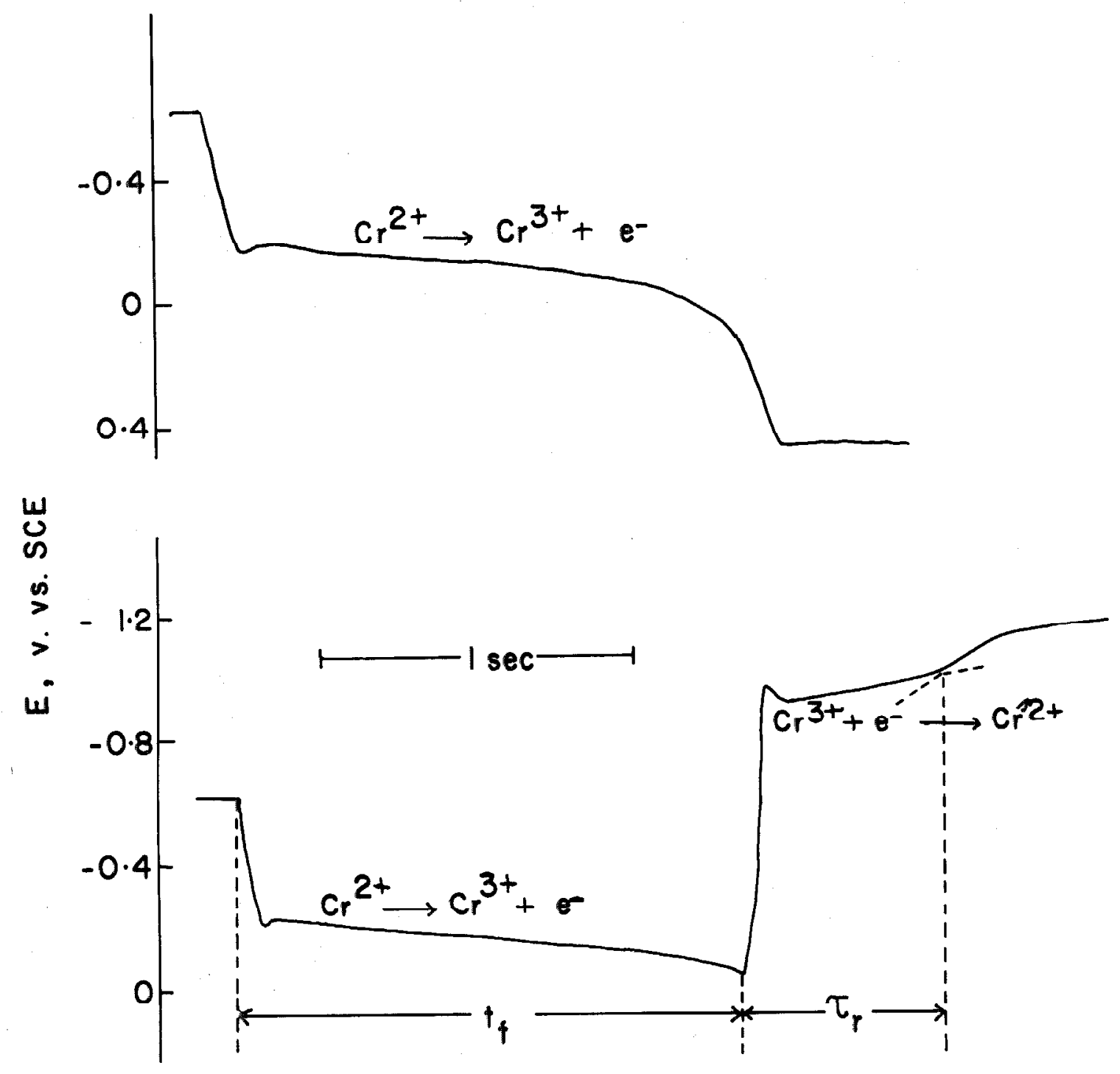

Tigure 6. Chronopotentiomctric behavior of $\mathrm{Cr}$ (II) in the absence of complexing ligands. Solution: $40 \mathrm{mF} \mathrm{Cr}$ (II) in $2 \mathrm{~F} \mathrm{HClO}_{4}$. 


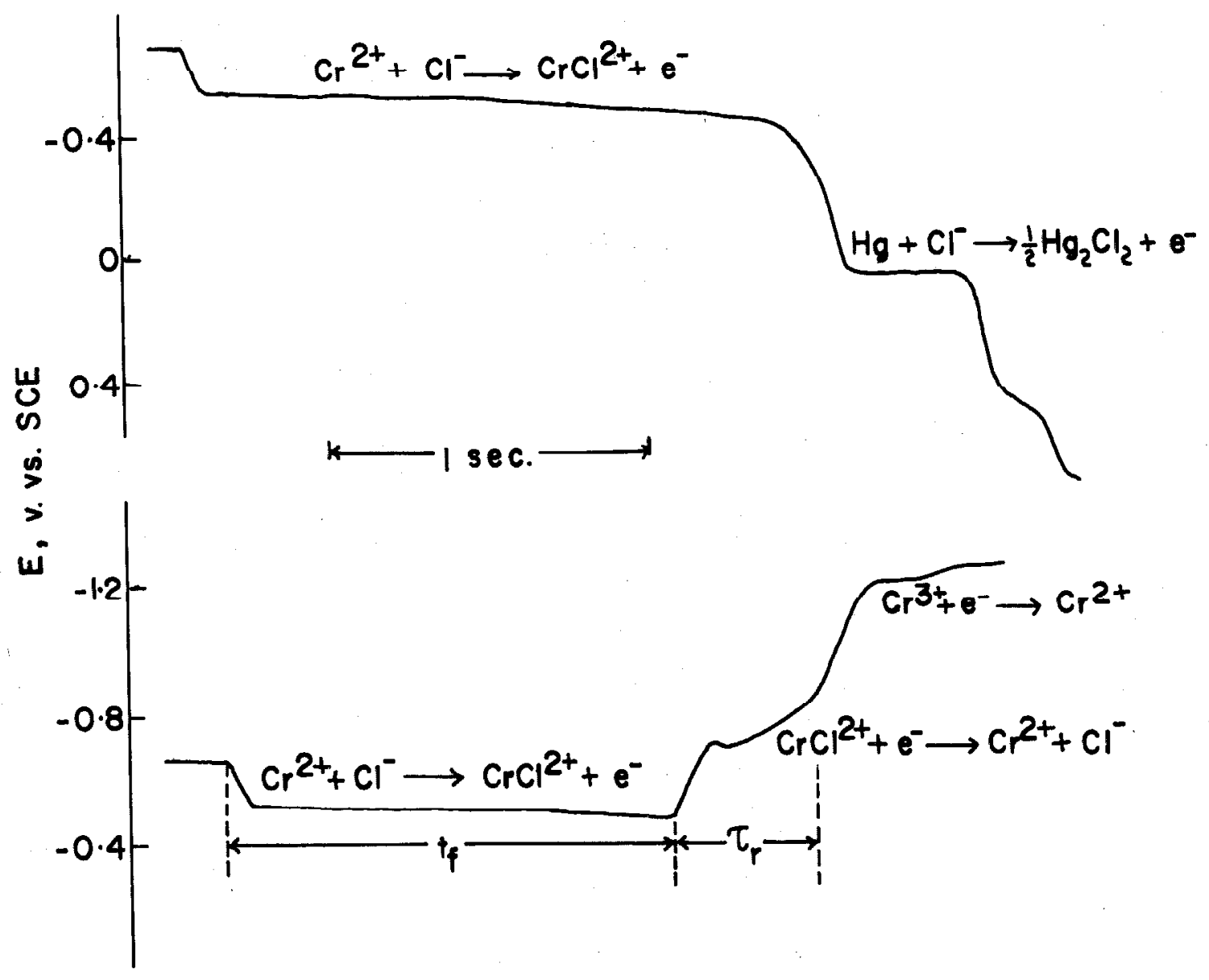

Figure 7. Chronopotentiometric behavior of $\operatorname{Cr}$ (II) in the presence of chloride. Solution: $40 \mathrm{mF} \mathrm{Cr}$ (II) in $0.5 \mathrm{~F} \mathrm{NaCl}, 2 \mathrm{~F} \mathrm{HClO}_{4}$. 


\section{Chronopotentiometric Behavior of $\operatorname{Cr}$ (II)}

In the Absence of Chloride

\section{Variation of the Chronopotentiometric}

Constant with Current Density.

The constancy of the chronopotentiometric constant with current density for $\operatorname{Cr}$ (II) in the absence of chloride is presented in Figure 8. Each $T$ value is an average of six trials. The values of $1 T^{\frac{1}{2}}$ are corrected for spherical diffusion as described in Appendix I. The slight trend to lower values of the chronopotentiometric constant at low current densities is caused by departure from the conditions of spherical arfusion due to the volume exeluded hy the support for the hanglng mercury drop electrode (Figure 13). This point is discussed further in Appendix I. The constancy of the chronopotentiometric constant with current density shows that the reaction is a simple electron transfer within the limits of the experimental conditions.

\section{Reverse Current Chronopotentiometric Behavior.}

The reverse current chronopotentiometric behavior of $\mathrm{Cr}$ (II) was studied in solutions $30 \mathrm{mF}$ in $\mathrm{Cr}$ (II) and $2 \mathrm{~F}$ in $\mathrm{HClO}_{4}$. The current density was $4 \mathrm{ma} / \mathrm{cm} .^{2}$ Two values of the ratio $t_{f} / \tau_{r}$ as defined in Figure 6 were obtained, each an average of five measurements. The values are $2.96 \pm 0.09$ and $3.03 \pm 0.10$. The closeness of these values to the theoretical value of 3.00 is somewhat misleading, for the raw ratios should be corrected upward approximately $8 \%$ to subtract out the effect of $\mathrm{Cr}^{3^{+}}$present in the solution, and corrected downward by approximately $8 \%$ to account for spherical diffusion effects for the $3-4$ 


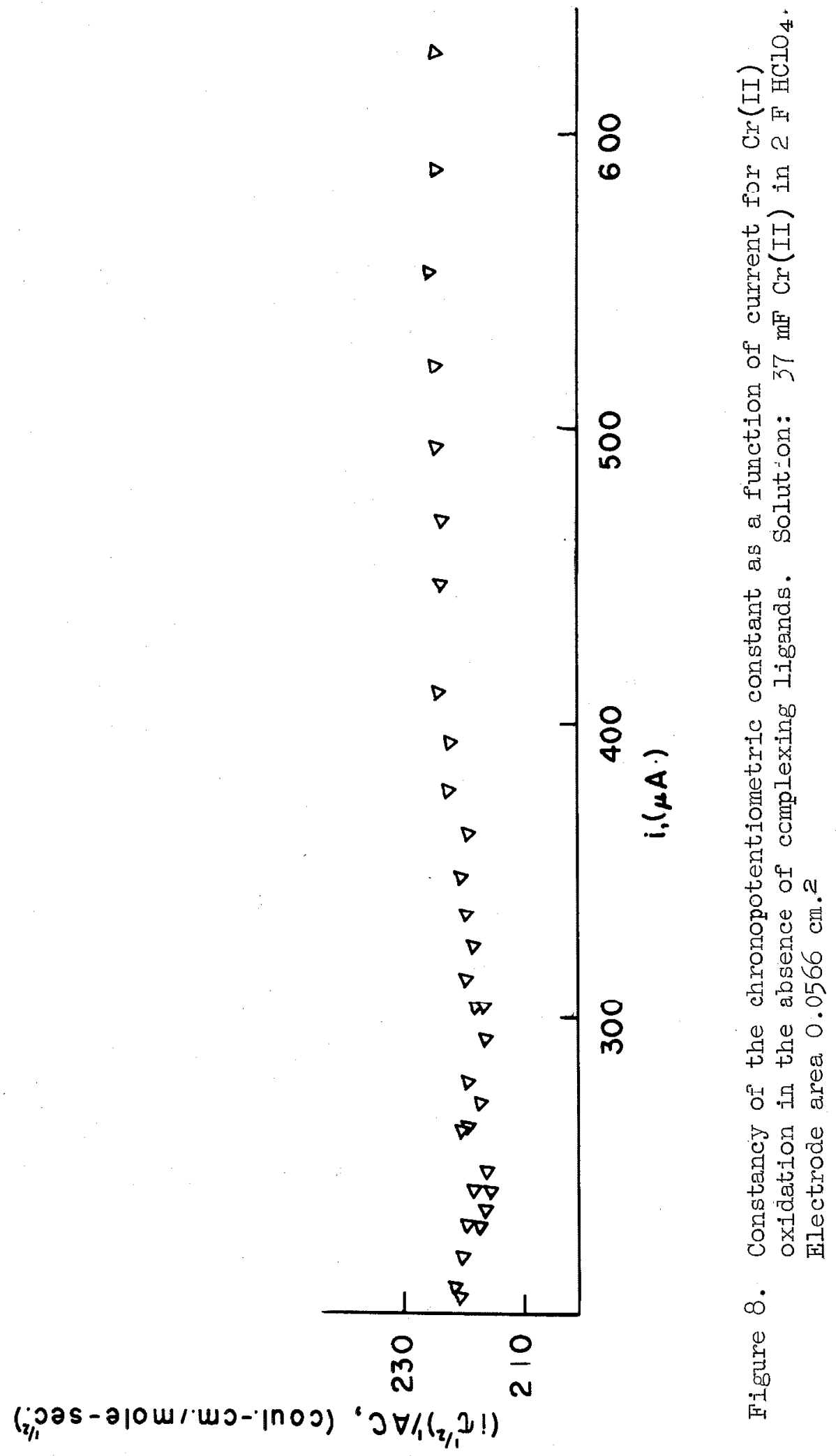


sec. forward times (cf. Appendix I).

The correction for the finite bulk concentration of $\mathrm{Cr}^{{ }^{3}}$ cunnut be made directly by subtraction of a cathodic blank because that transition time was too short and indistinct to measure. Instead it was calculated from the decrease in the forward transition time for Cr(II) from the time when the solution was acided to the cell. " The correction for spherical diffusion was calculated assuming no bulk concentration of the oxidized form. It should be emphasized that very small deviations from the true values of $t_{f}$ ano $\tau_{r}$ can make a very large change in the value of the ratio. However, the agreement shown above is falrly convincing evidence that there are no unexpected effects in the oxidation and reduction of $\mathrm{Cr}$ (II) in the absence of complexing ligands.

\section{Chronopotentiometric Behavior of $\mathrm{Cr}$ (II)}

\section{in the Hresence ot" ChLoride}

\section{Variation of the Chronopotentiometric}

Constant with Current Density.

The chronopotentiometric behavior of $\mathrm{Cr}$ (II) in the presence of cxecsa chloridc was stuaicd under a variety of conditions. The results are presented in Figure 9. There is clearly no variation of the chronopotentiometric constant with current density. These results show no complications for the oxtdation of $\mathrm{Cr}$ (II) In the presence of chloride over the range of conditions employed.

*A portion of the $\operatorname{Cr}$ (II) lost goes to $\mathrm{Cr}$ (III) dimers which are not reduced with $\mathrm{Cr}^{+}(23)$. 


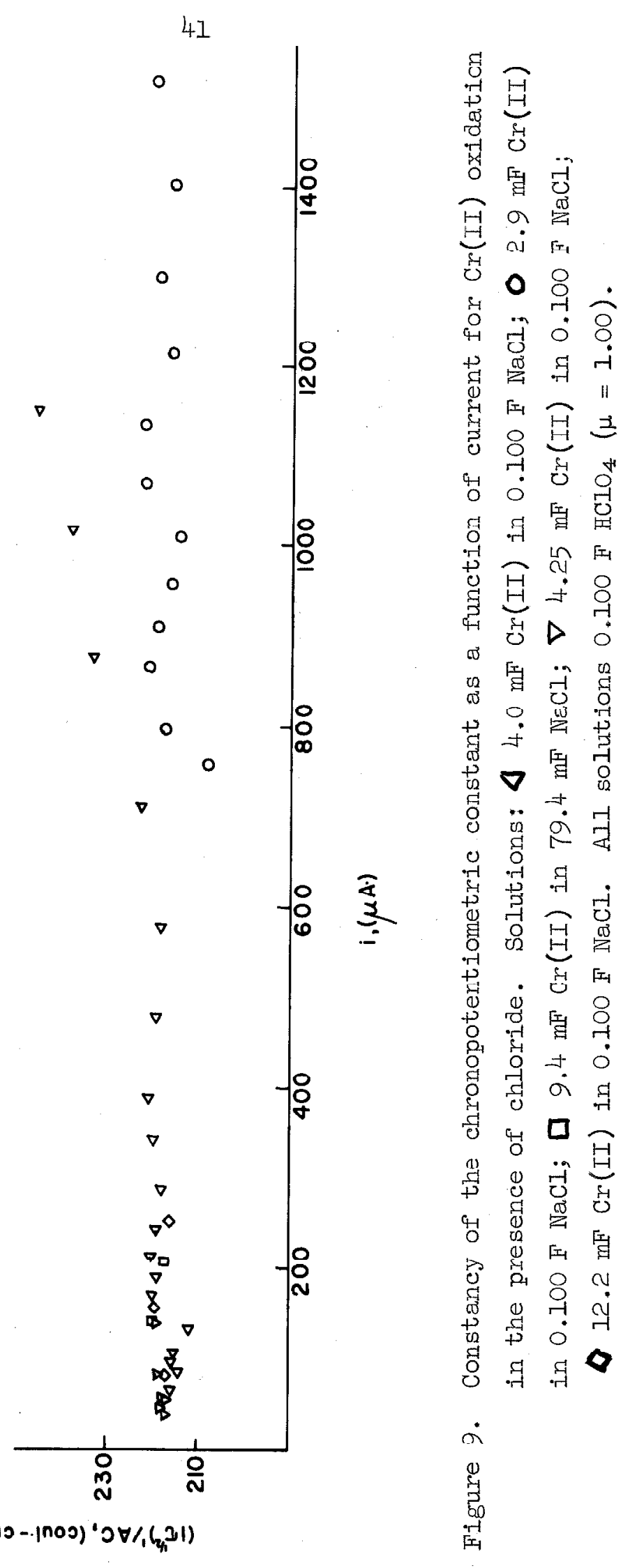


2. Reverse Current Chronopotentiometric Behavior.

The reverse current chronopotentiometric behavior of $\mathrm{Cr}$ (II) in the presence of chloride was studied in solutions $2 \mathrm{~F}$ in $\mathrm{HClO}_{4}, 0.5 \mathrm{~F}$ in $\mathrm{NaCl}$, and $30 \mathrm{mF}$ in $\mathrm{Cr}(\mathrm{II})$. Using forward times of $1-2 \mathrm{sec}$, values of $2.97 \pm 0.07$ and $3.15 \pm 0.02$ were obtained for the ratio of the forward time to the reverse transition time at currents of 263 and $225 \mu \mathrm{a}$. , respectively. Fucil ratio is an average of five values. These values are corrected for spherical aiffusion, the correction varying from 5 to $9 \%$ over the range of forward times used.

These results are acequate proof that in strong chloride solutions $\operatorname{Cr}$ (II) is quantitatively oxiajized to $\mathrm{CrCl}^{2^{+}}$as is to be expected from the results of the controlleo potential experiments.

\section{The Chronopotentiometric Behavior of $\mathrm{CrCl}^{2+}$.}

The chronopotentiometric behavior of the product complex, $\mathrm{CrCl}^{2^{+}}$, was investigated in order to confirm the concluslons drawn above. It is possible that the theoretical value of 3.00 for the ratio of forward time to reverse transition time for the oxiaation of $\mathrm{Cr}$ (II) in chloride solution can be achieved by the cancellation of two competing factors. The first, which tends lo incredse the ratio, is fallure to form $\mathrm{Cr}^{2} \mathrm{2}^{+}$ quantitatively during the anodie process. The second, which tencis to decrease the ratio, is adsorption of the product, $\mathrm{CrCl}^{2}$. The latter poocibility can be renderea extremely implausible by verifying that $\mathrm{CrCl}^{2+}$ is not adsorbed from solution.

The constancy of the chronopotentiometric constant witr current density for $\mathrm{CrCl}^{+}$reduction is 1llustrated in Figure 10. The trend toward lower values of the chronopotentiometric constant at low current 


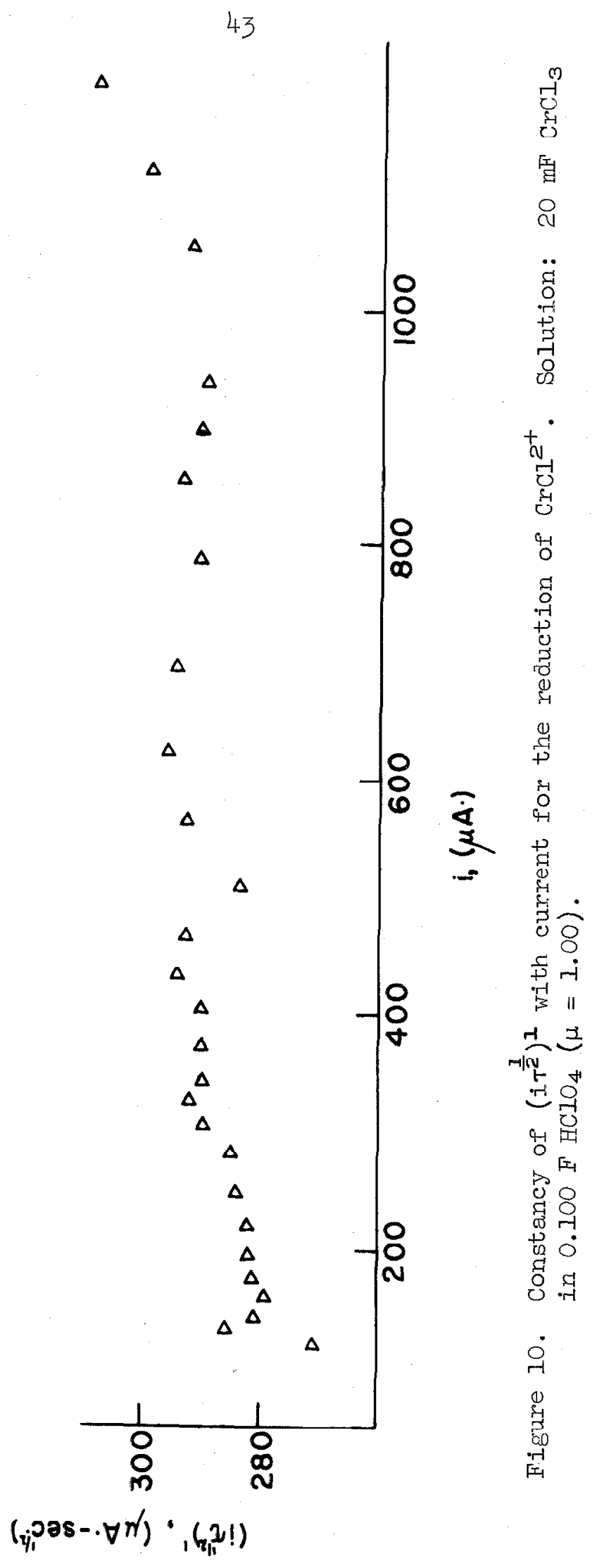


densities is discussed above (page 38). The trend to higher values at high current densities is thought to be an experimental artifact (cf. Figure 9). These results show that the reouction of $\mathrm{CrCl}^{2+}$ is not complicated by prior reaction or adsorption.

The reverse current chronopotentiometric behavior was also studied. The following values of $t_{f} / \tau_{r}$ were obtained:

\begin{tabular}{|c|c|}
\hline$i(\mu a)$. & $t_{f} / T_{r}$ \\
\hline 180 & $3.04 \pm 0.01$ \\
\hline 142 & $3.03 \pm 0.05$ \\
\hline 42 & $3.07 \pm 0.04$ \\
\hline 4.2 & $3.72 \pm 0.12$ \\
\hline
\end{tabular}

Tt is suspected that the high value for the ratio obtained at low current densities is attributable to the method of transition time measurement which tends to give low values for the transition times of indistinct waves such as those obtained for $C r$ (II) at low current densities. These results show that there is no product adsorption.

\section{Experimental Details}

Equipment. Chronopotentiometric experiments were carried out using the circuit shown in $H^{\prime}$ gure 11. The time delay circuit was suggested by Mr. George Lauer of.CIT. This eircuit is designed to allow pre-potentiostated chronopotentiometry with automatic current reversal at short times. It dLffers from wore lypically used and more satisfactory circuits in that the working (indicator) electrode is not grounded. This was not possible here because of severe pick-up of $30 \mathrm{Mc}$. noise if 


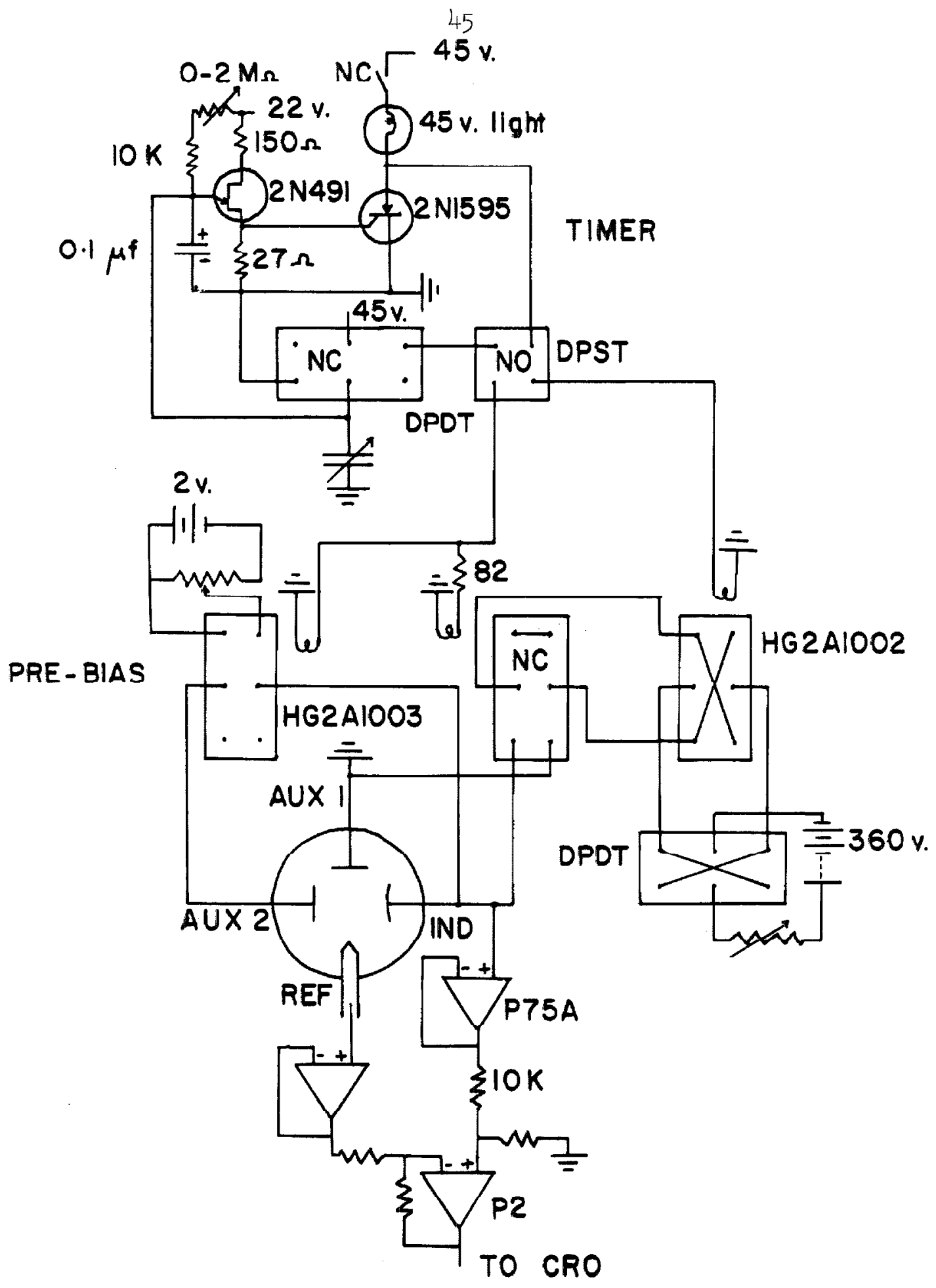

Figure 11. Circuit used in chronopotentiometric experiments. 
the working electrode was grounded. All high frequency pick-up was eliminated by grounding the auxiliary electrode. This circuit is not recommended for general use.

In most experiments it was necessary to adjust the initial potential of the auxiliary electrode to that of the ludicutor elechroue to avold a current pulse when these two electrodes were shorted by the DPDT make-before-break relay which initiates the current flow through the ce 7.7 .

Chronopotentiograms were recorded using either a Moseley X-Y Autograf recorder or a Tektronix Type 531 oscilloscope with Type D Plugin Unit, depending on the time scale of the experiment.

The cell used in most of the chronopotentiometric experiments is pictured in Figure 12. Figure 13 shows some of the accessories. The volume of solution held by the center compartment is approximately 270 ml. This large volume was chosen so that the total amount of $\operatorname{Cr}$ (II) in the cell would be fairly large, since the rate of loss of' cr(II) seems to be independent of the concentration or amount of Cr(II) present. The cell was surrounded by a water jacket (not shown) through which constant temperature watcr was circulatea to maintain the temperature at $27.0^{\circ} \mathrm{C}$.

A separate auxiliary compartment was used because Pt catalyzes the reduction of water by $\operatorname{Cr}(I I)$.

The indicator electrode, 7 in Figure 8, is a hanging mercury drop electrode of the Shain type. Drops of mercury are collected from the DME (5) In the spoon (6) and transferred to the amalgamated platinum button (7). The platinum button was made by sealing 0.020 in. platinum 


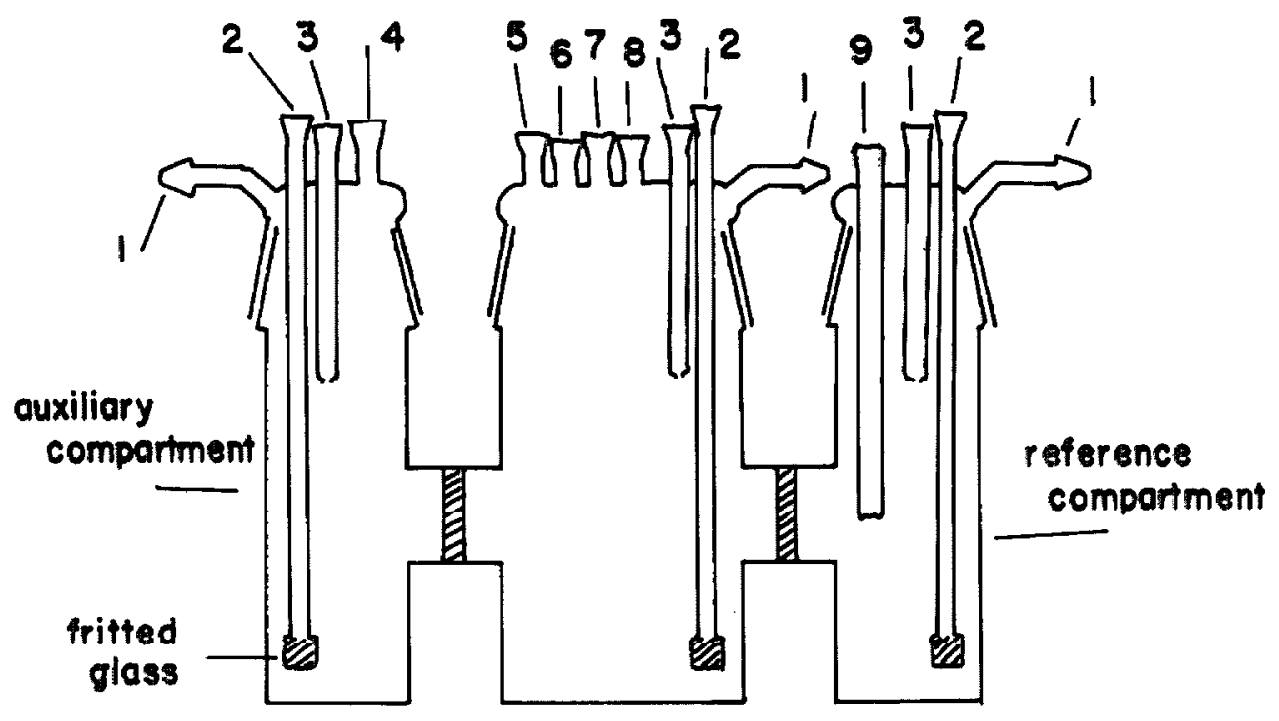

Flyure 12. Cell useä in chronopotentiometric experiments. 1: yas out let to trap; 2,3: $\mathbb{N}_{2}$ inlets; 4-7: inserts (see Figure 13); 8: delivery tube from $\mathrm{Cr}($ II) reservoir; 9: salt bridge of L\&N SCE reference electrode. 

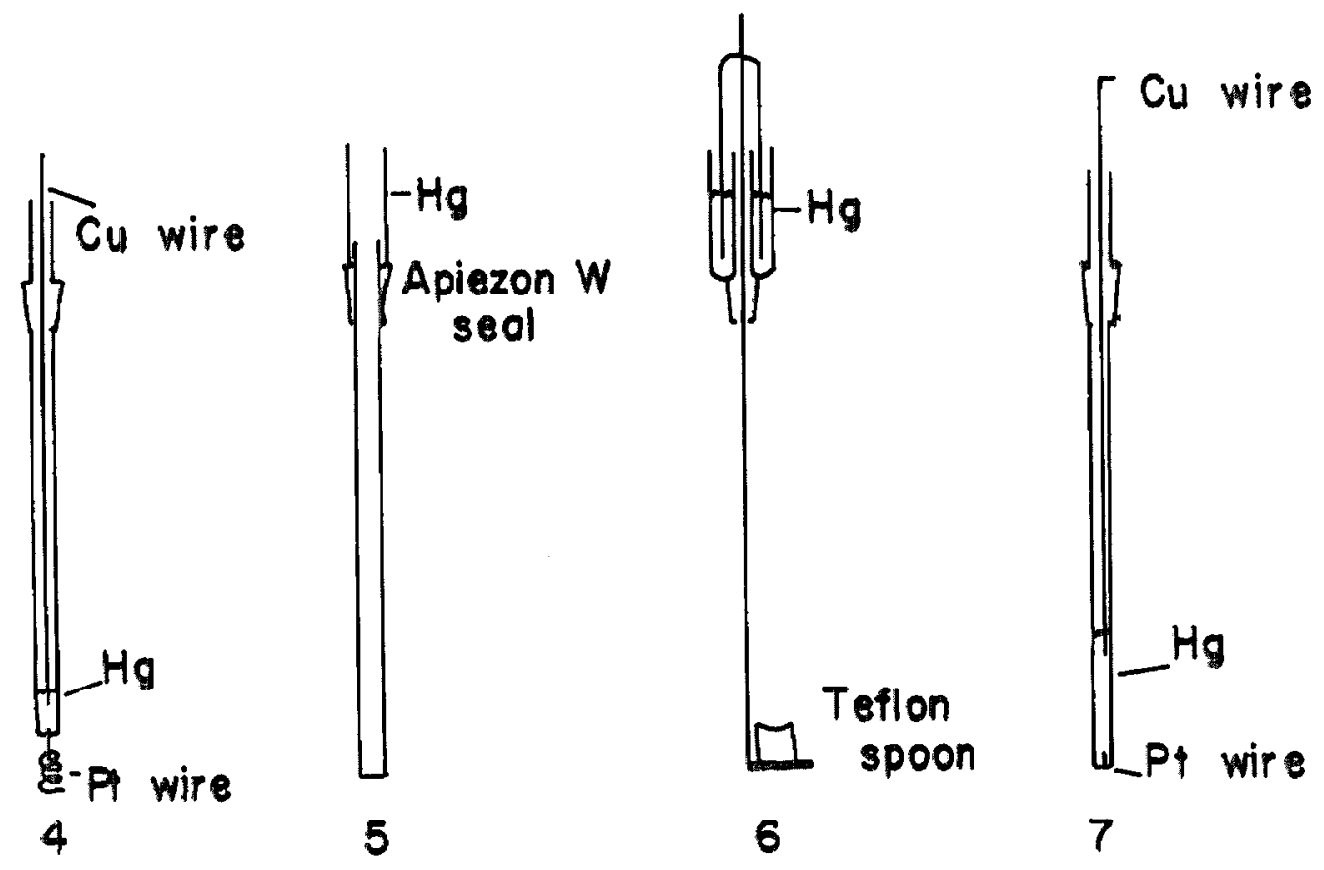

Figure 13. CeIl inserts. See Figure 12. 4: auxiliary electrode; 5: öropping mercury electrode; 6: teflon spoon with mercury seal; 7: indicator electrode. 
wire in pyrex, and then grinaing the end flat. The button was amalgamated by dipping it into sodium amalgam and washing with water.

The sodium amalgam was prepared by dissolving sodium in mercury. Three drops from the DNE were used for the hanging drop electrode. The radius was $0.0671 \mathrm{~cm}$. and the area $0.0566 \mathrm{~cm}^{2}$ as calculated from the weight of 50 drops.

'I'ne reterence electrode was ar I\&dV SCE whose salt bridge was sealed directly into the cell. The salt bridge was filled with saturated NaCl solution before each experiment. The electrode itself was soaked in saturated NaCl solution between cxperimenta. This treatment proventcō any $\mathrm{KClO}_{4}$ precipitation during experiments even though the electrode itself still had KCl present. The potential of the electrode remalned within the $12 \mathrm{mv}$. range between the KCJ_SCE and NaCl-SCE. This nartial conversion of a commercial SCE to NaCl-SCE is more difficult with electrodes having one piece construction.

The outlet trap consists of suceessive flasks containing V(II) in $1 \mathrm{FH}_{2} \mathrm{SO}_{4}$ and water, respectively. The $\mathrm{V}(\mathrm{II})$ solution was kept in the reduced state by zinc amalgan.

Materials. The nitrogen used was CIT nitrogen purified by passing through successive gas washing towers containing $0.1 \mathrm{~F} V($ II) in $1 \mathrm{~F}$ $\mathrm{H}_{2} \mathrm{SO}_{4}, \mathrm{C} .1 \mathrm{~F} \mathrm{Cr}(\mathrm{II})$ in $I \mathrm{~F} \mathrm{H}_{2} \mathrm{SO}_{4}$, and water. The $\mathrm{V}$ (II) and $\mathrm{Cr}(\mathrm{II})$ solutions were kept over zinc amalgam.

Cr(II) stock solutions were prepared by electrolysis as described in Chapter 2. 
Sodium chloride was purified by precipitation from NaCl solution with $\mathrm{HCl}$ gas liberated from $12 \mathrm{~F} \mathrm{ECl}$ by slowly adding $18 \mathrm{~F} \mathrm{H}_{2} \mathrm{SO}_{4}$. Sodium perchlorate stock solutions were prepared by filtering freshly prepared saturated $\mathrm{NaOH}$ solution into a known quantity of aralyzed concentrated $\mathrm{HClO}_{4}(60 \%)$ until the resulting solution was neutral to pH paper and then diluting to volume. Iron, which occurs as a signiflcant impurily in $\mathrm{NeOH}$, is quantititively precipitated as $\mathrm{Fe}(\mathrm{OI})_{3}$ on standing for several weeks. The solution, after filtering, is then ready for use.

This method of preparing $\mathrm{NaClO}_{4}$ solutions is preferred over the addition of $\mathrm{EClO}_{4}$ to $\mathrm{Na}_{2} \mathrm{CO}_{3}$ because of the extreme persistence of carbonate in non-equilibrium concentrations. $\mathrm{NaClO}_{4}$ solutions made with $\mathrm{Na}_{2} \mathrm{CO}_{3}$ on standing slowly develop a white gelatinous precipitate, prob$\operatorname{ably} \operatorname{Mg}(\mathrm{OH})_{2}$.

The source of $\mathrm{CrCl}^{2^{+}}$was Baker and Adamson Chromium Chloride which has the formula $\mathrm{CrCl}_{2}\left(\mathrm{H}_{2} \mathrm{O}\right)_{4} \cdot \mathrm{Cl}$. The major cationic species of this salt is $\mathrm{CrCl}_{2}{ }^{+}$wiich rapialy dissociates in water to give $\mathrm{CrCl}^{2^{+}}$. Solutions were prepared by adding a small amount of the salt to a convenient volume of supporting electrolyte solution $0.1 \mathrm{~F}$ in $\mathrm{HClO}_{4}$ and $0.9 \mathrm{I}$ in $\mathrm{NaClO}_{4}$ or $0.1 \mathrm{~F}$ in $\mathrm{HClO}_{4}$ and $0.9 \mathrm{~F}$ in $\mathrm{NaCl}$. The concentration of the resulting solutions was $5-20 \mathrm{mF}$ in $\mathrm{CrCl}^{+}$.

Procedured. Experiments were carried out in the following manner. A measured volume of supporting electrolyte solution with the desired concentrations of $\mathrm{NaCl}_{1} \mathrm{HClO}_{4}$, and $\mathrm{NaClO}_{4}$ was added to the cell and the solution anỏ cell purged of oxygen. The dropping mercury elec- 
trode anc $\operatorname{Cr}(I I)$ reservoir were then put in place ard after further deaeration and subsequent examination of the chronopotentiometric behavior of the background solution, the desired amount of $\mathrm{Cr}$ (II) stock solution was added through the delivery tube. The solutions are specified by their formal concentrations of $\mathrm{Cr}(\mathrm{II}), \mathrm{HClO}_{4}, \mathrm{NaCl}$, and the ionic strength. It is understood that $\mathrm{NaClO}_{4}$ is present as required to give the speciflea ionic strength.

Treatment of data. Trausition times were measured by the method of Voorhies and Furman (24). Correction for the current going to dosble layer charging was made where indicated by the initlal slope of the chronopotentiometric wave.

Transition times are corrected for spherical diffusion as described in Appenaix I. Corrected values of the product $i r^{\frac{1}{2}}$ are designated $\left(i T^{\frac{1}{2}}\right)^{\prime}$.

Experiments designed to determine the constancy of $i \tau^{\frac{1}{2}}$ with change in current density are complicated by the gradual decrease in the Cr(II) content of the solution due to air oxidation. Typically the $\operatorname{Cr}$ (II) concentration changed at a rate corresponding to 0.05 to 0.2 millimoles/hour. For this reason it was desirable to work at $\mathrm{Cr}$ (II) concentrations as high as possible. This has the second acivantage of requiring much higher current densities which in turm sharpens the poorly àefineā $\mathrm{Cr}$ (III) reduction wave.

In orajer to take into account the aecrease in Cr(II) concentration during the course of an experiment, the $\mathrm{Cr}$ (II) concentration was measured chronopotentiometrically at a fixed current denaity at inter- 
vals of 20 minutes during each run. The concentrations of $\mathrm{Cr}$ (II) were plotted versus real time to obtain the instantaneous bulk concentration of $\operatorname{Cr}(I I)$. The chronopotentiometric constant presented is calculated using this instantaneous concentration. The measured values of the concentration did not always lie on a smooth curve but the concentration was obtained as a function of real time by the best smooth curve through the points. This simply increases the scatter of the points and does not affect the general reliability of the results.

\section{Discussion}

The smallest it product is about $I \mu \mathrm{C}$ and the shortest transition time about $1 \mathrm{~ms}$, for these experiments. These two values fix the maximum amount of reactant adsorption and the minimum value of the product $k_{f}\left(k_{f}+k_{b}\right)^{\frac{1}{2}} / k_{b}$ for a prior chemical reaction. Assuming that a $10 \%$ variation in the chronopotentiometric constant indicates adsorption or prior chemical reaction, these limits are $1 \mu \mathrm{C} / \mathrm{cm} .{ }^{2}$ of adsorbed material and $k_{f}\left(k_{f}+k_{b}\right)^{\frac{1}{2}} / k_{b}=500 \mathrm{sec} .^{-\frac{1}{2}}$, respectively. These limits are extreme enough to imply that neither $\mathrm{Cr}$ (II) oxidation nor $\mathrm{CrCl}^{2^{+}}$reduction is complicated by reactant adsorption or prior chemical reaction.

The absence of any evidence for reactant adsorption in either case shows that the reaction does not proceed via a long lived adsorbed. intermediate. Absence of kinetic complications shows that $\mathrm{CrCl}^{+}$formation is not important to the chloride bridge oxidation mechanism.

These results eliminate two processes which were potentially important in bridge formation. However, the role of adsorbed chloride is still not well-defined. We can obtain more specific information 
about the role of adsorbed halide by studying the effects of bromide and lodide un Cr(II) oxidation ab mercury electrodes. Ellher Ifgand might have some unexpected effect that would clarify the role of adsorption. Failing this, a comparison of the effects of the three ligands should give some mechanistic information. 
Chapter 5

THE OXIDATION OF CR(II) AT MERCURY EIRCTRODES

IN BROMTDE SOLUTIONS

The smooth gradation in most of the properties of the halides from chloride through iodide leads us to predict that the effect of bromide on the oxidation of $\mathrm{Cr}$ (II) will be qualitatively similar to that of chloride.

Typical reverse current chronopotentiometric behavior of $\mathrm{Cr}$ (II) solutions with large excess bromide is shown in Figure 14. The reverse wave is for the reduction of $\mathrm{CrBr}^{2}$. The apparent reversibility is much greater than in the case of chloride (Figure 7). It is also interesting to note that the reduction of $\mathrm{CrBr}^{2^{+}}$takes place at potentials well anodic of the standard potential for the couple $\operatorname{Cr}(I I) / \mathrm{Cr}^{3^{+}},-0.65 \mathrm{v}$. Vs. SCE. This phenomenon is possible because the favored oxidation mechanism (1igand bridging) gives a thermodynamically unfavored product ( $\mathrm{CrBr} \mathrm{Z}^{+}$) which is not in equilibrium with the thermodynamically favored product $\left(\mathrm{Cr}^{3^{+}}\right)$. It is, in fact, observed because the reduction of $\mathrm{CrBr}^{2+}$ is suffictenliy reversivle lhat lhe chronopotentiometric wave occurs near the half-wave potential for the couple $\mathrm{Cr}(\mathrm{II}) / \mathrm{CrBr}^{2+}$. This is in contrast with $\mathrm{Cr}^{3^{+}}$which is so irreversibly reduced that under most circumstances there is concomitant hydrogen ion reduction. 


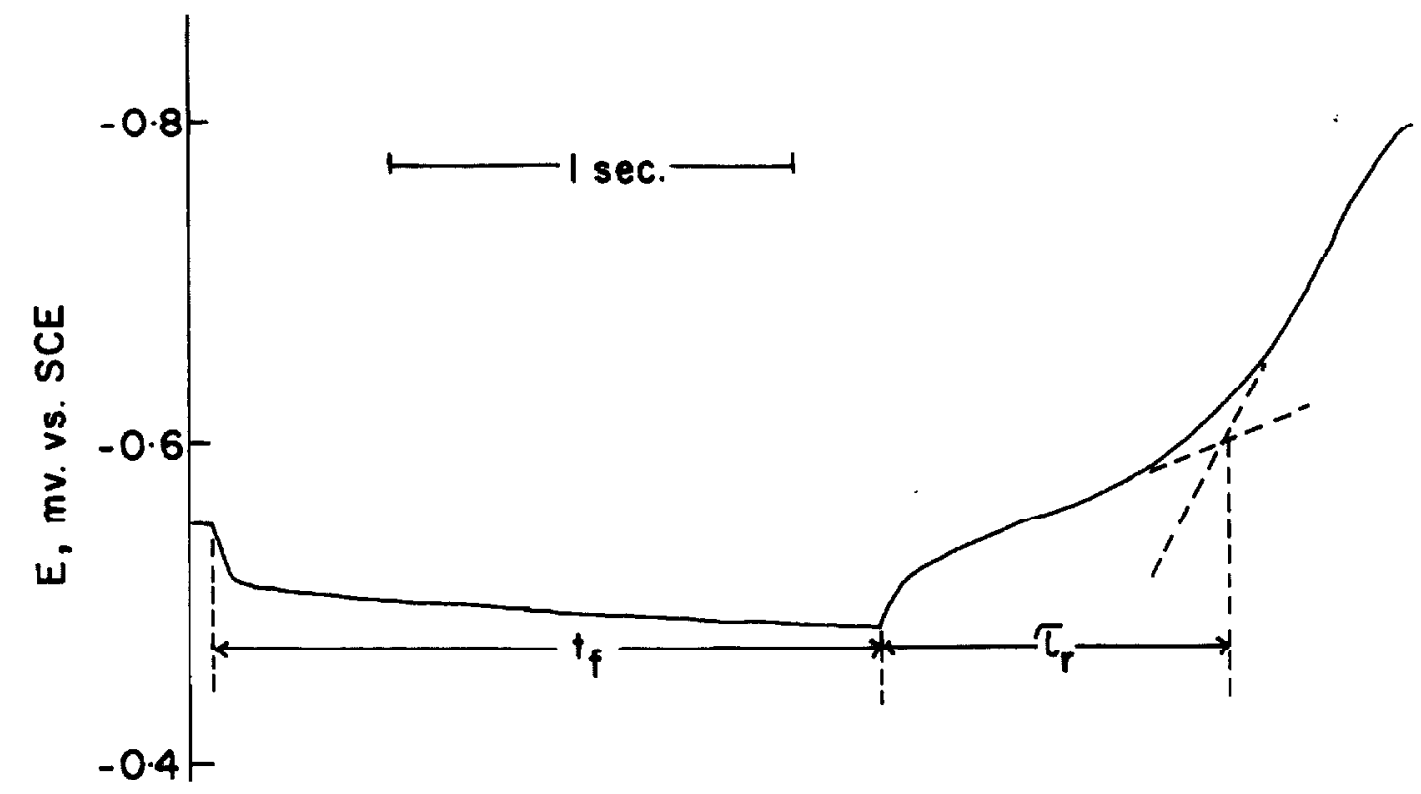

Figure IL. Skronopotentiometric wave with current reversal for Cr(II) in bromiae solution. Solution: $2.65 \mathrm{mF} \mathrm{Cr}$ (II) in $0.100 \mathrm{~F}$ $\mathrm{NaBr}, 0.100 \mathrm{FIClO}_{4}(\mu=1.00) \cdot i_{0}=155 \mu \mathrm{A} . / \mathrm{cm} .2$ 


\section{Chronopotentiometric Behavior}

1. Variation of the Chronopotentiometric Constant with Current Density; Solutions Containing Excess Bromide.

The oxidation of $\operatorname{Cr}$ (II) in excess bromide was studiec. chronopotentiometrically. It was found that there is no variation of the chronopotentiometric constant with current density as is illustrated in Figure 15. This shows that the reaction is a simple electron transfer as described in Chapter 4.

Bxperimental procedures. The equipment and procedures used in the investigation of the constancy of the chronopotentiometric constant with current density are described in Chapter 4.

Sodium bromide was purified by trealing a rol seblureted solution of the salt with decolorizing charcoal, recovering the salt as $\mathrm{NaBr} \cdot 2 \mathrm{H}_{2} \mathrm{O}$, drying at $150^{\circ} \mathrm{C}$. to obtain the anhyourous salt, and recrystallizing it twice from absolute cthanol. Thid is an cxtromcly unsatiafactory procedure and is not recommended.

2. Dependence of the oxidation of $\mathrm{Cr}$ (II) on Bromide concentration.

The oxidation of $\operatorname{Cr}$ (II) was also studied chronopotentiometrically in a series of solutions in which the concentration of Cr(II) was fixed. and the bromide concentration varied from zero to an excess amount. The results are shown in Figure 16.* I shows the wave which appears for $\operatorname{Cr}$ (II) oxidation in the absence of bromide. The composition of the

*Tho waver for Cr(II) oxidation become slightly shorter from I to IV in Figure 16 due to air oxidation of $\operatorname{Cr}(I I)$. 


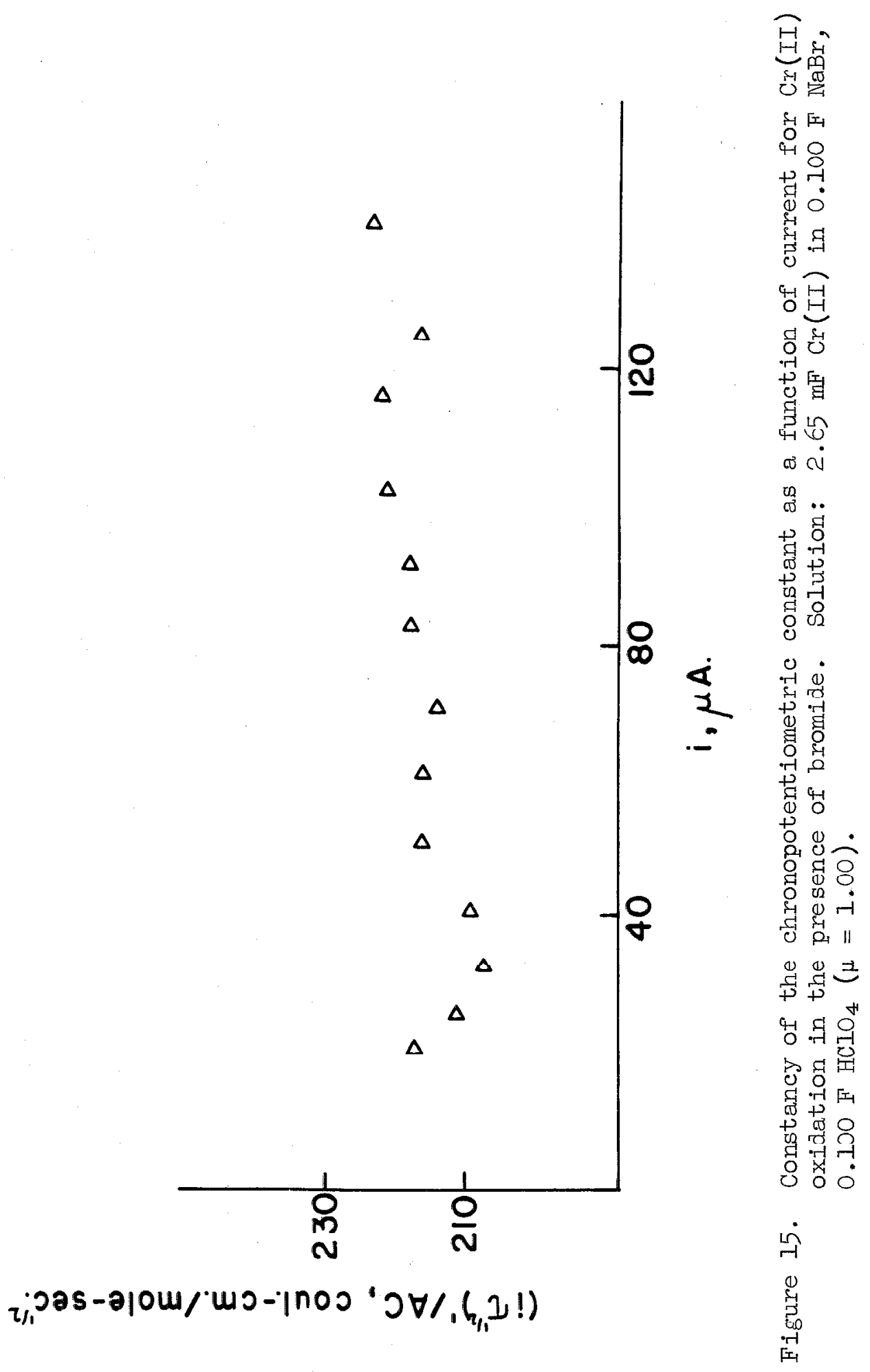


$\leftrightarrow-0.1 \sec \longrightarrow$

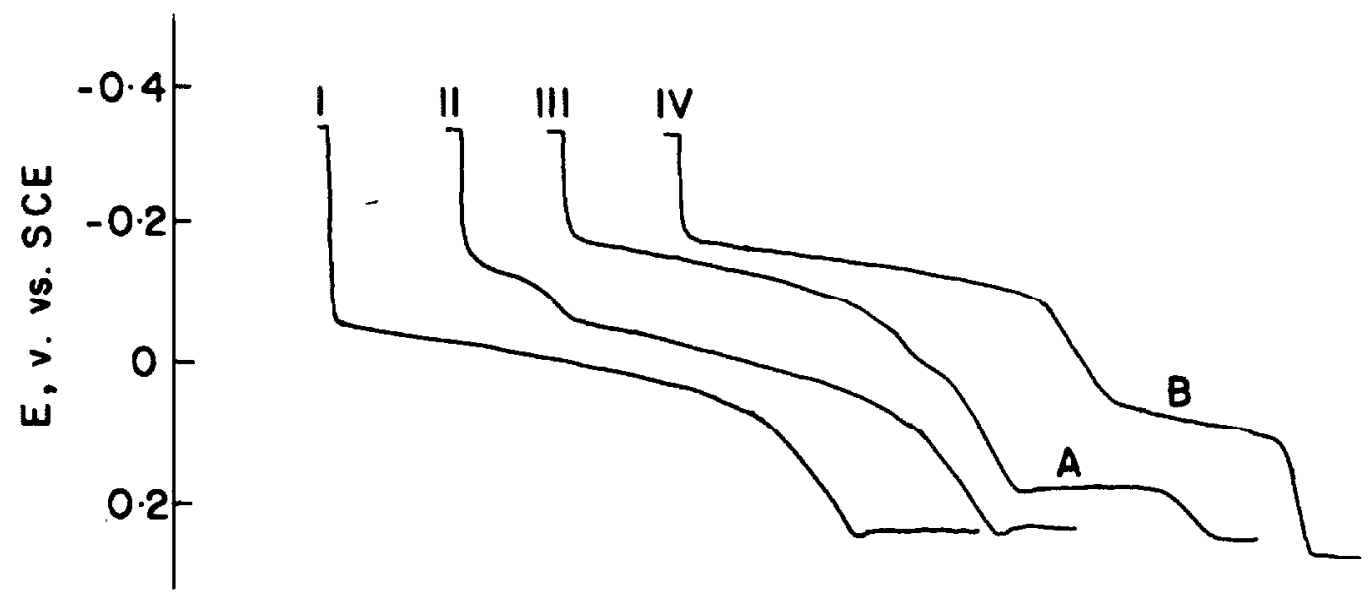

Figure 16. Chronopotentiometric behavior of $\mathrm{Cr}$ (II) in solutions containing small amounts of bromide. Values of the flux ratio, $\left(\mathrm{Br}^{-}\right) \mathrm{D}_{\mathrm{Br}^{\frac{1}{2}}} /\left(\mathrm{Cr}(\mathrm{II}) \mathrm{D}_{\mathrm{Cr}}{ }^{\frac{1}{2}}\right.$ are: I, O; II, 0.39 ; III, $0.90 ;$ IV, I.3I. 
solution is $0.219 \mathrm{~F} \mathrm{HClO}_{4}, 15.1 \mathrm{mF} \mathrm{Cr}(I I), 5.6 \mathrm{mF} \mathrm{Cr}^{3^{+}}(\mu=1.00)$.

In II we see the result of adding sufficient sodium bromide solution to make the bromide concentration $3.04 \mathrm{mF}$. A new wave whose length corresponds to a bromide concentration of $3.10 \pm 0.04 \mathrm{mF}$ appears at a potential cathodic to the originaI $\mathrm{Cr}$ (II) oxidation wave, This wave is due to the oxidation of $\mathrm{Cr}$ (II) via a bromide bridge to form $\mathrm{CrBr}^{2+}$.

Similar experiments were done in chloride solutions but there was no transition corresponding to a process diffusion limited by chloride. The fact that a transition appears in bromide solution inalcates that the formation of $\mathrm{CrBr}^{2^{+}}$via ligand bridging is more facilitated than the similar reaction with $\mathrm{CrCl}^{+}$as its product. It should also be polnted unt that the wave appearing in II is very sensitive to the experimental conditions. The absolute concentrations of $\mathrm{Cr}$ (II) and bromide as well as the current density must be properly adjusted in order to sec the ware.

II shows the result of adding an almost equivalent amount of bromide. The transition time for the bromide dependent process cannot be measured because of the indistinctness of the wave, but there is clearly a transition limited by bromide diffusion before the much sharper break in potential associated with the $\mathrm{Cr}$ (II) concentration. The following wave (A) which occurs at approximately $+0.135 \mathrm{v}$. is undoubtedly due to bromide. The question that immediately arises is why, if the concentration of bromide at the surface of the electrode is zero, as is required by the transition for the bromide diffusion limited process, does one see a wave which implies the presence of bromide. This is a 
well documented and reproducible effect which occurs with other ligands as well as bromide (25). The apparent contradiction between the absence of bromide and the presence of a mercurous bromide wave arises because attention is too closely focused on the condition that the concentration of bromide at the electrode surface is zero after the transition for the bromide diffusion controlled process. I'he important point is not this fact, but rather its cause, namely that the reaction rate demanded by the controlled. current is greater than the rate of diffusion of bromide to the electrode. The initial potential break occurs because the rate of bromidc diffusion is not sufficient to support the current demanded. A potential transition occurs then to a more anodic potential at which point a new reaction occurs, in this case the direct oxidation of $\mathrm{Cr}$ (II) unassisted hy bromide. While on the plateau for the bromide-independent process, the oxidation of $\mathrm{Cr}$ (II) assisted by bromide continues at a rate determined by the rate of diffusion of bromide to the electrode. When the concentration of $\mathrm{Cr}$ (II) at the electrode surface is reduced to zero another transition occurs. At this point the potential shifts to a still more anodic value until a third reaction begins (A). By comparing II and. III of Figure 16 we conclude that this reaction is due to bromide.

There is extensive evidence that there is more than one electron per bromide in the oxidation of mercury in the presence of bromide. This is illustrated in Figure 17 by the comparison of calculated and measured chronopotentiometrie constanls. It is also observed lial in reverse current chronopotentiometry the first wave for mercury oxidation in the presence of bromide exhibits a reverse wave which is much shorter than 


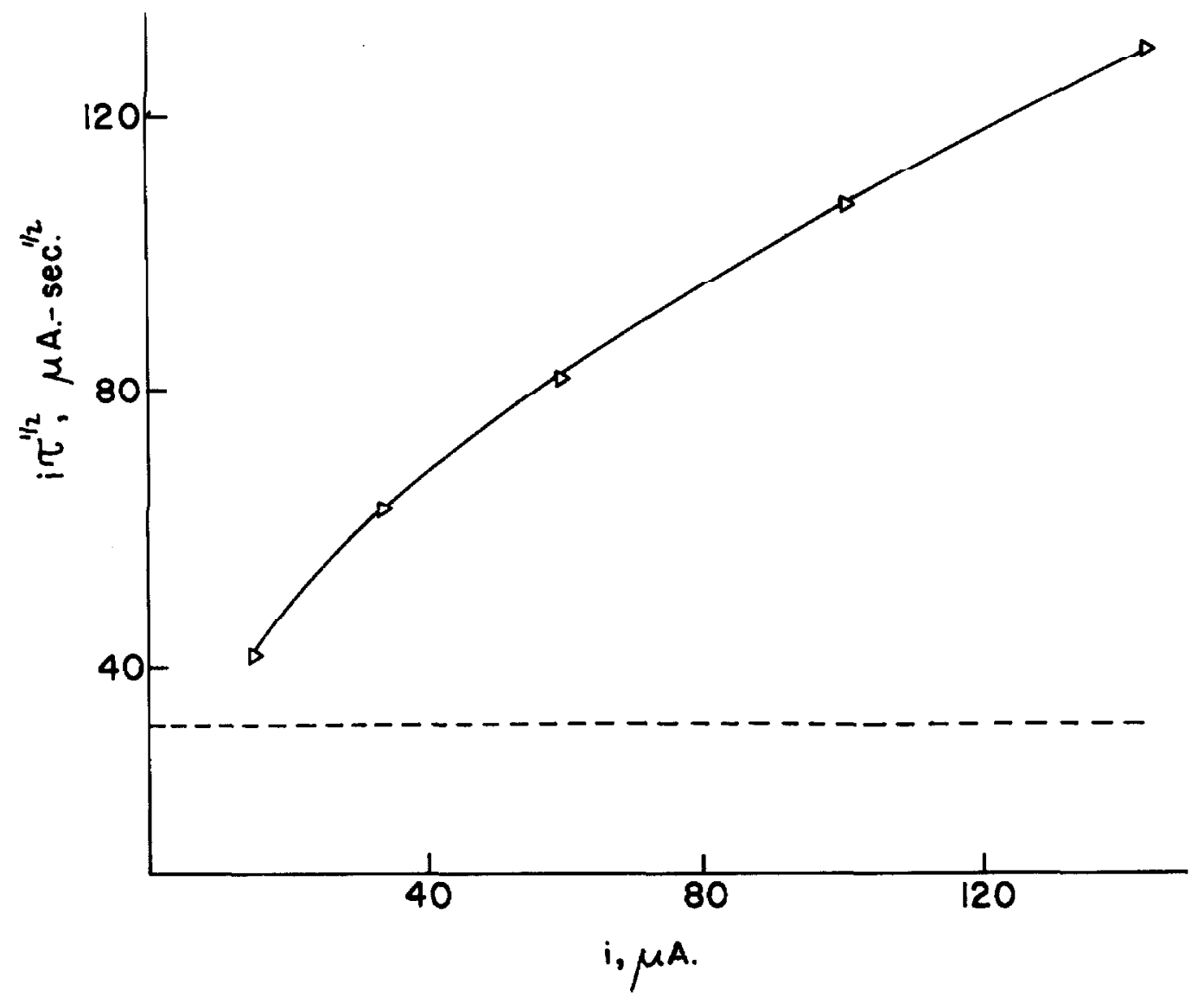

Figure 17. Variation of $i \tau^{\frac{1}{2}}$ with current for the oxidation of mercury in bromide solution. Solution: $1.01 \mathrm{mF} \mathrm{NaBr}$, $0.088 \mathrm{~F} \mathrm{HClO}_{4}(\mu=0.99)$. 
the forward time. This shows that the product of the oxidation is rot simply $\mathrm{Hg}_{2} \mathrm{Br}_{2}$, for if that were the case the product would stay on the electrode and the forward and reverse times would be equal.

By analogy with work that has been done on calomel formation (26) we may reasonably assume that the initial product in mercury oxidation in the presence of bromide is $\mathrm{HgBr}^{+}$so that the effective value of n tor promide is 2. The rate of mercury oxldablon lis known to be rapia (27); It is probable that at the potential of the first mercury wave the rate for mercury oxidation to $\mathrm{HgBr}^{+}$and $\mathrm{Cr}$ (II) oxidation to $\mathrm{CrBr}^{2}$ are comparale and the two processes compete for bromidc.

The effective $n$ value of 2 for the mercury process momentarily increases the effect of bromide sufficiently to satisfy the current requircment. Nosuming that the amount of current going to the mereury process is $1 / 3$ of the total current, the bromide wave corresponds to $240 \mu \mathrm{C} / \mathrm{cm}^{2}$ of material, which is a reasonable value for monolayer coverage. The sharn transition characteristic of processes which change the nature of the electrode surface is then aue to the passivation wich occurs when a monolayer of material has been deposited on tie electrode. These are plausible explanations for the observed behavior which are not intended to be conclusive. The posstbility of devising experiments to clarify the observed behavior is limited by the complexity of the oxidation of mercury in the presence of bromide alone, which is as yet poorly understood.

In IV of Figure 16 we see a well developed wave tor the oxidation of $\mathrm{Cr}$ (II) to $\mathrm{CrBr}^{2}$ in a significant excess of bromide over $\mathrm{Cr}$ (II). The $\operatorname{Cr}(I I)$ wave is followed by a wave for mercury oxidation (B). The 
potential of the wave $\mathrm{B}$ corresponois to that for $\mathrm{Hg}_{2} \mathrm{Br}_{2}$ formation at the calculabed effective concentration of bromidc. Its lcngth docd not cor respond to that concentration; this is typically observed for oxidation of mercury in the presence of bromide. However, waves $A$ and $B$ are equal In length within the uncertainty in determining the transition time.

Discussion. A point arises in the preceding discussion of the promide wave which, although not subtle, is sufflciently important to deserve further emphasis.

There is no mathematical distinction between saying that the concentration of bromiae at the electrode surface is zero and saying that bromide is used up as tast as it arrives at the surface. The statement that the transition occurs when the concentration of the reacting material at the electrode surface has reached zero, and that the cuncentrution remains zero from that time on is a general statement of general validity which applies as fully in this particular case as in more ordinary cases. The difficulty in interpretation arises because attention becomes focused on the simple statement of the boundary condition for the chronopotentiometric diffusion problem,

$$
C(0, t \geqq T)=0
$$

and the physical situation giving rise to this conoition is lost. The important thing to keep in mind is that for $t \geqq T$ the effective rate for the removal of the reacting species at the electrode is greater than the rate of diffusion of that species to the electrode. This effective rate may be the sum of pseudo-first-order rates for several processes. 
Experimental procedures. The circuitry, method of measurement, and sululions lueve been discussed above. The cell employcd in thodo crx periments is shown in Figure 18. The o-ring joint provides a good solution to the problem of making a greaseless airtight seal between cell top and battom. The cell volume is approximately $150 \mathrm{ml}$.

The reference electrode was a small Beckman SCE. The salt bridge was the cracked glass type made by sealing a soft glass bead into a pyrex tube. I $\mathrm{FNaNO}_{3}$ solution was used in the salt bridge.

The indicator electrode was a Kemula type hanging mercury drop electrode available from Brinkman Instruments, Inc. The electrode area was $0.0409 \mathrm{~cm}^{2}$ as calculated from the weight of 10 drops.

Mallinkrodt triple distilied quality mercury was used.

In these experiments the supporting electrolyte solution was added to the cell and the system deaerated. Then mercury was added to fill the two wells in the bottom of the cell (which served as mercury pool auxiliary clcetrodes) and the Kemula hanging mercury drop electrode was put in place. The seal between the Kemula electrode anci the cell joint was made air tight with Teflon tape. Finally, after further deaeration the $\operatorname{Cr}$ (II) reservolr was put in place ana the appropriate amount of $\operatorname{Cr}$ (II) stock solution adajed to the cell.

Successive $0.1 \mathrm{ml}$. portions of deaerated $\mathrm{NaBr}$ solution were added to the cell by syringe through a serum cap.

The same procedure was followed in other experiments using this cell with the exception that in most experiments it was not necessary to add solution to the cell after the $\operatorname{Cr}$ (II) had been added. 


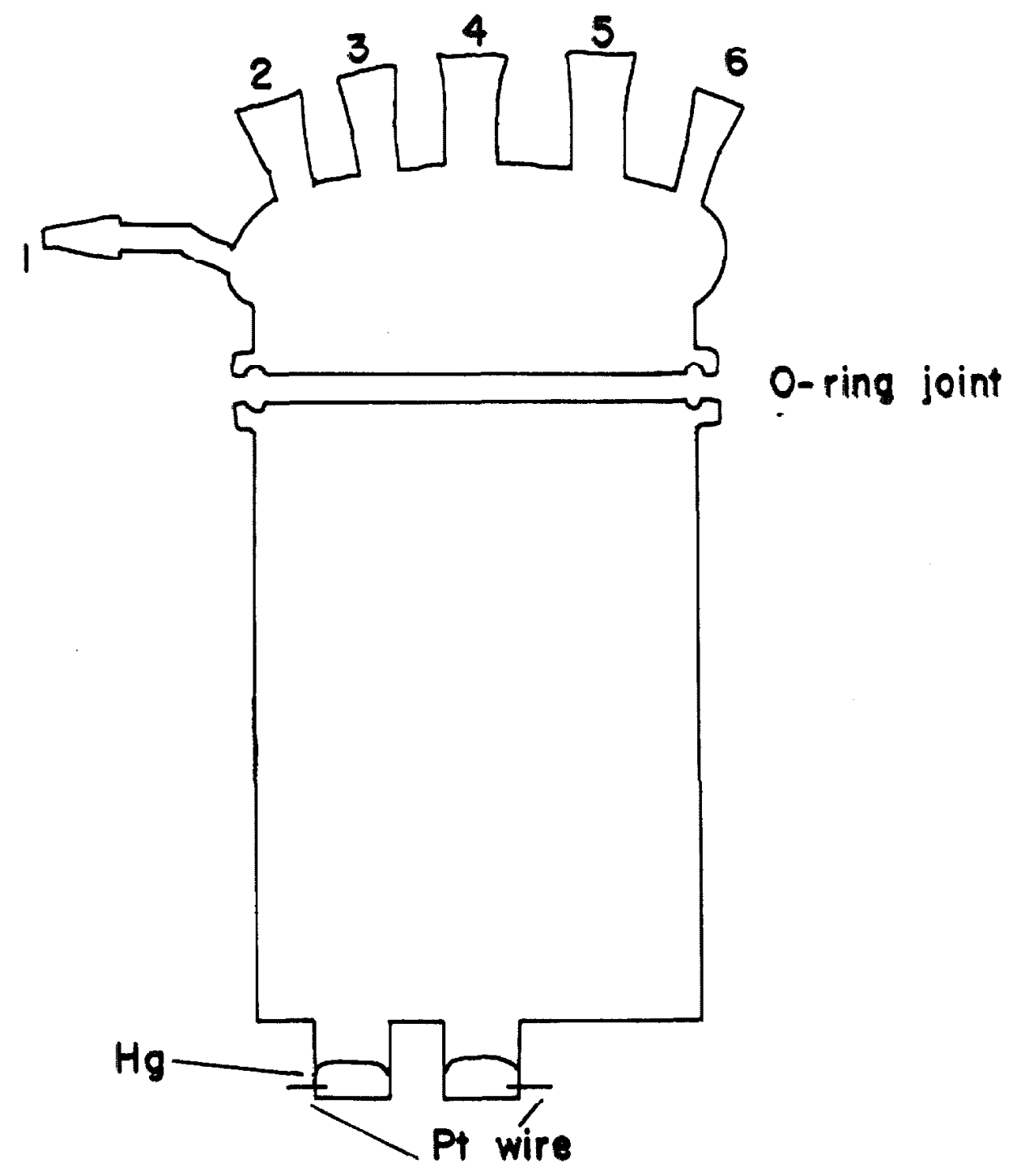

Figure 18. Cell used for electrochemical studies on $\mathrm{Cr}$ (II) solutions. 1: to outlet trap; 2: $N_{2}$ Inlet; 3 : salt bridge for reference electrode; 4: Kemula indicator electrode; 5: spare; 6: $\mathrm{Cr}$ (II) inlet. 
The cell shown in Figure 18 was also provided with a water jacket (not shown) which in conjunction with a constant temperature bath was used to maintain the temperature at $27.0^{\circ} \mathrm{C}$.

\section{Reverse Current Chronopotentiometric Rehavior;}

\section{Large Excess Bromlde.}

The oxidation of $\mathrm{Cr}$ (II) in excess bromide was investigated using reverse current chronopotentiometry in order to determine if the procuct of the oxidation is entirely $\mathrm{CrBr}^{2}$. If complete inclusion does occur, and the results are appropriately corrected for the effects of spherical diffusion as discussed ir Appendlx $I$, tine ratio of the forward time, $t_{f}$, to the reverse time, $\tau_{r}$, as defined in Figure 14 should be 3.00 .

Figure 19 gives some results obtained in $0.1 \mathrm{~F}$ bromide solution with $2.65 \mathrm{mF} \mathrm{Cr}(\mathrm{II})$. The dotted Iine shows the expected ideal behavior. Each point is an average of 3 to 7 measurements. The forward times are In the range 1.4 to $2.1 \mathrm{sec}$. and the currents 4 to $24 \mu \mathrm{a}$. The values are not corrected for spherical diffusion. However, as shown in Appendix I, the effect of spherical aiffusion is to increase the value of the ratio $t_{f} / T_{r}$, which would shift the points below the dotted line.

Several possible explanations for this behavior can be ruled out. The current was measured during the forward and reverse waves and found to be constant to $0.2 \%$. There was no anodic current spike on reversal. The cathodic background was carefully checked. No tracc of reduciblc impuritles was found. Product adsorption during the anodic cycle is virtually rulea out by the ideal benavior of $\mathrm{CrBr}^{2+}$ reduction, which is demonstrated below. 


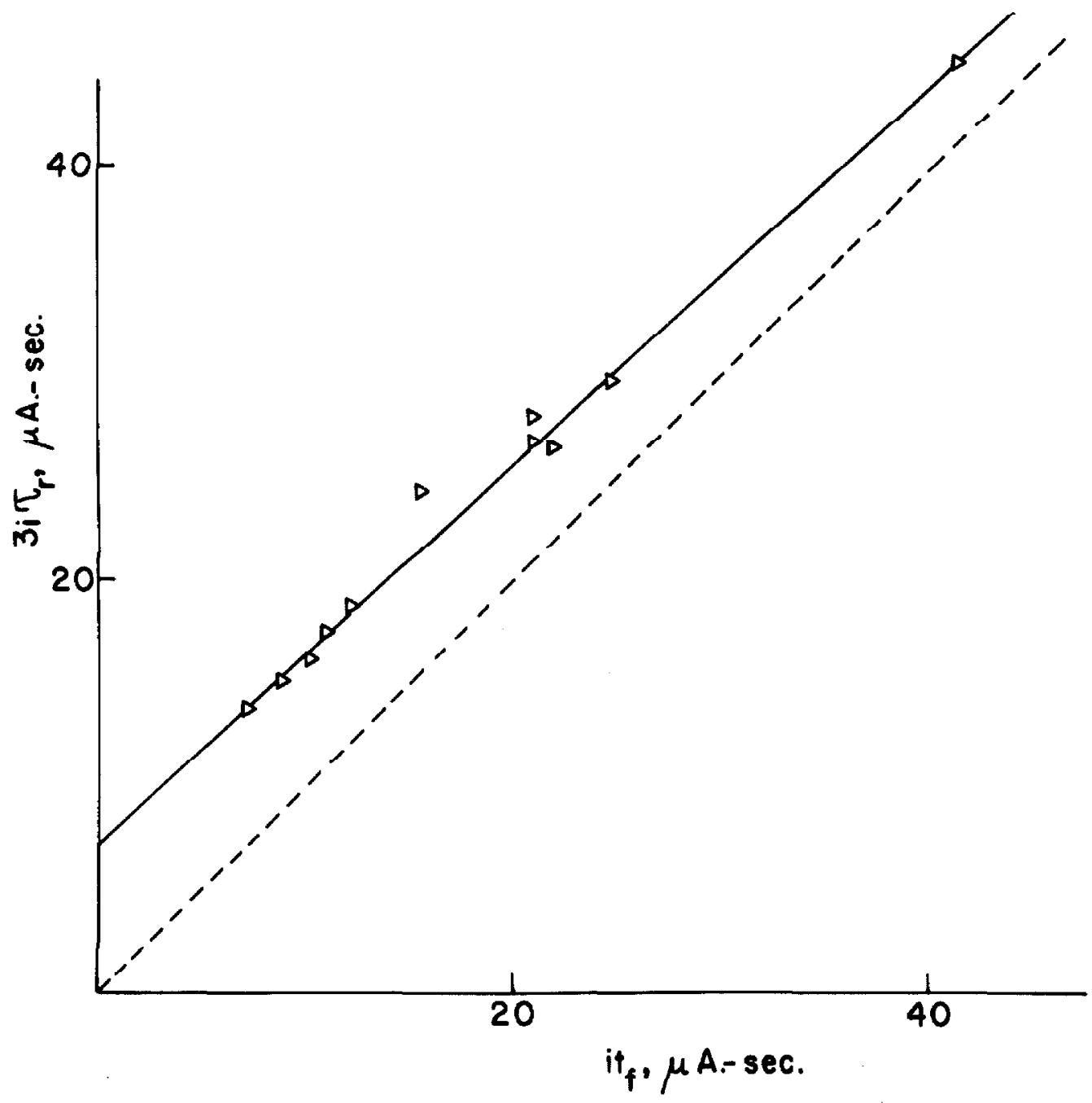

Figure 19. Reverse current chronopotentiometric behavior of $\mathrm{Cr}$ (II) in bromide solution. Solution: $2.65 \mathrm{mF} \mathrm{Cr}$ (II) in $0.100 \mathrm{~F}$ $\mathrm{NaBr}, 0.100 \mathrm{~F} \mathrm{HClO}_{4}(\mu=1.00)$. The dotted line shows the expected behavior for an ideal system under conditions of linear diffusion. 
It is suggested that the abnormally long reverse waves are due to having oxiaized material trapped in the wedge-shaped volume above the drop and below the glass caplllary. This trapping effect is discussed in more detail in Appendix I.

For purposes of comparison some data for the reverse current behavior of an ideal system, Fe(II) in pyrophosphate solution at $\mathrm{pH} 2$, is presented in Figure 20. These data were obtained at a current of $15 \mu \mathrm{a}$. with $t_{f}$ in the range 1.5 to $3.0 \mathrm{sec}$. The behavior is seen to be the same as that for Cr(II) oxidation in bromide solution.

Experimental procedures. The chronopotentiometric circuit is shown in Figure 11 and the cell in Figure 10.

other experimental details are discussed on Page 64. The experiments on the Fe(II) system are discussed in more detail in Appendix I.

Diccussion. These results are marred by the failure of the experimental conditions to correspond to the simple spherical diffusion case. However the explanation for the deviation of the results from the expected behavior is sufficiently convincing that these results are considered to be an adequate demonstration that in solutions with large bromide concentration the product of the oxidation of $\mathrm{Cr}$ (II) is entirely $\mathrm{CrBr}{ }^{2+}$

4. Solutions with Low Bromide Concentration

The results presented thus far for the oxidation of $\mathrm{Cr}$ (II) in the presence of bromide show the behavior predicted by the ligand bridging 


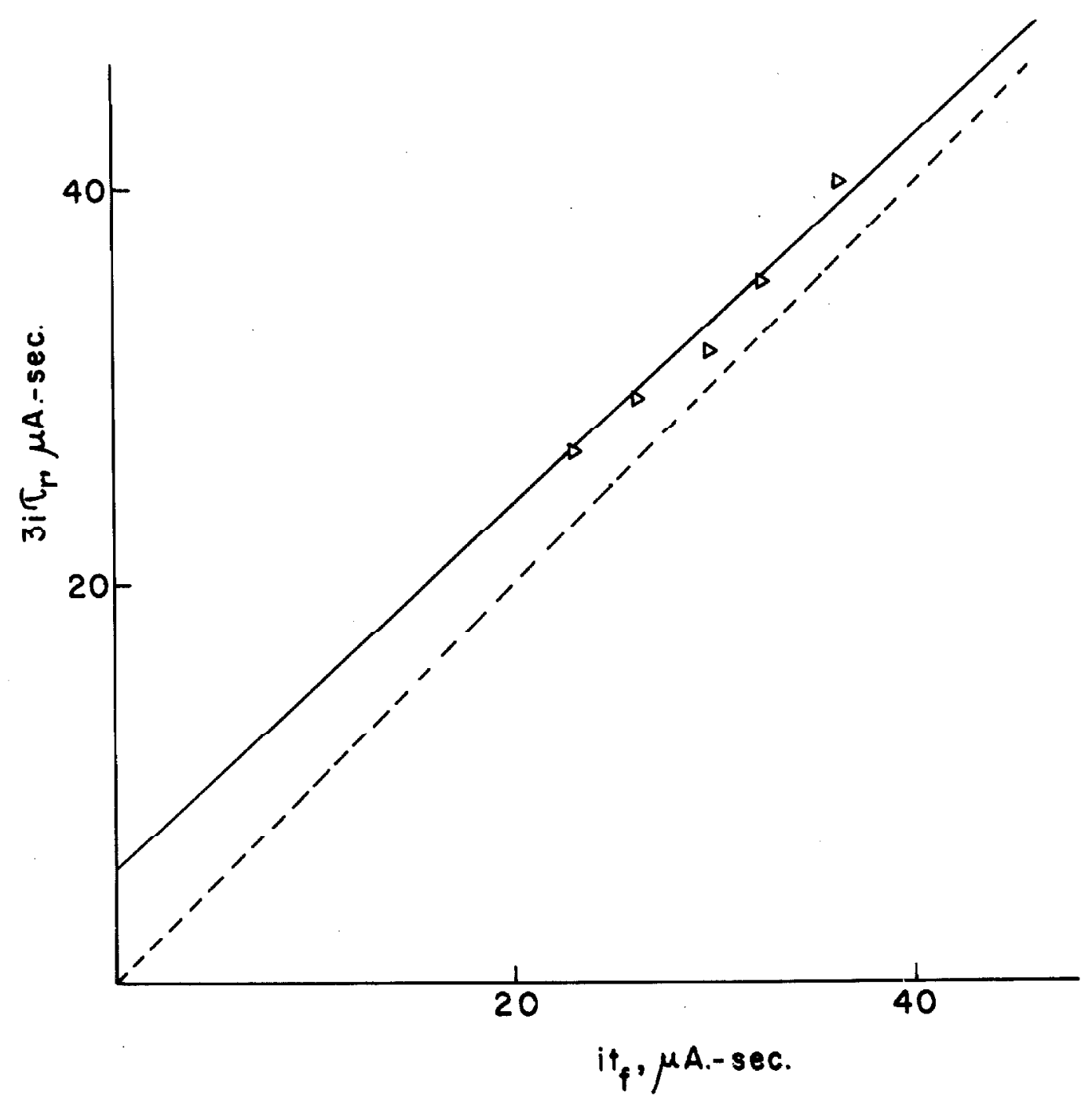

Figure 20. Reverse current chronopotentiometric behavior for an iceal system, $\mathrm{Fe}$ (II) in pyrophosphate. Solution: $30 \mathrm{mF} \mathrm{FeSO}_{4}$ in $0.5 \mathrm{~F} \mathrm{Na}_{4} \mathrm{P}_{2} \mathrm{O}_{7}$, pH 2 . The dotted line shows the cxpoctcd behavior for conditions of linear diffusion. 
model. The situation is somewhat more complex in solutions with very low bromide concentration.

The reverse current chronopotentiometry of $\mathrm{Cr}$ (II) was studied in solutions with $1.00 \mathrm{mF} \mathrm{NaBr}, 1.80 \mathrm{mF} \mathrm{Cr}(\mathrm{II}), 0.100 \mathrm{~F} \mathrm{HClO}_{4}(\mu=1.00)$. Thcoc concentrations provide equal fluxes of $\mathrm{Cr}$ (II) and bromide. Dver a wide range of conditions the ratio of forward to reverse times was found to be in the range 5.00 to 5.75 . This shows a pronounced shortening of the reverse wave and is clear evidence for lack of complete inclusion of bromide under conaitions where there is at least a stoichiometrically equivalent amount present at the electrode.

Similar experiments were done in solutions with $20 \mathrm{mF} \mathrm{Cr}$ (II). In this case the forward time was restricted to values less than the calculated transition time for bromide at the current density used. This insured that there was always a stolchiometric excess of bromide at the electrode. The reverse wave obtained was always much shorter than $1 / 3$ of the forwand time.

It was found that the ratio of forward to reverse times is potential dependent under these conditions. As an illustration, some results obtainen with a current of about $10 \mu \mathrm{a}$. and s forward time of approximately $3 \mathrm{sec}$, are presented in Table 4. 


\section{TABIE 4}

$\begin{array}{cc}\text { F, mv. VS. SCE } & \frac{t_{f} / T_{r}}{-440} \\ -420 & 106 \\ -400 & 31.2 \\ -380 & 13.6 \\ -370 & 9.58 \\ -360 & 7.50 \\ & 6.45\end{array}$

For the current density used, the potential was constant to within $10 \mathrm{mv}$. for at least the final 2/3rds of the forward time. This value is given to the nearest $10 \mathrm{mv}$. In Table 4. The varlation in potentiäl is difficult to explain in cetail but is not surprising because the amount of $\mathrm{CrBr}^{2}$ formed depends on but also determines the potential. From thcse resulto it is clear that the fraction of $\mathrm{CrBr}^{2}$ in the product of $\operatorname{Cr}$ (II) oxidation is a strong function of the potential at which the oxidation occurs, and that the more anodic that potential, the larger the percent of oromide inclusion. This in turn suggests that the technique of chronopotentiometry is ill suited to the study of the problem, for potential dependence of the results implies that only a method which employs potential control will yield any definitive information or more detailed information about tie mechanism.

The behavior in $3.6 \mathrm{mF} \mathrm{Cr}$ (II) was found to be that to be expected in view of the above discussion. Reverse current chronopotentiometry showed a varlation of forward time to reverse transition time ratios from 4 to 10. The ratio depended heavily on current density as one 
would expect, for at higher current densities, the wave, being irreversible, is shiftcd to more anodic potentials, and a higher fraction of Dromide inclusion occurs.

5. Summary and Discussion.

The chronopotentiometric experiments in $\operatorname{Cr}$ (II) solutions with bromide present demonstrate the following points.

1) At sufficiently large bromide concentrations the product of oxtdation of $\mathrm{Cr}$ (II) in the presence of bromide is entirely $\mathrm{CrBr}^{2}$.

2) The oxidation does not always result entirely in the product $\mathrm{CrBr}^{2}$ when there is a stoichiometric excess of bromide.

5) 'the traction of the product appearing as crBr ${ }^{2+}$ when a mixture of $\mathrm{CrBr}^{2}$ and $\mathrm{Cr}^{3^{+}}$is formec is potential dependent and is greater at more anodic potentials.

These results provide a qualitative description of the proceasco going on at the electrode and agree well with results obtained in chloride solutions. A quantitative discussion of the behavior is not possible from the chronopotentiometric results because chronopotentiometry is inherently unable to give detalled information about potential dependent processes. To obtain that information it is necessary to turn to experimental methods which employ potential control rather than current control. A more detailed discussion of the implications of the chronopotentiometric results is inappropriate without consideration of the results presented below. 


\section{Double Potential Step Chronocoulometric Behavior}

The principles of double potential step chronocoulometry are developed and alscussed in detail by Christie et al. (28,29). The application of this technique to the stuay of the oxidation of Cr(II) in bromide solution is fruitful because, as suggested by comparison of Figure 6 anc Figure 14, $\mathrm{CrBr}^{2^{+}}$is reduced at sufficiently anodic potentifals that potentials exist for which the reduction of $\mathrm{CrBr}^{+}$is diffusion limited but no reduction of $\mathrm{Cr}^{3}$ occurs. The application of the technique is illustrated in Flgure 21 which shows the potential function applied to the cell and the resulting charge/time behavior for the faradaic reaction.

In order to use this method with confidence it is first necessary to define the range of potential for which $\mathrm{CrBr}^{2+}$ is reduced ano verify that that reduction is 1deally behaved.

1. The Reduclior of Cr.Br ${ }^{2+}$.

The ideal behavior of the reduction of $\mathrm{CrBr}^{2}$ under potential step chronocoulometric conditions is illustrated in Figure 22. The agrecmont of intercepts with measured intercepts for double layer chargIng and the constancy of slope was maintained for starting potentials in the range -0.200 to $-0.300 \mathrm{v}$. Vs. SCE and final potentials in the range -0.750 to $-0.850 \mathrm{v}$. vs. SCE. The definition of allowable final potential is of importance, for the potential must be sufficiently cathodic that the electrode reaction is diffusion controllea, yet sufficiently anodic that no $\mathrm{Cr}^{3^{+}}$present is reduced. 


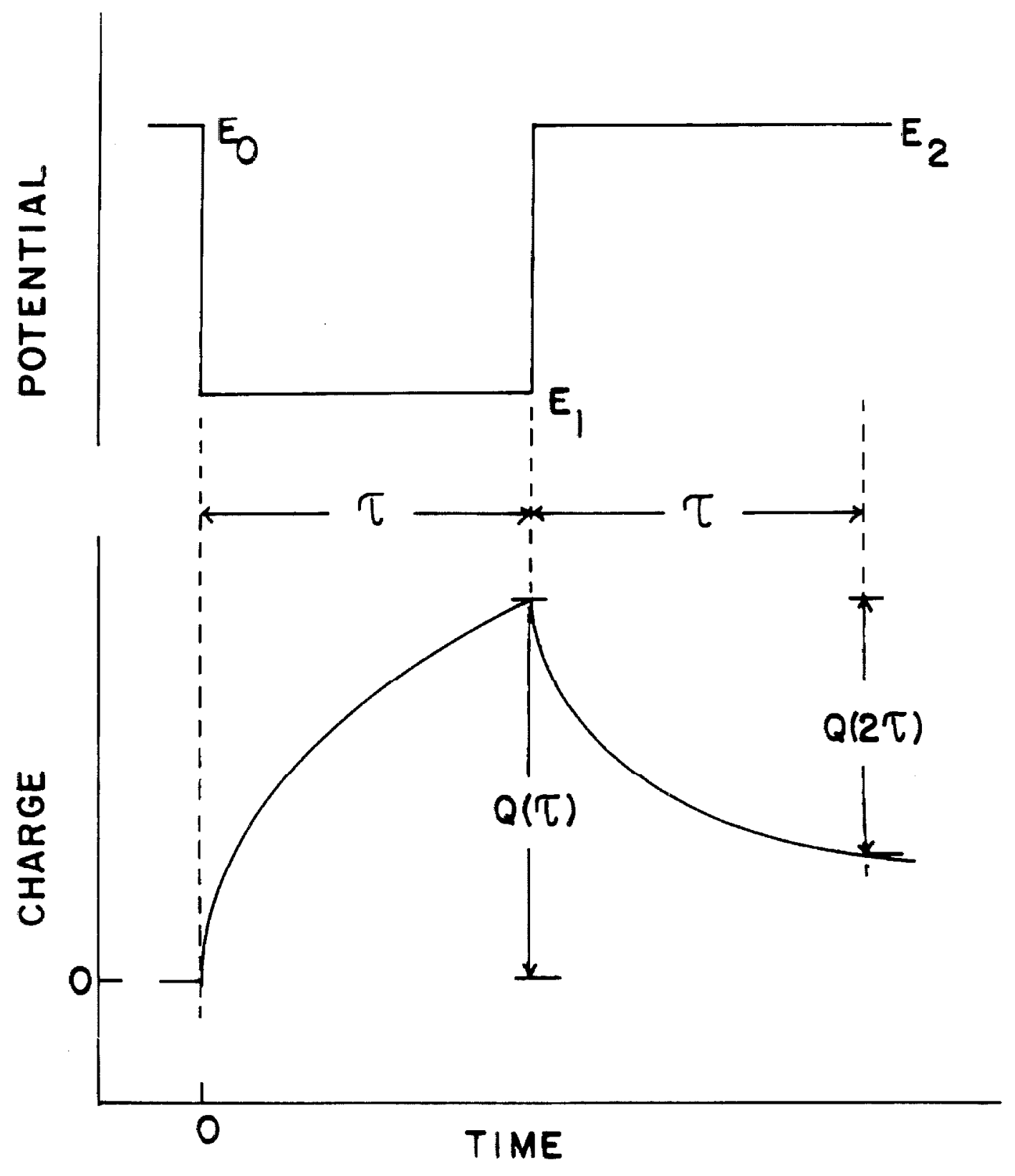

F:gure 21. Typical double potential step chronocoulometric behavior. 


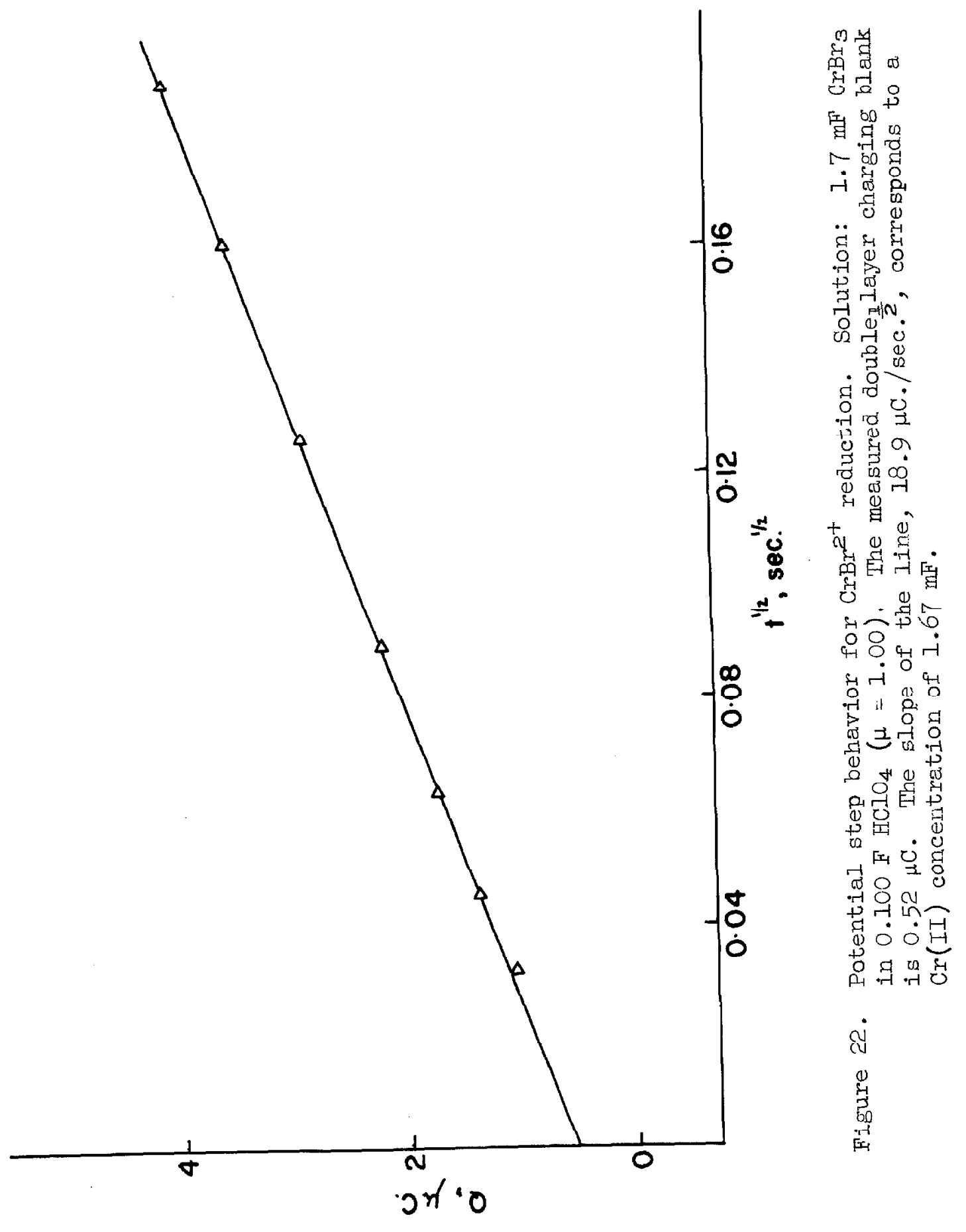


The agreement of intercepts also indicates that $\mathrm{CrBr}^{2}$ is not adoorbcd in significant amounts.

Experimental details. These experiments were carried out with the aid of a general purpose electrochemical instrument using solid state amplifier circuitry. The instrument was designed by Mr. George Lauer of C.I.T. and is described in detail in his thesis (30). The indicator electrode was a Kemula hanging mercury drop electrode available from Brinkman Instruments, Inc. It was used in conjunction with a cell of standard design, also from Brinkman.

The reference electrode was a small Beckman SCE. The auxiliary electrode was a piece of platinum wire.

Solutions were purged of oxygen with a stream of prepurified nitrogen. Flow of nitrogen through the cell above the solution was maintained during the course of each experiment.

Supporting electrolyte solutions were $0.1 \mathrm{~F} \mathrm{HClO}_{4}$ with $\mathrm{NaBr}$ variable and $\mathrm{NaClO}_{4}$ to maintain $\mu=1.00$. Free bromide concentration in the solutions investigated varied from approximately $0.5 \mathrm{~F}$ to $3 \mathrm{mF}$. The source of $\mathrm{CrBr}^{2}$ was Chromic Bromide available from $\mathrm{K} \& \mathrm{~K}$ Laboratories, Plainview, New York. The major cation of this salt is $\mathrm{CrBr}_{2}^{+}$which rapidy dissociates in water to give the complex $\mathrm{CrBr}^{2}$. This complex is sufficiently stable (see Chapter 2) that no correction for dissociation of the salt need be made for times less than about 30 $\min$.

The experiments were carrled out in the following manner. The dnount of charge required to charge the double layer when the potential 
is stepped from the initial to the final potential was measured in the deaerated supporting electrolyte solution for the potentials of interest. A small amount of the dry Chromic Bromide salt was then added to the cell and the solution deaerated further for about five minutes to allow for complete decomposition of the dibromo complex.

$$
Q \text { - } t \text { curves obtained from the potential steps were displayed on }
$$

a Tektronix Type 564 storage oscilloscope equipped with Type 3 AT2 ană 3B3 Plug-In units. Satisfactory traces were recorced on Polaroid film.

2. The Inclusion of Bromide in Cr(II) Oxidation.

The oxidation of $\mathrm{C} r$ (II) in solutions containing large excesses of bromide was studied by double potential stcp chronocoulometry. Figure 23 shows the method of analysis of the aata and illustrates a typical result. The agreement of the forward and reverse intercepts with each other and with the value measured independently in the supporting electrolyte solution is well within the accuracy of the method. The identity of the forwara and reverse slopes shows that the product of the oxication of $\mathrm{Cr}$ (II) under these conditions is entirely $\mathrm{CrBr} 2^{+}$.

Double potential step chronocoulometry experiments were done in solutions $0.5-3 \mathrm{mF}$ in $\mathrm{Cr}$ (II) and with bromide concentrations of $0.878 \mathrm{~F}$, $0.439 \mathrm{~F}, 0.219 \mathrm{~F}, 0.110 \mathrm{~F}$, and $0.0549 \mathrm{~F}$. The value of $\mathrm{T}$ was approximately $20 \mathrm{~ms} ., 40 \mathrm{~ms} .$, or $80 \mathrm{~ms}$. The initial and final potentials, $E_{0}$ and $E_{2}$ in Figure $2 \perp$, were $-0.30 \mathrm{~V} . \mathrm{VS}$. SCH and the anodic step potential, $E_{1}$ in Figure 21, was varied between the anodic limit set by the oxidation of mercury and the cathodic limit $(-0.300 \mathrm{~V}$. Vs. SCE) set by the irreversiWility of $C_{\perp}$ (II) oxidation. 


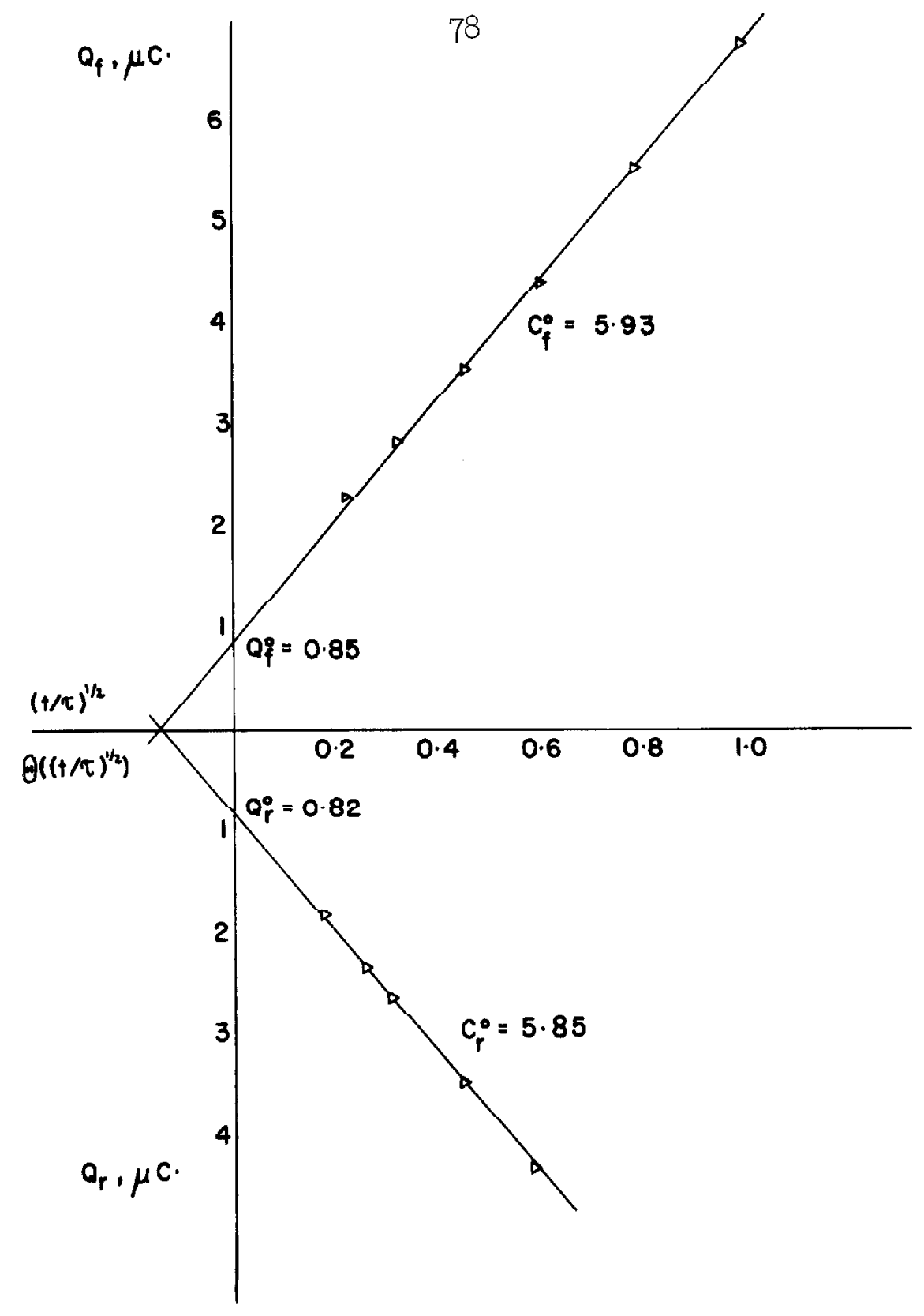

Figure 23. Reouced time function plot of double potential step chronocoulometric behavior for $\mathrm{Cr}$ (II) in excess bromide. Solu-

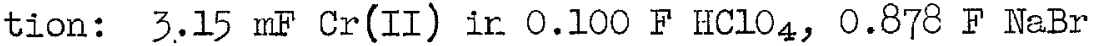
$(\mu=1.00) . \quad E_{0}=E_{2}=-0.750$ v. vs. SCE; $E_{1}=-0.250$ v. vs. $\mathrm{SCE}$. The measured double layer blank is $0.90 \mu \mathrm{C}$. The forward and reverse slopes correspond to $\mathrm{Cr}$ (II) concentrations of 2.67 and $2.64 \mathrm{mF}$, respectively. $T=0.0385$. The difference between the buIk concentration of $\mathrm{Cr}$ (II) and that given by the slopes is caused by air oxication of the $\mathrm{Cr}$ (II) solution in the course of the experiment. 
In about 30 cases including a suitable coverage of the variation of parameters the $Q-t$ traces obtained were plotted as in Figure 23 . There were some deviations from the expected ideal behavior which are discussed below, but none of the experiments for which the $Q-t^{\frac{1}{2}}$ plots were made showed any evidence of failure to form entirely $\mathrm{CrBr}^{2}$ in the oxidation of $\mathrm{Cr}$ (II).

If the charge passed in the forward and reverse steps, $Q_{f}$ and $Q_{b}$, be measured at times $\tau$ and $2 \tau$, respectively, as defined in Figure $2 I$, the ratio ${ }^{*} \mathrm{Q}_{\mathrm{b}}(2 \mathrm{~T}) /{ }^{*} \mathrm{Q}_{\mathrm{f}}(\mathrm{T})$ should be 0.586 (28). It is assumed that the measured values of $Q$ are corrected for double layer charging by subtracting from them the amount of charge required to charge the double layer, $Q_{\mathrm{d} I}$, measured by duplicating the experiment in the absence of electroactive material. ${ }^{*} \mathrm{Q}$ is the double-layer-corrected value of $Q$.

The use of this criterion for ideality without examining the $Q-t^{\frac{1}{2}}$ behavior is open to a good deal of criticism. The most obvious point is that the siopes and intercepts may vary in such a way that the ratio of charges is 0.586 but neither the slopes nor the intercepts have the correct value.

Over $200 \mathrm{Q}-t$ traccs wcre obtaincd under 127 different sets of conditions. The average value of the ratio ${ }^{*} \mathrm{Q}_{\mathrm{b}}(2 \tau) /{ }^{*} \mathrm{Q}_{\mathrm{f}}(T)$ was found to be $0.585 \pm 0.005$. There was no significant variation of the ratio with any of the parameters. These results show that there is complete inclusion of bromide in the oxidation of $\operatorname{Cr}$ (II) under conditions where the reaction is sufficiently fast to be diffusion controlled under the conditions of double potential step chronocoulometry and there is a substantial excess of bromide present. 
When the bromide concentration is very low we obtain somewhat different and more interesting results. An example is presented in Table 5 which gives results of experiments performed in $1.93 \mathrm{mF}$ bromide solutior. The quantities given are those defined by the $Q-t^{\frac{1}{2}}$ plots in Fipure 23.

\section{TABIE 5}

\begin{tabular}{|c|c|c|c|c|c|c|c|}
\hline $\mathrm{E}_{1}$ & v. VS. SCE & $\tau$, sec. & $Q_{d I}, \mu C$. & $Q_{f}^{O}, \mu C$. & $Q_{-2}^{O}, \mu C$. & $\mathrm{C}_{f}, \mathrm{mF}$ & $C_{r}, m F$ \\
\hline & -0.300 & 0.0404 & 0.50 & -0.01 & 0.46 & 1.41 & 1.14 \\
\hline & -0.250 & 0.0402 & 0.55 & 0.03 & 0.42 & 1.58 & 1.40 \\
\hline & -0.200 & 0.0598 & 0.59 & 0.37 & 0.46 & 1.58 & 1.57 \\
\hline & -0.150 & 0.0400 & 0.57 & 0.57 & 0.58 & 1.49 & 1.50 \\
\hline & -0.100 & 0.0400 & 0.73 & 0.54 & 0.57 & 1.55 & 1.58 \\
\hline & -0.050 & 0.0401 & 0.89 & 0.65 & 0.65 & $1 . \div 9$ & 1.49 \\
\hline
\end{tabular}

$$
A=0.0409 \mathrm{~cm}^{2}
$$

In theae experiments the variation in slopes from one experiment to the next and the aiscrepancy between measured double layer intercept and the Intercept from the $Q-t^{\frac{7}{2}}$ plot is rather larger than often observen, but the intermal consistency of each experiment is sufficiently good that the results are convincing. From examinations of the intercepts and the slopes (concentrations) it is clear that at $-0.300 \mathrm{v}$, and $-0.250 \mathrm{v}$. the oxidation of $\mathrm{Cr}$ (II) is not diffusion controlled and that, furthermore, there is not complete inclusion of bromide, though there is clearly a stolchiometric excess of bromide over $\mathrm{Cr}$ (II). 
At $-0.200 \mathrm{v}$. and more anodic potentials, however, the oxidation Is apparenliy diffusion controlled, as shown by the agrocment of the forward and reverse intercepts and the constancy of the forward slope with potential. Also, there is complete inclusion of bromide, as shown by the identity of the reverse and forward slopes in exch case.

Experimenta 7 procedures. The equipment used is discussed on page 76 .

The cell and general procedures for filling are discussed on page 64.

Experiments were carried out at $27.0^{\circ} \mathrm{C}$. Cr(II) stock solutions were prepared and analyzed as discussed In Chapter 2 .

Supporting electrolyte solutions were prepared from $\mathrm{HClO}_{4}$, $\mathrm{NaBr}$, and $\mathrm{NaCLO}_{4}$ solutions prepared as previously described. The concentrations were such that the mixture of supporting electrolyte solution and $\operatorname{Cr}$ (II) stock solution giving the desired $\mathrm{Cr}$ (II) concentration would have the desired bromide concentration and $0.100 \mathrm{~T} \mathrm{IClO}_{4}(\mu=1.00)$.

The value of $Q_{d I}$ for each set of conditions was measured in the appropriate supporting electrolyte solution just before adding the Cr(II) solution.

Discussion of the data. In many cases the data, while showing no evidence of failure of $\mathrm{Cr}$ (II) to be oxidized quantitatively to $\mathrm{Cr} \mathrm{Br}^{2+}$, did not correspond to the ideal double potential step chronocoulometric behavior. 
The most common deviation from expected behavior was failure of the forward and reverse intercents, $Q_{ \pm}^{0}$ and $Q_{\mathrm{p}}^{0}$, to agree with the independently measured value, $Q_{a}$. The values of $Q_{f f}^{0}$ and $Q_{x}^{0}$ usually agreed to within a few percent but frequently aiffered from $Q_{a l}$ by $10 \%$ or more.

A second and apparently independent phenomenon was the tendency for the forward intercept to be larger than the reverse intercept and the forward slope to be less than the reverse slope. These two effects appear together; the greater the difference in intercepts, the greater the difference in slopes.

These characteristics ao not always appear, but do appear repeatedly. They have been observed in similar experiments with $0.5 \mathrm{mF}$ $\mathrm{Cd}(\mathrm{II})$ in I $\mathrm{F} \mathrm{NaIO}_{3}$ solution. We feel that the se anomalous results require a pertinent wirndug to the experimenter but have no bearing on the valiaity of our conclusions (31).

\section{Discussion.}

The chronocoulometric results confirm and add detail to the conclusions of the chronopotentiometric experiments. At potentials more anodic than $-0.300 \mathrm{v}$. vs. SCE and oromide concentrations higher than $0.055 \mathrm{~F}, \mathrm{Cr}(\mathrm{II})$ is quantitatively oxiaized to $\mathrm{CrBr}^{2}$. Therefore under these conditions $\operatorname{Cr}($ II) is oxidized by a bromide bridge mechanism.

The chronopotentiometric result that $\mathrm{CrBr}^{2}$ is not quantitatively formed on $\operatorname{Cr}$ (II) oxidation at cathodic potentials even in excess bromide is confirmed by the chronocoulometric experiments.

These results are predicted by the theory of parallel reactions for potential step chronocoulometry. When the anodic step is applied 
two reactions take place; the oxidation of $\mathrm{Cr}$ (II) via a bromide bridge to form the product $\mathrm{CrBr}^{2}$, and the oxidation of $\mathrm{Cr}$ (II) by the mechanism prevailing in the absence of bromide to form $\mathrm{Cr}^{3^{+}}$. These two reactions have different kinetic parameters and are isolated from each other by the lack of equilibrium between the products.

A detailed general mathematical description of this situation is presented in Appendix II. The qualitative result is that when the rates for the two processes are comparable both products are formed, in amounts roughly proportional to their respective rates. The rate parameters for the two processes were determined and are discussed in Part III. These constants were used with the equations of Appendix II to calculate the expected product distribution for the potential step oxidation of $\mathrm{Cr}$ (II) In the presence of cxccos bromide. It was found that when the oxidation of $\operatorname{Cr}(I I)$ is sufficiently fast that diffusion control is attained, the product of the reaction should be entirely $\mathrm{CrBr}^{2^{+}}$; but, when the bromide concentration is sufficiently low, and the potential sufficiently cathodic, some $\mathrm{Cr}^{3^{+}}$should be formed.

Double potential step chronocoulometric verification that an amount of $\mathrm{CrBr}^{2}$ is formed which corresponds to the fraction of $\mathrm{Cr}$ (II) oxidized via bromide under conditions where less than $100 \%$ of the $\mathrm{Cr}$ (II) occurs via the bromide-dependent path has little chance of success. The algebraic complexity of the equations for parallel reactions isolates the observable quantities from the parameters of interest so effectively that convincing agreement between measured and calculated amounts of $\mathrm{CrBr}{ }^{+}$formed surely would not be obtained. 
Chapter 6

THE OXIDATION OF CHROMIUM(II) IN THE PRESENCE OF IODIDE:

RATE COMPETITION WITH CHLORIDE

In Chapter 5 we df scussed the competition hetween the electrode reactions

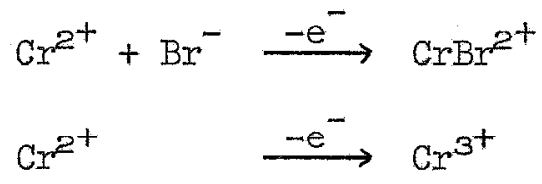

and 1to cffect on the ratio of producto formod. In that cadc the cffect was seen as a nuisance. However, if one of the reactions of interest is the now well-characterized oxidation of $\operatorname{Cr}($ II) via a chloride bridge, and the other the oxidation of $\operatorname{Cr}(T T)$ via another halide hridge, the chloride-assisted reaction may be used as a probe to determine how the other reaction proceeds.

This approach is especially attractive in the case of iodide. The rate of aquation of $\mathrm{CrI}^{2^{+}}$is sufficiently large that any technique for finding the amount of $\mathrm{CrI}^{2^{+}}$formed in the electrochemical oxidation of $\mathrm{Cr}(I I)$ in the presence of iodide must have a characteristic time of a second or less. However, double potential step chronocoulometry is not applicable because in iodide solutions $\operatorname{Cr}($ II) oxidation and mercury oxidation are not well separated. This problem occurs at all iodide concentrations because although lowering the iodide concentration moves the mercury oxidation to a more anodic potential it also decreases the rate of $\mathrm{Cr}$ (II) oxidation so that a greater overpotential is required for diffusion control. 
The use of the chloride bridged oxidation of Cr(II) as a probe removes this difficulty, for an clcetrolyoio can be carricd out under diffusion controlled conditions and the long lived product, $\mathrm{CrCl}^{+}$, will record the reaction path.

\section{Cyclic Voltammetry of $\mathrm{Cr}$ (II) in Iodide Solutions}

At low lodide concentrations the oxidation of $\mathrm{Cr}$ (II) is sufficiently separated from the depolerization of mercury that cyclic voltammetry at slow sweep rates may be used to study the reaction qualitatively. Figures 24-28 illustrate the behavior observed. In each case the sweep was begun at $-0.700 \mathrm{v}$. vs. SCE with the first half-cycle anodic; the cathodic limit of the sweep was approximately $-1.20 \mathrm{v}$. Vs. SCE.

Higure 24 shows the general teatures in a solution with a slight excess of iodide. The calculated flux ratio is 1.00 , but there is a slight excess of lodide because of the air oxidation of $\operatorname{Cr}$ (II). The peak A corresponds to the oxidation of $\mathrm{Cr}$ (II) by the lodide path, B to the reduction of $\mathrm{CrI}^{2}$, and $\mathrm{C}$ to the reduction of $\mathrm{Hg}_{2} \mathrm{I}_{2}$ (or some other mercury species). The identification of $\mathrm{C}$ is clearly established by comparison with the background in the solution containing lodide alone. The succeding igures show the effect of increasing the Cr(II) concentration. Taken together, these voltammograms show the following characteristics. The peak at $A$ remains in the same position and does not change in helght as the $\operatorname{Cr}$ (II) concentration is increased. Therefore It must be iodia.e diffusion controlled. The fact that the cathodic peak $B$ maintains its position and helght as the Cr(II) concentration is In- 


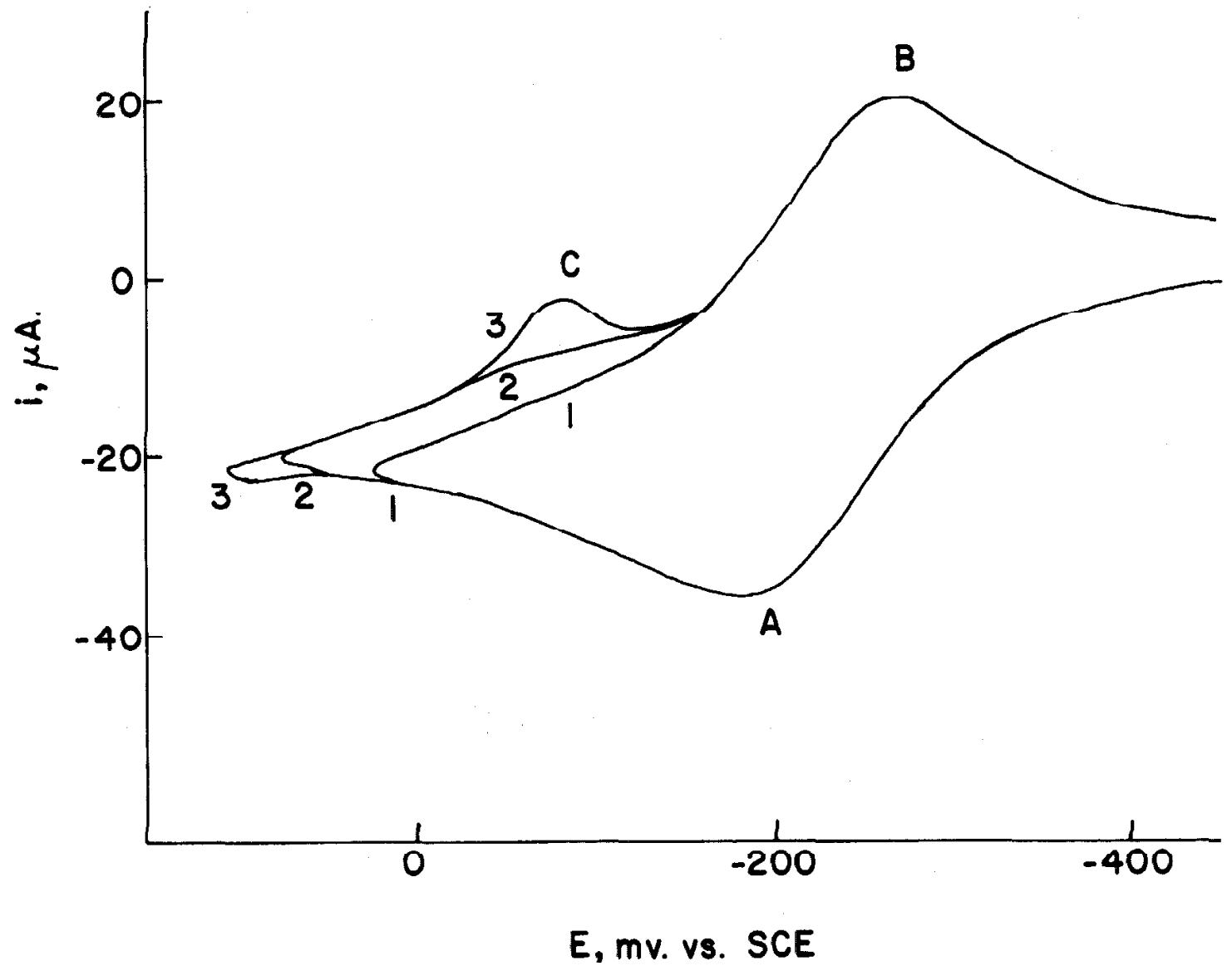

Figure 24. Cyclic voltanmetry of $\mathrm{Cr}$ (II) in iodide solution. Solution: $1.30 \mathrm{mF} \mathrm{NaI}, 0.100 \mathrm{~F} \mathrm{HClO}_{4}(\mu=1.00)$ with $\mathrm{D}_{\mathrm{Cr}} \frac{1}{2}(\mathrm{Cr}(I I)) /$ $D_{I}^{\frac{1}{2}}\left(I^{-}\right)=1.00$. See text for d1scussion. 


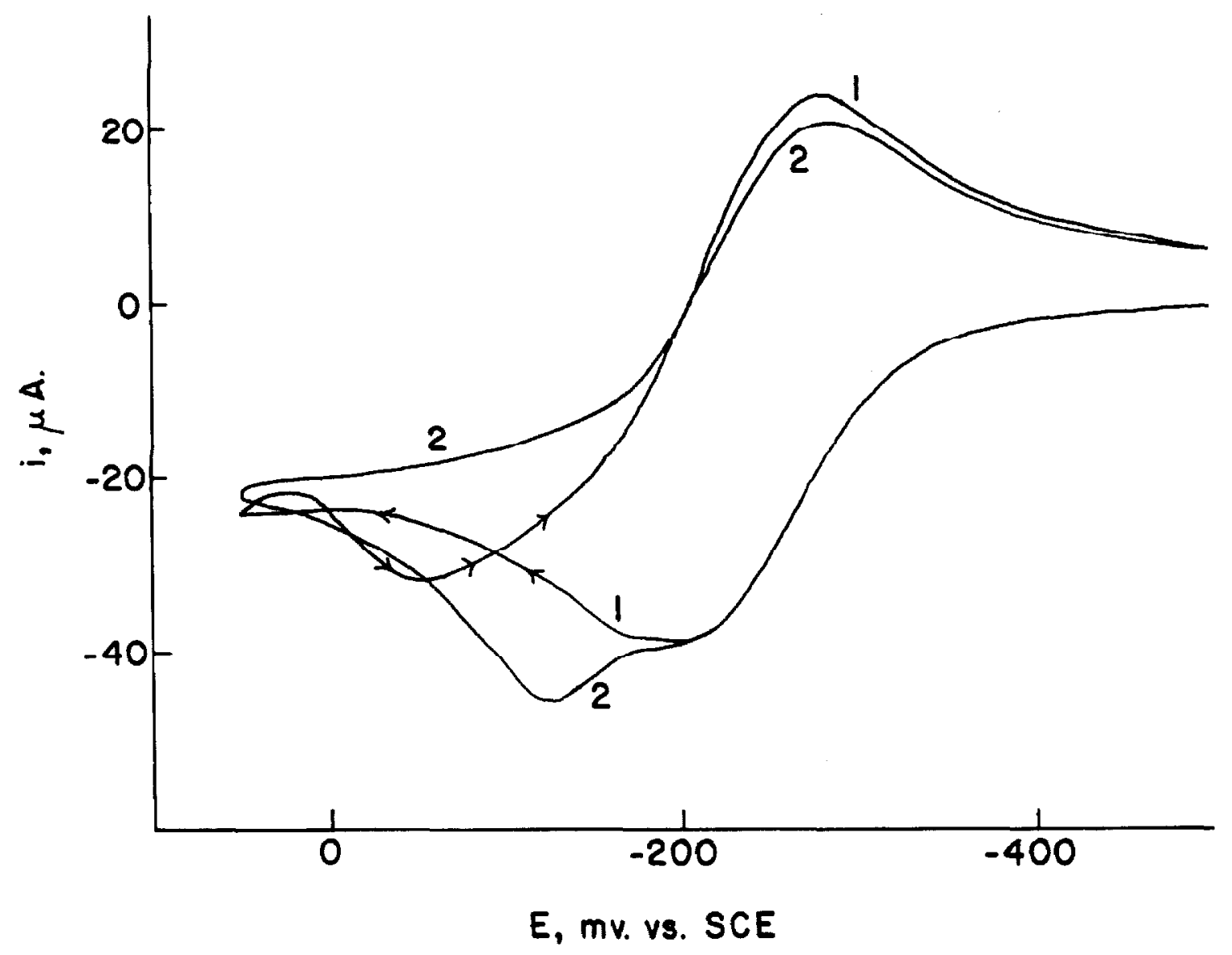

Figure 25. Cyclic voltammetry of $\mathrm{Cr}$ (II) in iodide solution. Solution: $1.28 \mathrm{mF} \mathrm{NaI}, 0.100 \mathrm{FHClO}_{4}(\mu=1.00)$ with $\mathrm{D}_{\mathrm{Cr}} \frac{\frac{1}{2}}{2}(\mathrm{Cr}(\mathrm{II})) /$ $\mathrm{D}_{I^{\frac{1}{2}}}\left(I^{-}\right)=1.51$. 


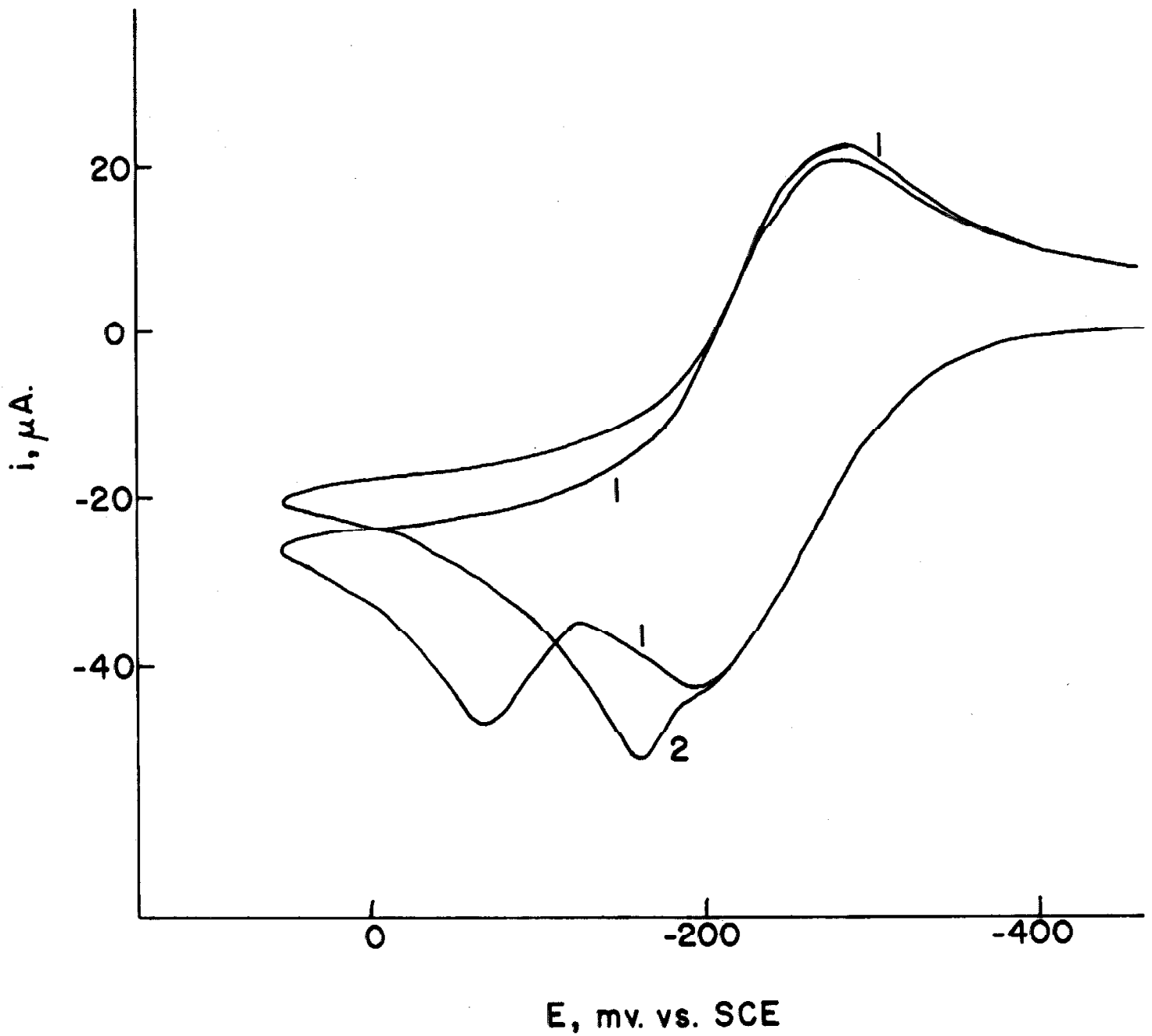

Fioure 26. Cyclic voltammetry of $\mathrm{Cr}$ (II) in iodide solution. Solution: $1.28 \mathrm{mF}$ IVI, $0.100 \mathrm{~F} \mathrm{HClO}_{4}(\mu=1.00)$ with $\mathrm{D}_{\mathrm{Cr}}^{\frac{1}{2}}(\mathrm{Cr}(\mathrm{II})) /$ $D_{I}^{\frac{1}{2}}\left(I^{-}\right)=1.76$. 


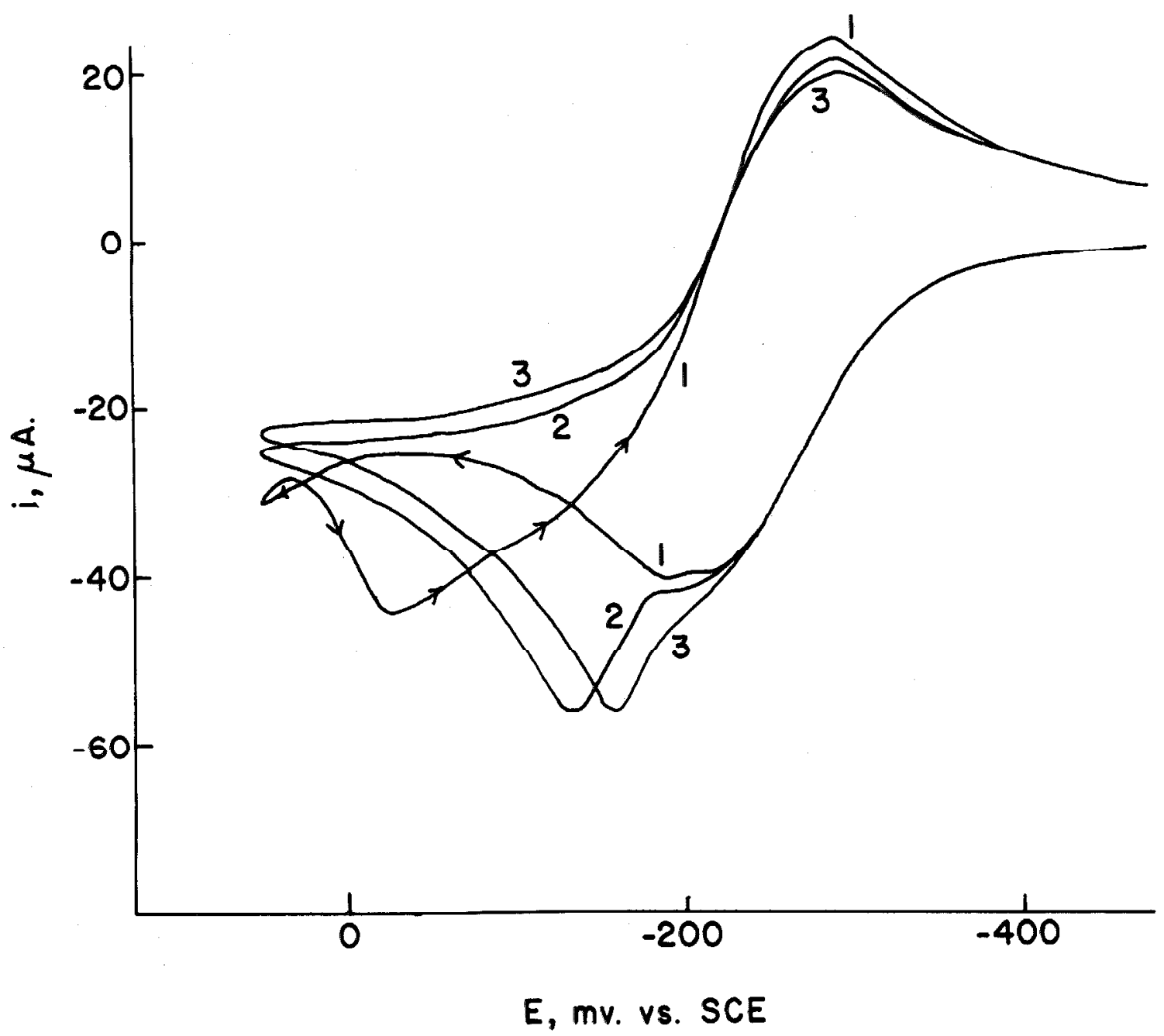

Figure 27. Cyclic voltammetry of $\mathrm{Cr}$ (II) in iodide solution. Solution: $1.27 \mathrm{mF} \mathrm{NaI,} 0.100 \mathrm{FHClO}_{4}(\mu=1.00)$ with $\mathrm{D}_{\mathrm{Cr}} \frac{1}{\frac{1}{2}}(\mathrm{Cr}(I I)) /$ $D_{I^{\frac{1}{2}}}^{\frac{1}{-}}\left(I^{-}=2.03\right.$. 


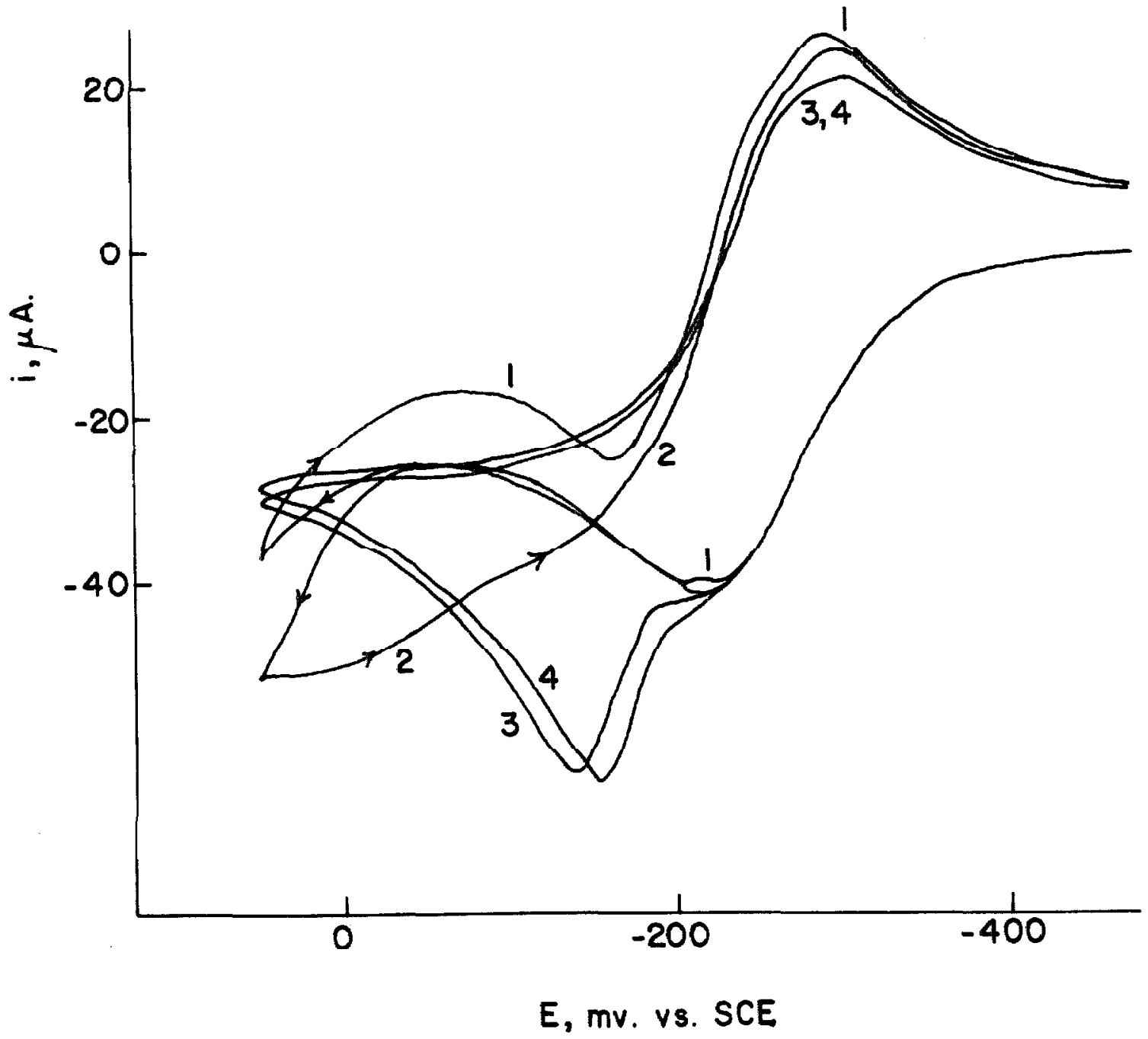

Figure 28. Cyclic voltammetry of $\mathrm{Cr}$ (II) in iodide solution. Solution: $1.25 \mathrm{mF} \mathrm{NaI}, 0.100 \mathrm{FHClO}_{4}(\mu=1.00)$ with $\mathrm{D}_{\mathrm{Cr}^{2}}^{\frac{1}{2}}(\mathrm{Cr}(I I)) /$ $D_{I^{\frac{1}{2}}}\left(I^{-}\right)=2.50$. 
creased confirms the diagnosis that it is due to the reduction of the product of $\mathrm{A}\left(\mathrm{CrI}^{\mathrm{C}^{+}}\right)$.

In excess $\operatorname{Cr}($ II) solutions a second anodic peak appears whose helght increases with increasing $\mathrm{Cr}$ (II) concentration and whose position Is heavily dependent on the number of the cycle. The irreproducibility from the first to succeeding cycles is a phenomenon which we cannot explain. In each case the last cycle shown is the steady state behavior. This behavior is independent of the age of the drop in the solution, or whether the drop has been used before. It is also remarkably reproducible from one trial to the next.

The constant height and position of the anodic peak $A$ and cathodic peak $B$ at constant jodide concentration and varying excess Cr(II) is convincing evidence that $\mathrm{Cr}$ (II) is oxidized via an iodide bridge to form $\operatorname{CrI}^{2^{+}}$.

Experimental detalls. These experiments were carried out using the cell described on page 65 and the multipurpose instrument described on page 76 . I'he voltammograms were recorded using a Moseley Autograph $\mathrm{X}-\mathrm{Y}$ recorder. The sweep rate was $0.134 \mathrm{v} \cdot / \mathrm{sec}$.

II. Controlled Potential Electrolysis of Chromium(II) Solutions: Oxidation in the Presence of Chloride-Iodide Mixtures

The oxidation of $\mathrm{Cr}$ (II) in the presence of chloridemiodide mixtures presents the intriging possibility that the product distribution might differ from that predicted by the parallel reaction theory because 
lodide is adsorbed on mercury to a greater extent than is chloride. To investigate this possibility, large-scale electrolyses similar to those described in Chapter 3 were carried out in solutions containing both Lodide anà chloride.

The oxidations were done at $-0.192 \mathrm{v}$. vs. 3CF instead of at -0.012 v. Vs. SCE to avold oxidation of mercury. The product solutions were analyzed for the amount of iodide and for the total amount of free hallde by potentiometric titration with stannaro silver solution. The amount of $\mathrm{CrCl}^{2^{+}}$formed was found by difference. The initial conditions and the amount of free chloride found in the product solutions are given in Table 6. In each experiment the inftial chloride to iodide ratio was about 10 .

The results are presented in Figure 29. The slope of the Iine defined by the experimental points is $0.75 \mathrm{meq} . \mathrm{CrCl}^{2^{+}} / \mathrm{meq} . \mathrm{Cr}(\mathrm{II})$. In the three experiments with the largest $\mathrm{Cr}$ (II) concentrations the difference vetween the amount of $\mathrm{CrCl}{ }^{2+}$ formed and the amount that would have been formed had no loaide been present is greater than the amount of 1odide. This is possible because the time required for electrolysis (about one hour) is long comparen with the lifetime of Cr. $\mathrm{I}^{+}$, so that. lodide is being freed at a rate commensurate with its use.

There is no point in attempting even an approximate sreatment of the problem of mass transfer to a stirred mercury pool electrode. However, the results of Appendix II suggest that the firaction of $\mathrm{CrCl}^{2}$ formea in these experiments should be approximately equal to the ratio of the rate of formation of $\mathrm{CrCl}^{2^{+}}$to the sum of the rates for all possible oxtdation paths. 


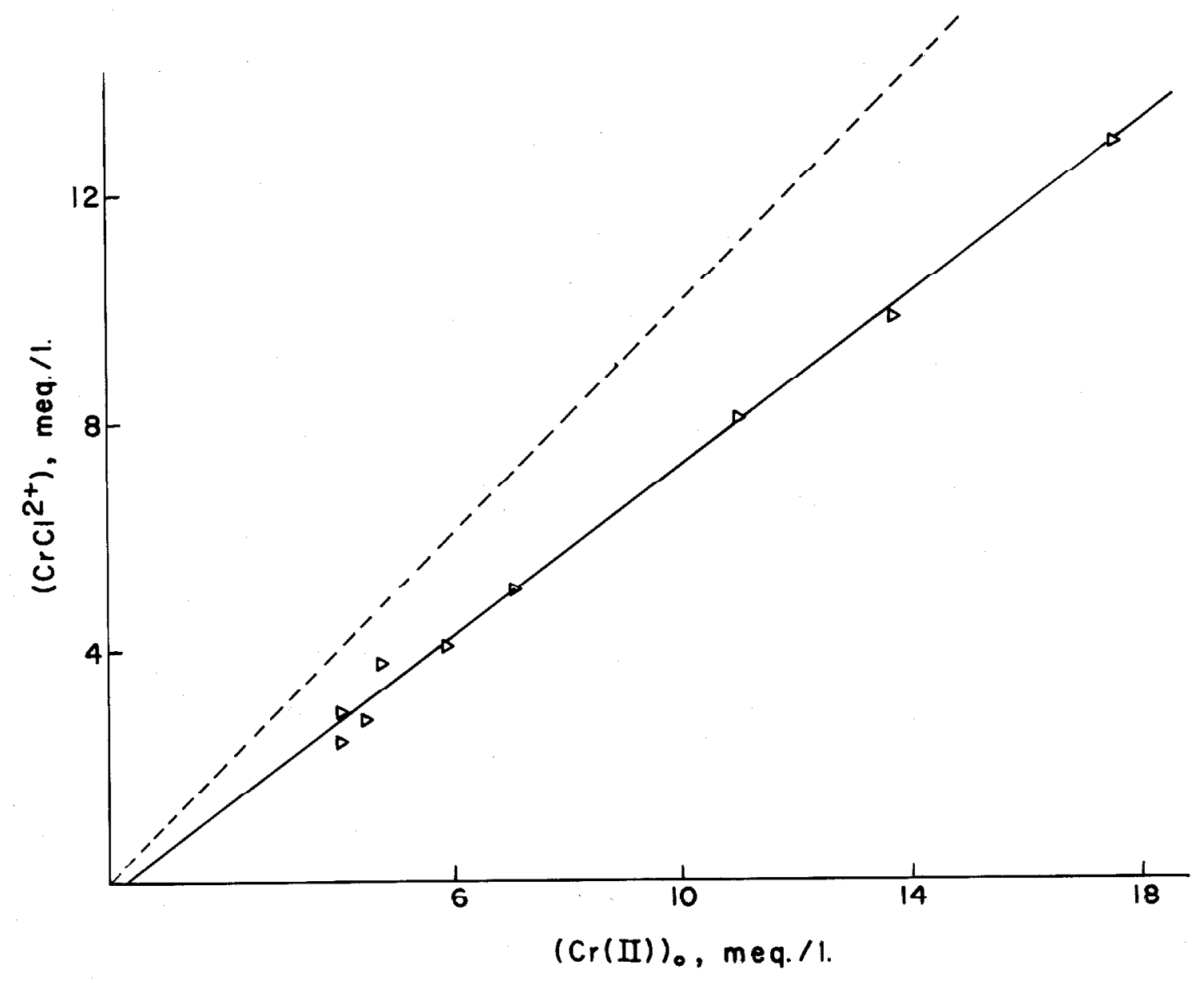

Figure 29. The effect of iodide on the inclusion of chloride in the controlled polenlial oxidation of $\mathrm{Cr}$ (II). The dotted. line shows the behavior to be expected in the absence of iodide. See Table 6 for conditions. 
TABIE 6

Controlled Potential Electrolysis of $\mathrm{Cr}$ (II) Solutions Containing Chloride and Iodide

\begin{tabular}{cccc}
\hline$\left(I^{-}\right)_{I}$ & $\left(\mathrm{CI}^{-}\right)_{1}$ & $(\mathrm{CrII})_{0}$ & $\left(\mathrm{CI}^{-}\right)_{I}$ \\
\hline 0.1008 & 1.007 & 0.3010 & 0.798 \\
$"$ & $"$ & 0.7020 & 0.506 \\
0.0978 & 1.018 & 0.9007 & 0.357 \\
$"$ & $"$ & 0.5199 & 0.636 \\
$"$ & $n$ & 0.1753 & 0.892 \\
$"$ & $"$ & 0.2074 & 0.856 \\
$"$ & $"$ & 0.1747 & 0.915 \\
\hline
\end{tabular}

1 refers to initial amounts

$f$ refers to free chloride found after electrolysis (CrTT) $)_{0}$ is the value obtained from the integrator for the amount of $\mathrm{Cr}$ (II) oxidized electrochemically. All rigures are given in total number of milliequivam lents of material in the solution. The solution volume in these experiments varied from 42 to $50 \mathrm{ml}$.

From Figure 2 of Reference 6 we can extract the following rate constants for the oxidation of $\mathrm{Cr}$ (II) at $-0.192 \mathrm{v}$. vs. SCE:

$$
\begin{aligned}
\mathrm{k}_{1} & =0.14 \times 10^{-2} \mathrm{~cm} \cdot / \mathrm{sec} . \\
\left(\mathrm{CI}^{-}\right) \mathrm{k}_{2} & =2.73 \times 10^{-2} \mathrm{~cm} \cdot / \mathrm{sec} . \\
\left(I^{-}\right) \mathrm{k}_{2} & =6.40 \times 10^{-2} \mathrm{~cm} \cdot / \mathrm{sec} . \\
\left(\mathrm{CI}^{-}\right) & =\left(I^{-}\right)=5 \times 10^{-6} \text { moles } / \mathrm{cm}^{3}
\end{aligned}
$$


Here $k_{1}$ is the rate constant in the absence of bridging ligands and $\left(\mathrm{CI}^{-}\right) \mathrm{k}_{2}$ and $\left(\mathrm{I}^{-}\right) \mathrm{k}_{2}$ are the pseudo-first-order ratc conotonto in the presence of chloride and iodide, respectively, for the ligand bridged path alone.

For the experiments described above the value of the rate ratio is

$$
\frac{\left(\mathrm{cI}^{-}\right) \mathrm{k}_{2}}{\left(\mathrm{CI}^{-}\right) \mathrm{k}_{2}+\left(\mathrm{I}^{-}\right) \mathrm{k}_{2}+\mathrm{k}_{1}}=0.74 \pm 0.03
$$

In calculating this ratio it was assumed that the iodide concentration is equal to its initial value, $\left(I^{-}\right)_{1}$, given in Table 6 , and that the chloride concentration is equal to $\frac{2}{3}\left(\mathrm{CI}^{-}\right)_{f}+\frac{1}{3}\left(\mathrm{CI}^{-}\right)_{i}$, which is approximately the average value of the chloride concentration during the electrolysis.

The value of the ratio given in Equation 2, $0.7^{4}$, is in remarkable agreement with the value of 0.75 given by the slope of the line in Figure 29. This agreement between experiment and the prediction of parallel reaction theory suggests that the influence of halide adsorption on the mechanism is contained in the rates themselves. The mechanistic implications of the rate parameters are discussed in Clapter 7 .

Expcrimental proccduree. The gencral procedurco and cquipment used are described in Chapter 3.

The product solutions were made $5 \%$ in $\mathrm{Ba}\left(\mathrm{ClO}_{4}\right)_{2}$ before analysis to suppress the adsorption of silver ion on precipitated sitver indide. Analysis of standard chloride-iodide mixtures showed that the determination is capable of $0.2 \%$ accuracy in chloride determination when the 
chloride to iodide ratio is 10:1. The accuracy drops with decreasing chloride to iodide ratio.

Several blanks were done in which all components except the $\mathrm{Cr}$ (II) were added to the cell, the solution was electrolyzed at $-0.192 \mathrm{v}$. vs. SCE for about one hour, and then analyzed for chloride. A maximum of 0.001 mllifequivalent of current was passed; the chloride analysis was $0.5 \%$ 10w. 
Chapter 7

THE RATE OF OXIDATION OF CHROMIUM(II)

Ihe role of bridging ligands in the oxidation of $\operatorname{Cr}$ (II) at mercury electrodes can be studied by determining the effect that those ligands have on the rate of the oxidation. There are two ways in which the determination of ratco holpo to define the mechanism. First, the dependence of the pseudo-first-order heterogeneous rate constant for the reaction on the ligand concentration can be determined. Second, the rate parameters for different ligands can be compared and the differences in rate correlated with differences in the properties of the ligands. The theory of electrode kinetics is discussed by Delahay (32). The general equation describing the rate of an electrode reaction is

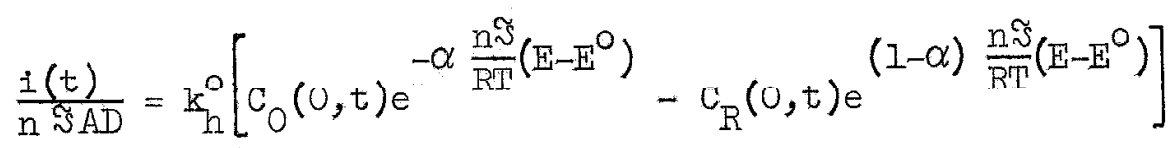

When the reaction is sufficientiy irreversible, one of the terms In the right hand side of Equation $I$ may be neglected and data are easily analyzed without prior knowledge of the standard potential, $E^{\circ}$, although the standard potential must be known to evaluate the standard rate constant, $\mathrm{k}_{\mathrm{h}}^{0}$. When the reaction is quasi-reversible both terms must be considered. This increases the complexity of the relationship between the rate and the rabe paraluters, aud requires that $\mathrm{F}^{\circ}$ be known independently, since it is used in the analysis.

The rate parameters for a reaction are usually found by studying a reduction rate, sometimes an oxidation rate, rarely both. However, if 
rate parameters are determined for both the anodic and cathodic processes and they agree with each other, the results are much more convincing than those based on a single determination.

I. Kinetic Parameters for the Couple $\mathrm{Cr}(\mathrm{II}) / \mathrm{Cr}^{3}$

in Perchlorate Solutions

In the absence of bridging ligands the $\mathrm{Cr}$ (II) $/ \mathrm{Gr}^{3^{+}}$couple is highly irreversible at mercury electrodes. This means that simple techniques can be used to measure the rates and the kinetic parameters are easily extracted from the measured rates. We have measured the rate of oxidation of $\mathrm{Cr}$ (II) and the rate of reduction of $\mathrm{Cr}^{3+}$ and have determined the rate parameters for each reaction.

1. The Rate of Reduction of $\mathrm{Cr}^{3^{+}}$.

We have measured the rate of reduction of $\mathrm{Cr}^{3^{+}}$polarographically. The data were analyzed by straightforward application of the theory of totally irreversible polarographic waves (33). Semi-logarithmic plots of $f\left(i / i_{d}\right)=(12 t / 7)^{\frac{1}{2}} \lambda$ vs. potential are shown in Figure 30 . The derived rate parameters are presented in Table 7 . The scatter in results is well within that typically observed in electrochemical rate measurements. 


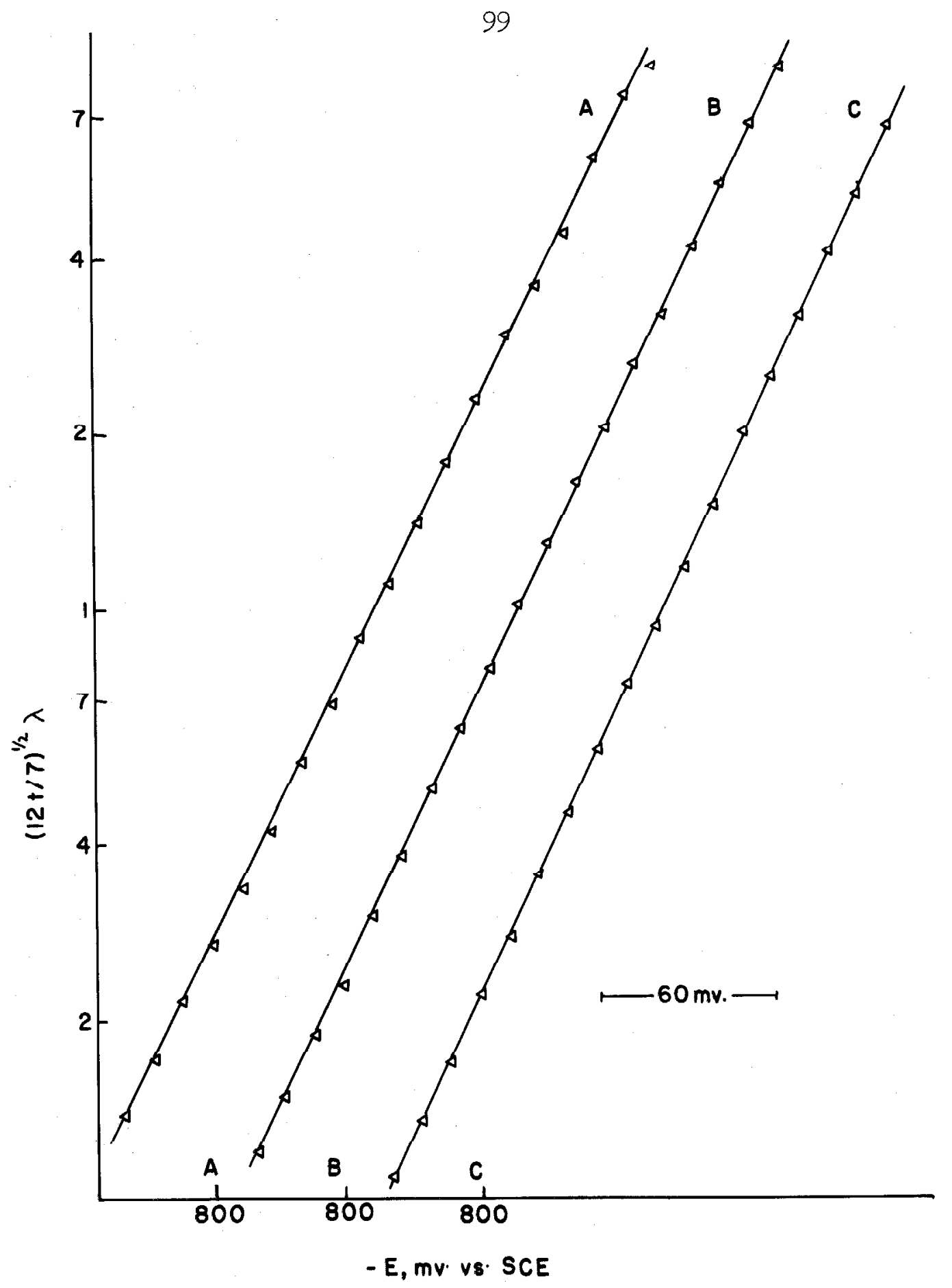

Figure 30. Semi-logarithmic plot of $\lambda$ as a function of potential for the polarographic reduction of $\mathrm{Cr}^{3^{+}}$. Solutions:

A, $0.712 \mathrm{mF} \mathrm{Cr}^{3+}, 0.0728 \mathrm{~F} \mathrm{HClO}_{4}(\mu=0.98)$;

$\mathrm{B}, 1.420 \mathrm{mF} \mathrm{Cr} 3^{+}, 0.0797 \mathrm{~F} \mathrm{HClO}_{4}(\mu=1.00)$;

C, $2.12 \mathrm{mF} \mathrm{Cr}^{+}, 0.0868 \mathrm{FHClO}_{4}(\mu=1.01)$. 
TABLE 7

\begin{tabular}{lcc}
\hline$\left(\mathrm{Cm}^{3^{+}}\right), \mathrm{mM}$ & $\mathrm{k}_{\mathrm{h}}^{0} \times 10^{5}, \mathrm{~cm} . / \mathrm{sec}$. & $\alpha$ \\
\hline 0.71 & 0.86 & 0.61 \\
1.42 & 0.66 & 0.62 \\
2.12 & 0.55 & 0.64 \\
$\mathrm{Av}$. & $0.69 \pm 0.11$ & $0.62 \pm 0.01$
\end{tabular}

$E^{\circ}=-0.650 \mathrm{v} \cdot \mathrm{vs} . \mathrm{SCE}$

Experimental procedures. Digital polarograms were obtained using a three-electrode polarograph and recorded with a Brown millivolt recorder. Solutions were prepared by adaing a measurea volume of $\mathrm{Cr}$ (III) stock colution (proparcd ao dcscribod in Chapter 2) to a measured volume of supporting electrolyte solution with $0.066 \mathrm{~F} \mathrm{HClO}_{4}$ and $0.908 \mathrm{~F} \mathrm{NaClO}_{4}$. The background current was measured in the deaerated supporting electrolyte solution before adding the Cr(III) solution.

A drop knocker was used with the dropping mercury electrode to maintain a drop time of 4 sec. The reference electrode was a Beckman SCE connectea to the solution by a cracked glass bead salt bridge containing I $\mathrm{F} \mathrm{NaNO}_{3}$. The auxiliary electrode was a platinum wire.

2. The Rate of Oxidation of $\operatorname{Cr}(I I)$.

Tree rale or uxtdalion of $\operatorname{Cr}$ (II) was measurea using potential step chronocoulometry (34). For irreversible oxianations the charge-time relationship for potential step chronocoulometry is 
where

$$
{ }^{*} Q_{Q}=\frac{K}{\lambda^{2}}\left(\exp \left(\lambda^{2} t\right) \operatorname{erfc}\left(\lambda t^{\frac{1}{2}}\right)+\frac{2 \lambda t^{\frac{1}{2}}}{\sqrt{\pi}}-1\right)
$$

and

$$
K=-n \widetilde{A K} \mathrm{~h}_{\mathrm{h}}^{\cup} \mathrm{e}^{(I-\alpha) \frac{\mathrm{n} \tilde{S}}{\mathrm{RT}}\left(\mathrm{E}-\mathrm{E}^{0}\right)}
$$

$$
\lambda=\frac{\mathrm{k}_{\mathrm{h}}^{\circ}}{\mathrm{D}^{\frac{1}{2}}} c(I-\alpha) \frac{\mathrm{n} \tilde{S}}{\mathrm{RT}}\left(\mathrm{E}-\mathrm{E}^{\circ}\right)
$$

${ }^{*} Q=Q-Q_{d I}$ is the charge due to faradaic reaction alone. The total measured charge, $Q$, includes the charge $Q_{\lambda}$ r required to charge the double layer from the initial potential where no reaction takes place to the final potential.

For a diffusion controlled reaction, the charge is

$$
\begin{aligned}
& * Q_{\alpha}=\frac{2 n \pi A D^{\frac{1}{2}} C^{0}}{\sqrt{\pi}} t^{\frac{1}{?}} \\
& { }^{*} Q_{a}=\frac{2}{\sqrt{\pi}} \frac{K}{\lambda} t^{\frac{1}{2}}
\end{aligned}
$$

Substituting Equation 6 into Equation ? we obtain

$$
\frac{2}{\sqrt{\pi}}\left(1-\frac{{ }^{*} Q}{{ }^{*} Q_{d}}\right)=\frac{1}{\lambda t^{\frac{1}{2}}}\left(1-\exp \left(\lambda^{2} t\right) \operatorname{erfc}\left(\lambda^{\frac{1}{2}}\right)\right)
$$

A working curve was constructed from calculated values of the function

$$
f\left(\lambda t^{\frac{1}{2}}\right)-\frac{1}{\lambda t^{\frac{1}{2}}}\left|1-\exp \left(\lambda^{2} t\right) \operatorname{erfc}\left(\lambda t^{\frac{1}{2}}\right)\right|
$$


which are presented in Table 8. From this working curve values of $\lambda t^{\frac{1}{2}}$ were obtained for various values of ${ }^{*} Q /{ }^{*} Q_{d}$. This method of determining kinetic parameters is analogous to that used in polarography. Q-t traces were obtained over $40 \mathrm{msec}$. Intervals for potentials from $-0.300 \mathrm{v}$. to $-0.050 \mathrm{v}$. vs. SCE. Q-t traces were obtained at +0.200 v. vs. SCE to give ${ }^{*} Q_{d}$ as a function of time. The plots obtained from derived values of $\lambda t^{\frac{1}{2}}$ are shown in Figure 31 . The values of the rate parameters obtained from these plots are given in Table 9.

TABIE 9

\begin{tabular}{ccc}
\hline t, moce. & $\mathrm{k}^{0} \times 10^{5}, \mathrm{~cm} \cdot \mathrm{sec}$. & $\alpha$ \\
\hline 10 & 8.4 & 0.72 \\
20 & 5.1 & 0.69 \\
30 & 2.9 & 0.61 \\
40 & 1.8 & 0.64 \\
\hline
\end{tabular}

$$
\mathrm{E}^{\mathrm{O}}=-0.650 \mathrm{v} \cdot \mathrm{Vs} \cdot \mathrm{SCE}
$$

The trend to higher values of the standard rate constant and transfer coefficient at shorter times is probably due to uncertainty in the double layer correction. The longer the time, the smaller $Q_{d \perp}$ is in comparison with ${ }^{*} Q$ and the smaller the effect of an error in $Q_{d I^{*}}$ Both $Q_{d 1}$ and ${ }^{*} Q$ are potential dependent, but ${ }^{*} Q$ increases faster with more anodic potential than $Q_{a I}$ does, so error in $Q_{d I}$ affects the transfer coefficient as well as the standard rate constant. The kinetic parameters obtained from the data at $40 \mathrm{msec}$. are probably closest to the true values. 
TABIE 8

$$
f(x)=\frac{1}{x}\left[1-\exp \left(x^{2}\right) \operatorname{erfc}(x)\right]
$$

\begin{tabular}{|c|c|c|c|}
\hline$x$ & $f(x)$ & $x$ & $f(x)$ \\
\hline 0.0001 & 1.1300 & 0.24 & 0.9257 \\
\hline 0.0002 & 1.1289 & 0.25 & 0.9186 \\
\hline 0.0005 & 1.8804 & 0.26 & 0.9116 \\
\hline 0.001 & 1.1276 & 0.27 & 0.9048 \\
\hline 0.002 & 1.1265 & 0.28 & 0.8980 \\
\hline 0.005 & 1.1034 & 0.89 & 0.8913 \\
\hline 0.01 & 1.1184 & 0.30 & 0.8847 \\
\hline 0.02 & 1.1087 & 0.31 & 0.8781 \\
\hline 0.03 & 1.0990 & 0.32 & 0.8717 \\
\hline 0.04 & 1.0896 & 0.33 & 0.8653 \\
\hline 0.05 & 1.0802 & 0.34 & 0.8591 \\
\hline 0.06 & 1.0710 & 0.35 & 0.8529 \\
\hline 0.07 & 1.0619 & 0.36 & 0.8468 \\
\hline 0.08 & 1.0530 & 0.37 & 0.8407 \\
\hline 0.09 & 1.0441 & 0.38 & 0.8347 \\
\hline 0.10 & 1.0354 & 0.39 & 0.8288 \\
\hline 0.11 & 1.0268 & 0.40 & 0.8230 \\
\hline 0.12 & 1.0184 & 0.41 & 0.8173 \\
\hline 0.13 & 1.0101 & 0.45. & 0.7950 \\
\hline 0.14 & 1.0018 & 0.50 & 0.7686 \\
\hline 0.15 & 0.9938 & 0.55 & 0.1458 \\
\hline 0.16 & 0.9858 & 0.60 & 0.7203 \\
\hline 0.17 & 0.9779 & $0.7^{0}$ & $0.677^{2}$ \\
\hline 0.18 & 0.9701 & 0.80 & 0.6386 \\
\hline 0.19 & 0.9625 & 0.90 & 0.6038 \\
\hline 0.20 & 0.9549 & 1.00 & 0.5724 \\
\hline 0.21 & $0.9^{1.74}$ & 1.10 & 0.5439 \\
\hline 0.22 & 0.9401 & 1.20 & 0.5179 \\
\hline 0.23 & 0.9328 & 1.30 & 0.4941 \\
\hline
\end{tabular}


104

TABIF 8--Continued

\begin{tabular}{|c|c|c|c|}
\hline$x$ & $\rho(x)$ & $x$ & $f(x)$ \\
\hline 1.35 & 0.4830 & 4.2 & 0.20695 \\
\hline 1.40 & 0.4723 & 4.4 & 0.19883 \\
\hline 1.50 & 0.4523 & 4.6 & 0.19132 \\
\hline 1.60 & 0.4338 & 4.8 & 0.18435 \\
\hline 1.70 & 0.4167 & 5.0 & 0.17786 \\
\hline 1.80 & 0.4008 & 5.2 & 0.17181 \\
\hline 1.90 & 0.3860 & 5.4 & 0.16615 \\
\hline 2.0 & 0.3723 & 5.6 & 0.16086 \\
\hline 2.1 & 0.3595 & 5.8 & 0.15588 \\
\hline 2.2 & 0.3474 & 6.0 & 0.15120 \\
\hline 2.3 & 0.3362 & 6.2 & 0.14680 \\
\hline 2.4 & 0.3256 & 6.4 & 0.14254 \\
\hline 2.5 & 0.3157 & 6.6 & 0.13871 \\
\hline 2.6 & 0.3063 & 6.8 & 0.13498 \\
\hline 2.7 & 0.29745 & 7.0 & 0.13146 \\
\hline 2.0 & 0.28909 & 7.4 & 0.12492 \\
\hline 2.9 & 0.28117 & 7.8 & C.11901 \\
\hline 3.0 & 0.27366 & 8.2 & 0.11362 \\
\hline 3.1 & 0.26654 & 8.6 & 0.10870 \\
\hline 3.2 & 0.25977 & 9.0 & 0.10419 \\
\hline 3.4 & 0.24720 & 9.5 & 0.09905 \\
\hline 3.6 & 0.23576 & 10.0 & 0.09439 \\
\hline 3.8 & 0.22532 & & \\
\hline 4.0 & 0.21575 & & \\
\hline
\end{tabular}




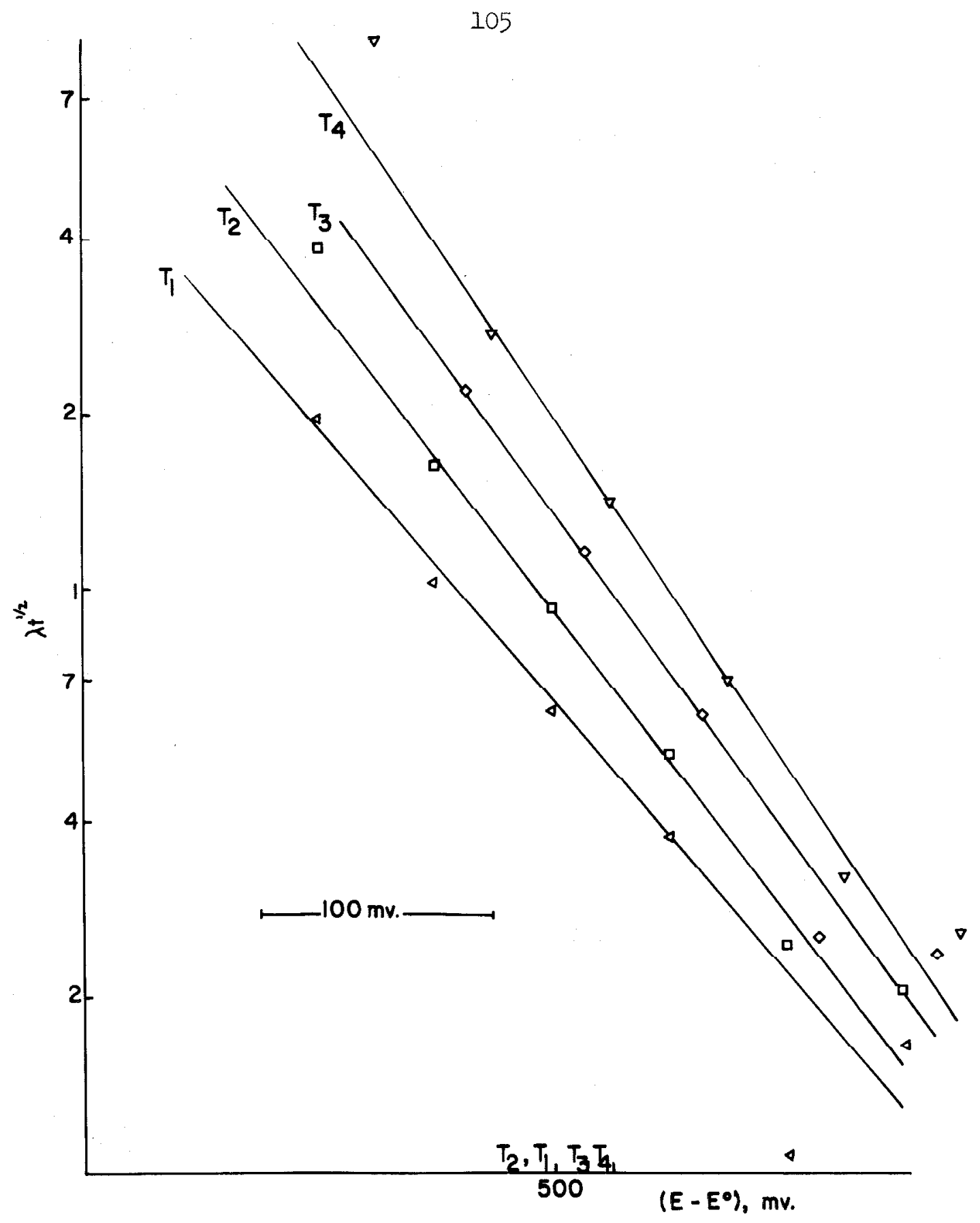

Figure 31. Semi-logarithmic plot of $\lambda t^{\frac{1}{2}}$ as a function of potential for the potential step chronocoulometric oxidation of $\mathrm{Cr}$ (II). Solution: $1.09 \mathrm{mF} \mathrm{Cr}$ (II), $0.100 \mathrm{~F} \mathrm{HClO}_{4}(\mu=1.00)$. The letters refer to the measurement time for each set of points: $\mathrm{T}_{1}, 10 \mathrm{~ms} . ; \mathrm{T}_{2}, 20 \mathrm{~ms} . ; \mathrm{T}_{3}, 30 \mathrm{~ms} . ; \mathrm{T}_{4} ; 40 \mathrm{~ms}$. 
Experimental details. The experiments were carried out as described on page 100. Solutions were $0.5 \mathrm{mF} \mathrm{Cr}(\mathrm{II}), 0.100 \mathrm{~F} \mathrm{HClO}_{4}$ $(\mu=1.00)$.

The rate of oxidation of $\mathrm{Cr}$ (II) in solutions $0.5-7.0 \mathrm{mF}$ in $\mathrm{Cr}$ (II), 0.1-0.01 $\mathrm{F}$ in $\mathrm{HClO}_{4}$, and $1 \mathrm{~F}$ in $\mathrm{NaClO}_{4}$ was determined by Aikens and Ross (6) using a potentiostatic technique. They extrapolated $1 \mathrm{vs.}$ $t^{\frac{1}{2}}$ to give the intercept $i_{0}=\mathrm{kn} \Im \mathrm{AC}$, where the equation defines their value of $\mathrm{k}$. We have plotted their rate data (Figure 32) to obtain the ratc paramctcro $\mathrm{k}_{\mathrm{h}}{ }^{0}=0.78 \times 10^{-5} \mathrm{~cm} \cdot / \mathrm{sec} \cdot\left(\mathrm{E}^{\circ}=-0.650 \mathrm{v} \cdot \mathrm{vs} . \mathrm{SCE}\right)$ and $\alpha=0.63$.

3. Discussion.

The best values of the rate parameters for the couple $\mathrm{Cr}^{2+} / \mathrm{Cr}^{3^{+}}$ are given in Table 10. The agreement among these values is quite good. When the transfer coefficient for an electrochemical reaction is 0.5 the rate of the reaction as a tunction of potential is symmetrical about the standard potential for the couple. The pronounced asymmetry observed if $\alpha \neq 0.5$ is illustrated by the normalized polarogram shown in Figurc 33. The polarogram was calculated ueing the value $k_{h}{ }^{\circ}=$ $10^{-5} \mathrm{~cm} \cdot / \mathrm{sec}$, and $\alpha=0.63$.

TABIE 10

\begin{tabular}{ccc}
\hline $\mathrm{k}_{\mathrm{h}}^{0} \times 10^{5}, \mathrm{~cm} . / \mathrm{sec}$. & $\alpha$ & Reference \\
\hline 0.69 & 0.62 & Talle 0 \\
1.8 & 0.64 & Table 9 \\
0.78 & 0.63 & Reference 6 \\
\hline $\mathrm{E}^{0}=-0.650$ v. vs. SCE
\end{tabular}




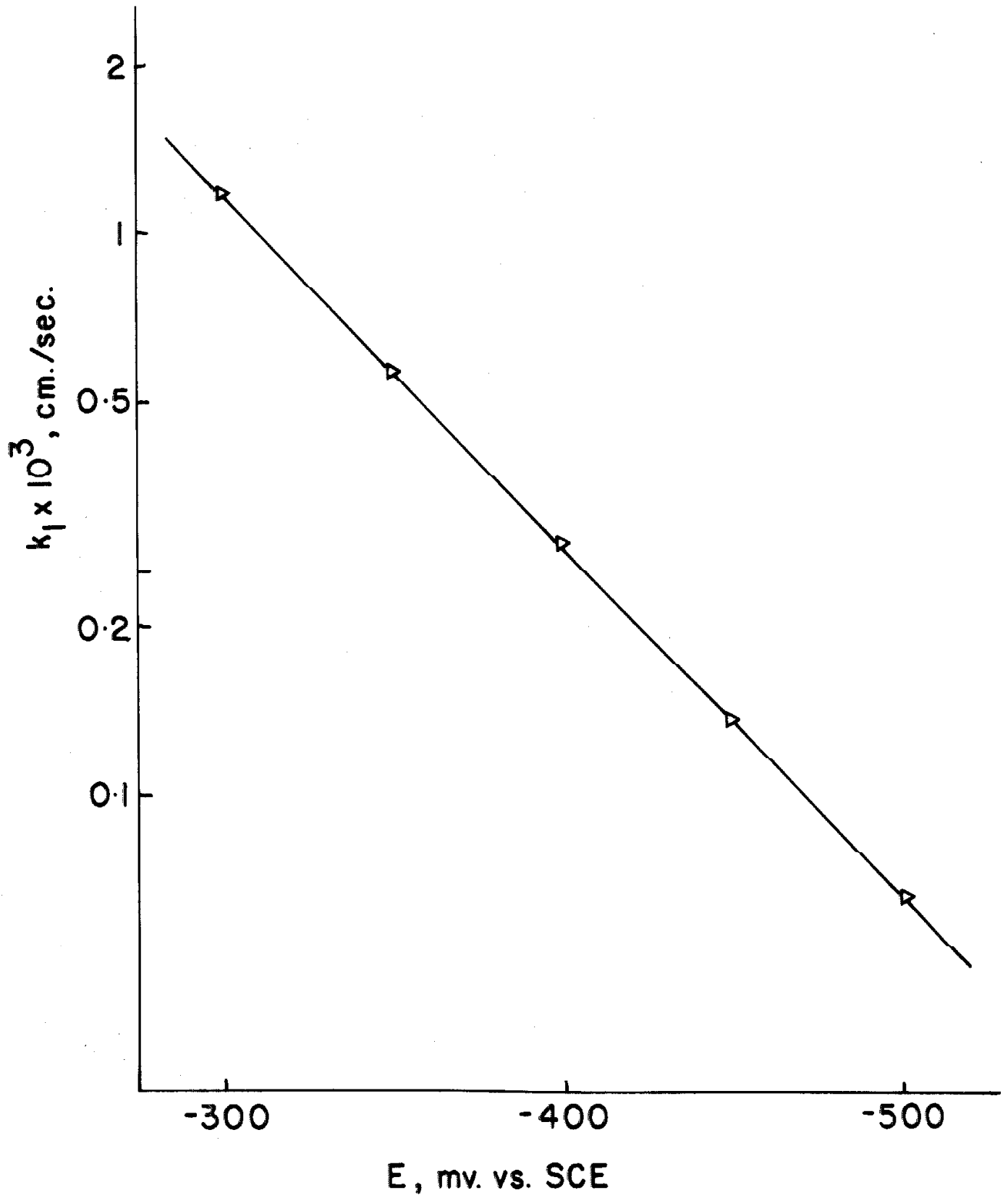

Figure 32. Semi-logarithmic plot of the potential dependence of the rate of the reaction $\mathrm{Cr}^{2^{+}} \rightarrow \mathrm{Cr}^{3^{+}}+e^{-}$from the data of Aikens and Ross (6). 


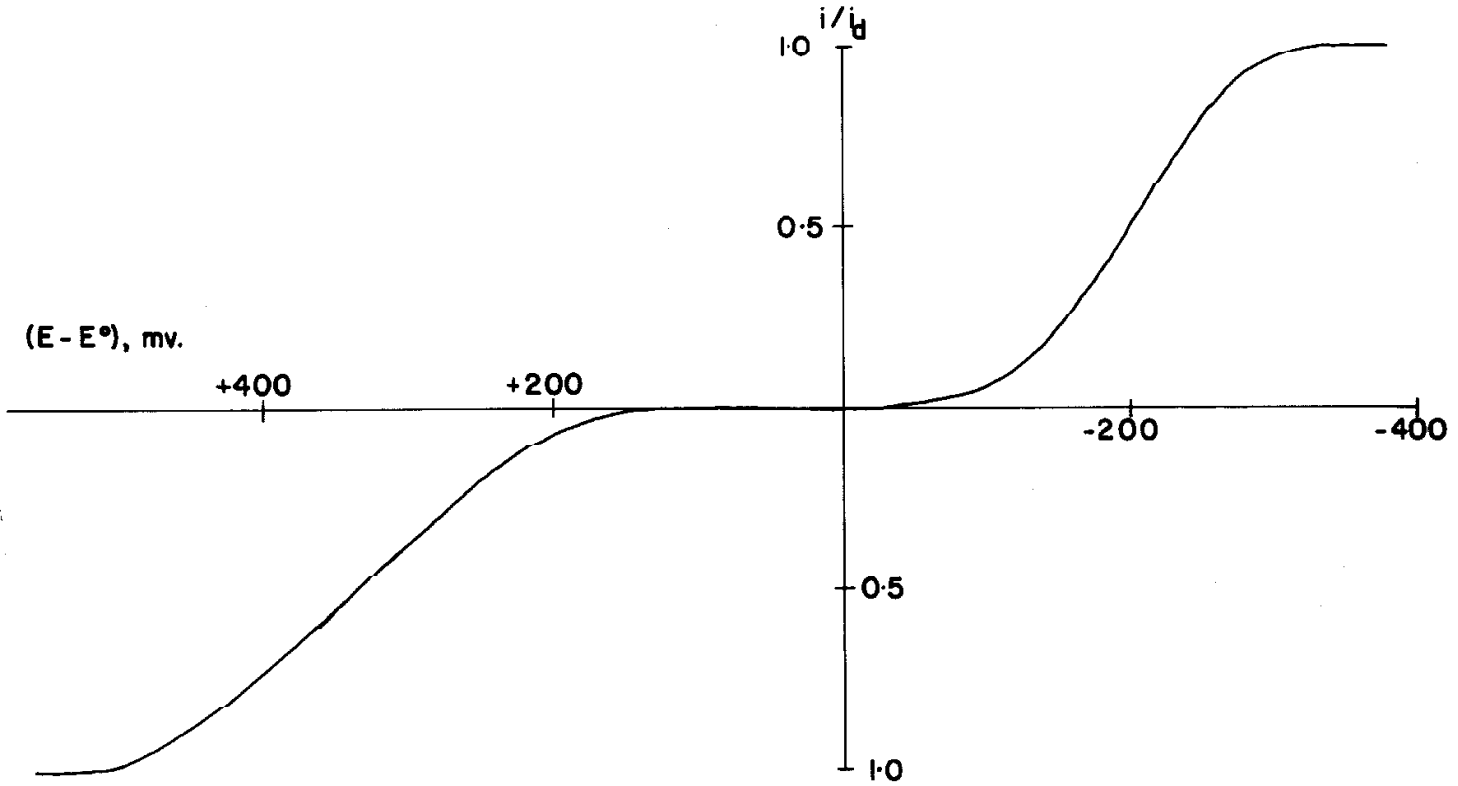

Figure 33. Normalized polarogram for the kinetic parameters $\mathrm{k}_{\mathrm{h}}{ }^{u}=10^{-5} \mathrm{~cm} . / \mathrm{sec}$, and $\alpha=0.63$ with $\mathrm{n}=1, \mathrm{D}^{\frac{1}{2}}=$ $0.00254, \mathrm{~T}=27^{\circ} \mathrm{C}$. 


\section{Kinetic Parameters for the Couple $\mathrm{Cr}$ (II)/CrCl${ }^{+}$}

Alkens and Ross (6) present data which can be used to obtain the kinetic parametera for the rcaction

$$
\mathrm{Cr}^{2^{+}}+\mathrm{Cl}^{-} \stackrel{-e^{-}}{\longrightarrow} \mathrm{CrCl} 2^{+}
$$

We cannot calculate the standard rate constant because the standard potential is not known. However, from the plot of this data shown in Figure 34 we obtain the value of the transfer coefficient, $\alpha=0.43$. This is in contrast to the value of 0.63 for the reaction

$$
\mathrm{Cr}^{2^{+}} \stackrel{-\mathrm{e}^{-}}{\longrightarrow} \mathrm{Cr}^{3^{+}}
$$

From unpublished rate data obtained by Aikens and Ross (35) we derive the value $\alpha=0.39$ for the reduction of $\mathrm{CrCl}^{2+}$ in perchlorate Dolution at $\mathrm{pH} 2(\mu=1.00)$. From aimilar data for reduction of $\mathrm{Cr}^{3^{+}}$ (35) we extract the value $\alpha=0.62$ (cf. Table 10), which supports the validity of the method and indicates that the difference between the transfer coefficients for $\mathrm{Cr}^{3^{+}}$reduction and $\mathrm{CrCl}{ }^{2^{+}}$reduction is real.

III. Kinetic Parameters for the Couple Cr(II)/Cr(III)

\section{in Bromide Solution}

In bromide solution under conditions where the oxidation of $\operatorname{Cr}(I I)$ is not dittusion limited, the oxidation takes place via two paths,

$$
\begin{array}{r}
\mathrm{Cr}^{2^{+}}+\mathrm{Br}^{-} \stackrel{-e^{-}}{\longrightarrow} \mathrm{CrBr}^{2^{+}} \\
\mathrm{Cr}^{2^{+}} \stackrel{-e^{-}}{\longrightarrow} \mathrm{Cr}^{3^{+}}
\end{array}
$$




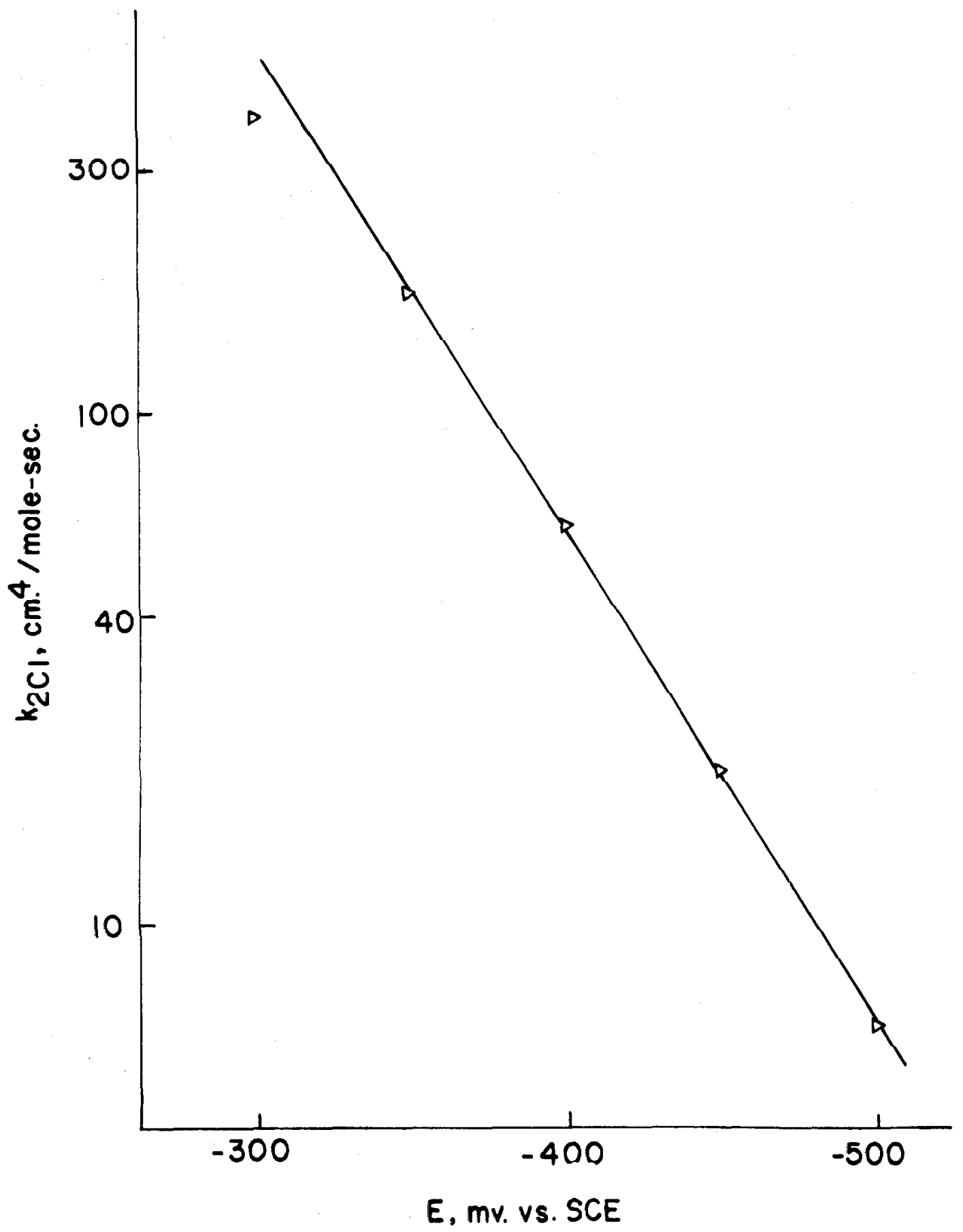

Figure 34. Semi-logarithmic plot of the potential dependence of the rate of the reaction $\mathrm{Cr}^{2+}+\mathrm{Cl}^{-} \rightarrow \mathrm{CrCl}^{2^{+}}+e^{-}$from the data of Aikens and Ross (6). 
as has been discussed above (page 82).

To determine the kinetic parameters for the bromide-dependent process we must measure the combined rate as a function of bromide concentration and extract from those data the bromide-dependent part of the rate.

The situation is slightly different for the cathodic process:

$$
\begin{gathered}
\mathrm{CrBr}^{2^{+}} \stackrel{+e^{-}}{\longrightarrow} \mathrm{Cr}^{2^{+}}+\mathrm{Br}^{-} \\
\mathrm{Cr}^{3^{+}} \stackrel{+e^{-}}{\longrightarrow} \mathrm{Cr}^{2^{+}}
\end{gathered}
$$

because the reduction of $\mathrm{CrBr}^{2^{+}}$is diffusion controlled under most conditions at potentials anodic of $\mathrm{Cr}^{{ }^{+}}$reduction. 'l'his means that the rate of Reaction 12a can be measured alrectly without interference from Reaction $12 \mathrm{~b}$.

1. Chronopotentiometric Measurement of the Rate of Oxidation of $\operatorname{Cr}$ (II) in Dilute Bromide Solution.

The rate of oxidation of $\mathrm{Cr}$ (II) in $1 \mathrm{mF} \mathrm{NaBr}$ solution was determined chronopotentiometrically at a hanging mercury drop electrode.

The chronopotentiograms were analyzed as totally irreversible waves. The potential-time relation is obtained by substituting the chronopotentiometric equation for $c_{R}(0, t)(36)$ in Equation 1 with $\mathrm{C}_{\mathrm{O}}(\mathrm{O}, \mathrm{t})=\mathrm{O}$, giving

$$
\begin{aligned}
E=E^{\circ}-\frac{R T}{(1-\alpha) n \Im s} & \ln \frac{k^{0} r_{0}}{D}-\frac{R T}{(1-\alpha) n \Im} \operatorname{In}\left[\exp \left(\frac{D t}{r_{0}}\right) \operatorname{erfc}\left(\frac{(D t)^{\frac{1}{2}}}{r_{0}}\right)\right. \\
& \left.-\exp \left(\frac{D T}{r_{0}^{2}}\right) \operatorname{erfc}\left(\frac{(D T)^{\frac{1}{2}}}{r_{0}}\right)\right]
\end{aligned}
$$


The calculation of the time-dependent term is more readily done by expanding the argument of the logarlthm in power series. This removes some of the dependence on the diffusion coefficient, $D$, and the radius of the electrode, $r_{0}$. Only three terms of the expansions need be taken. The resulting equation is

$$
\begin{aligned}
\mathrm{E}_{\mathrm{I}}=\mathrm{E}_{0} & -\frac{\mathrm{RT}}{(1-\alpha) n \tilde{N}} \ln \frac{2 \frac{K_{1}^{0}}{\sqrt{\pi D}}-\frac{R T}{(1-\alpha) n \mathcal{N}} \ln \left[\left(T^{\frac{1}{2}}-t^{\frac{\pi}{2}}\right)\right.}{} \\
& \left.-\frac{\sqrt{\pi}}{2} \frac{D^{\frac{1}{2}}}{r_{0}}(T-t)+\frac{2}{3} \frac{D}{r_{0}^{2}}\left(T^{\frac{3}{2}}-t^{\frac{3}{2}}\right)\right]
\end{aligned}
$$

A 1ogarithmic plot of a chronopotentiogram according to this equation is shown in Figure 35. The derived values of the kinetic parameters are $\alpha=0.50$ and $\mathrm{k}_{\mathrm{h}}=1.25 \times 10^{-5} \mathrm{~cm} . / \mathrm{sec}$. , where the rate constant is referred to $\mathrm{E}=0 \mathrm{~V}$. Vs. SCE. A similar plot for another chronopotentiogram gave the values $\alpha=0.45$ and $\mathrm{k}_{\mathrm{h}}=0.72 \times 10^{-6} \mathrm{~cm} . / \mathrm{sec}$. Experimental details. 'l'he chronopotentiograms were obtained as described on pp. $64 f f$.

The experimental solution had $1.69 \mathrm{mF} \mathrm{Cr}$ (II), $0.100 \mathrm{FF}^{\mathrm{HClO}} 4$, $1.00 \mathrm{mF} \operatorname{NaBr}(\mu-1.00)$.

Transition times were about 2.3 sec.

2. Polarographic Determination of the Bromide

Dependence of the Rate of $\operatorname{Cr}$ (II) Oxidation.

The rate of oxidation of $\mathrm{Cr}$ (II) in solutions with varying bromide concentration was determined polarographically. At large bromide concentrations the rate is sufficlently large that the quasi-reversible analy- 


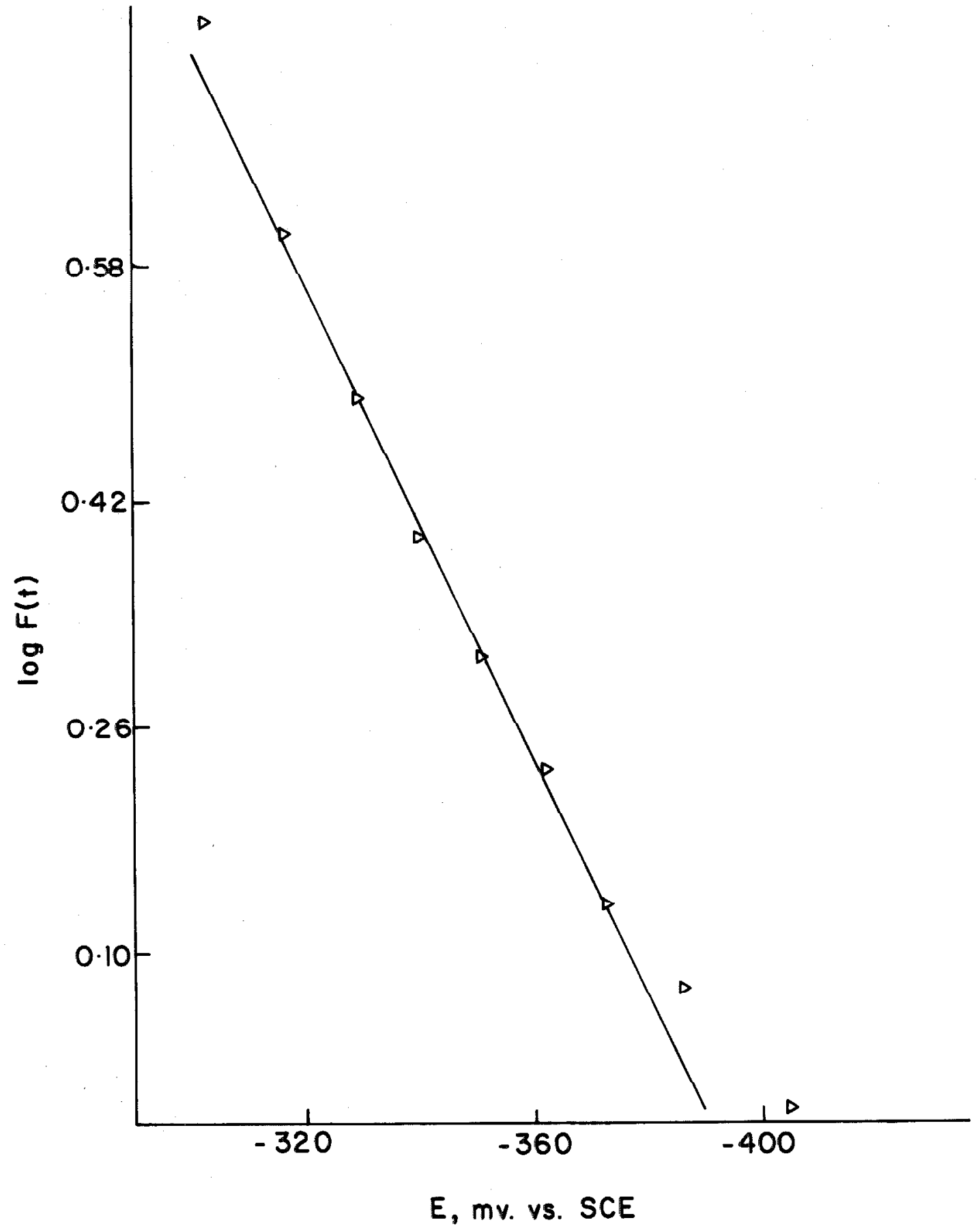

Figure 35. Chronopotentiometric determination of the rate of $\mathrm{Cr}$ (II) oxidation in dilute bromide solution. Solution: $1.7 \mathrm{mF}$ $\mathrm{Cr}$ (II), $1.01 \mathrm{~min} \mathrm{NaDr}, 0.100 \mathrm{FHClO}_{4}(\mu=1.00)$. The data is plotted according to Equation $14 . F(t)$ is the argument of the second logarithmic term in that equation. 
sis must be used. The method is discussed in detail by Delahay (37). The value of the effective half-wave potential for use in the analysis was determined by the extrapolation procedure of Koryta (38) which is illustrated below in Figure 38 .

When the points used in the analysis of the polarograms are $0.120 \mathrm{v}$. or more from the half-wave potential, the backward reaction contributes less than $1 \%$ of the current. For all but the two highest bromide concentrations, the totally irreversible analysis was uscd for the polarograms by selecting only points near the head of the wave as far from the half-wave potential as possible. The values of $\alpha$ obtained from the semi-logarithmic plots of rate vs. potentlal for each bromide concentration are given in Table 11.

TABIE 11

\begin{tabular}{cc}
$\left(\mathrm{Br}^{-}\right)$, moles $/ 1$. & $\alpha$ \\
\hline $0.87^{1}$ & 0.29 \\
0.436 & 0.28 \\
0.0546 & 0.28 \\
0.00192 & 0.27 \\
0.00154 & 0.49 \\
0.00106 & 0.49
\end{tabular}

Figure 36 shows the bromide dependence of the rate at several different potcntialo. Thedc roulto show that the pseudo first order heterogeneous rate constant for the oxidation of $\mathrm{Cr}$ (II) in the presence of bromide can be written in the form $\mathrm{k}=\mathrm{k}_{1}+\mathrm{k}_{2}\left(\mathrm{Br}^{-}\right)$. From the slopes of the lines in Figure 36 we obtain the constant for the bromide dependent path, $\mathrm{k}_{2}$, and the intercepts give $\mathrm{k}_{1}$. 


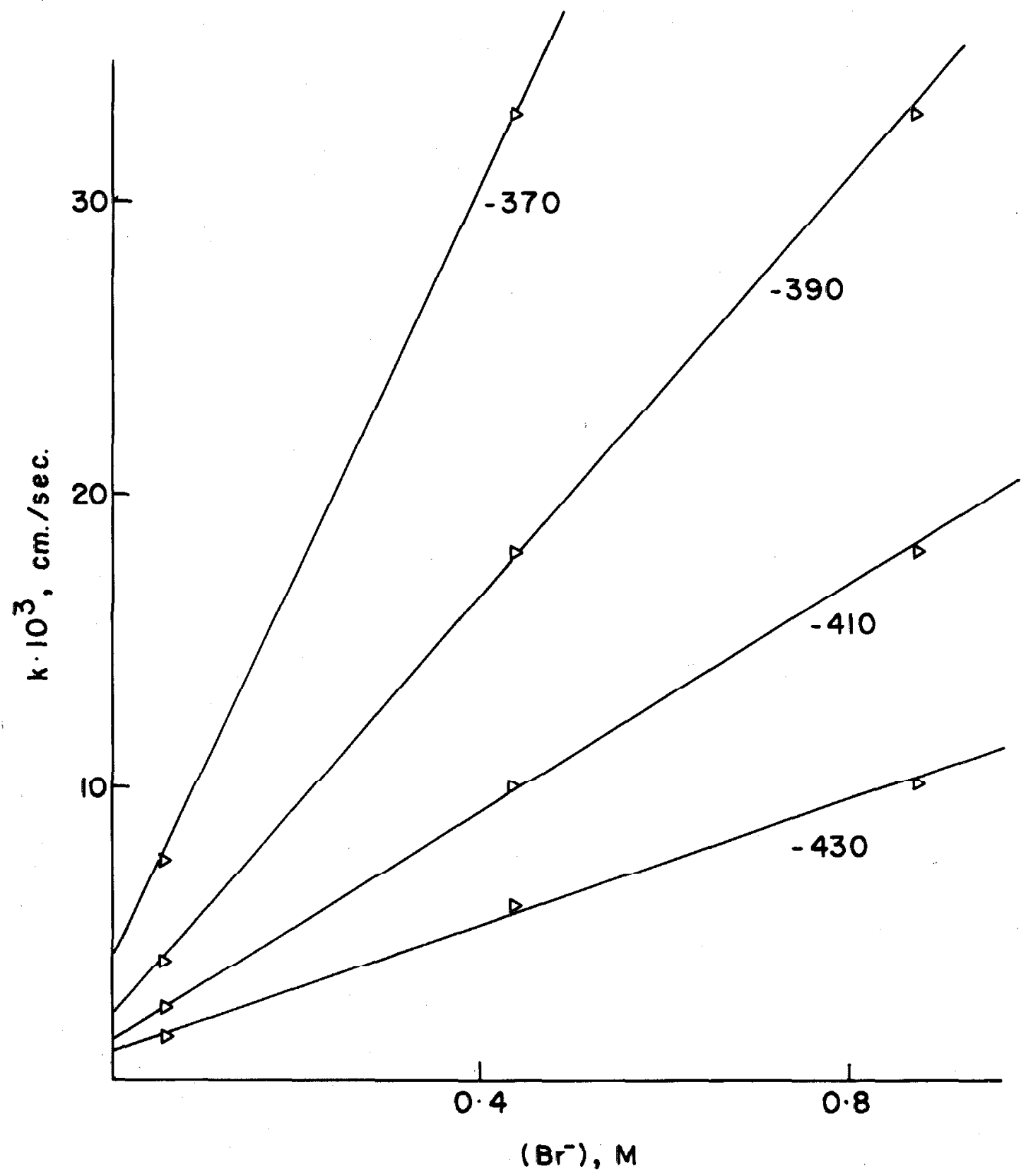

Figure 36. The variation of the rate of $\mathrm{Cr}$ (II) oxidation with bromide concentration. The numbers on the lines are the potentials at which the rate was measured. See Page 116 for conditions. 
The semi-logarithmic plot in Figure 37 shows the potential dependence of $\mathrm{k}_{2}$. From this plot we obtain the transfer coeffictenl $\alpha=$ 0.21 . The rate constant is $\mathrm{k}_{\mathrm{h}}^{0}=1.82 \mathrm{~cm} .4 /$ mole. sec. referred to $\mathrm{E}=$ $-0.500 \mathrm{v}$. vs. SCE. The logarithm of the $\mathrm{k}_{1}$ values obtained from the Intercepts do not show a lincor dopendenec on the potontial. The un certainty in these values is so large that such a relationship could hardly be expected. However, the values are all within a factor of 2 of the rates calculated from the $\alpha$ values and standard rate constants given in Table 10.

Experimental details. The polarograms were obtained with a Sargent Model XV Polarograph.

An $\mathrm{H}$-cell of standard design was used with a large $\mathrm{NaCl} \mathrm{SCE}$ reference electrode connected to the solution compartment by a I F NaFagar salt bridge with coarse fritted disk. The potentials in Figures 36-37 are given with respect to this reference electrode which is +0.012 v. vs. SCE.

The dropping mercury electrode had a drop time of 3.60 sec. With $\mathrm{m}^{2 / 3} \mathrm{t}^{1 / 6}=2.33 \mathrm{mg} \cdot{ }^{2 / 3}$ sec. $^{-1 / 2}$.

The solutions were prepared by adding a measured amount of Cr(II) stock solution to a meacured amount of deaerated supporting electrolyte solution in the cell. The composition of the resulting solution was $3.65 \mathrm{mF} \mathrm{Cr}_{\text {(II) }} 0.105 \mathrm{FHClO}_{4}$, and $0.874,0.436,0.0546,0.00192$, 0.00154 , or $0.00106 \mathrm{Fr} \operatorname{Na.Rr}(\mu=1.00)$.

Background current was measured in the deaerated supporting electrolyte solution before ading the Cr(II) solution. 


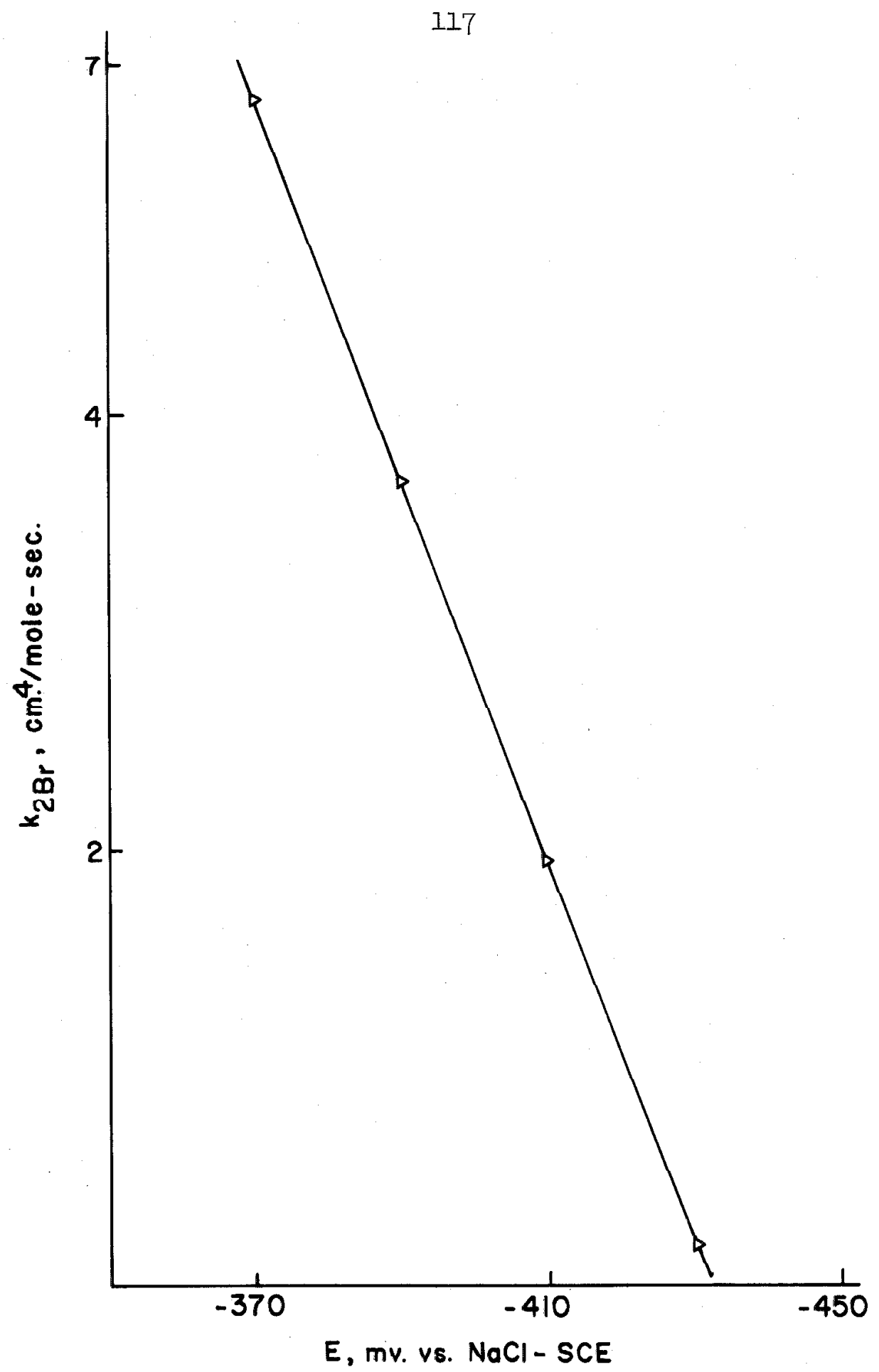

Figure 37. Semi-logarithmic plot of the potential dependence of the rate of the reaction $\mathrm{Cr}^{2+}+\mathrm{Br}^{-} \rightarrow \mathrm{CrBr}^{2+}+e^{-}$. The points are the slopes of the lines in Figure 36. 
3. Polarographic Determination of the Rate of Reduction of $\mathrm{Cr}_{\mathrm{Br}}{ }^{+}$.

The rate of the reduction of $\mathrm{CrBr}^{2}$ was determined polarographically in $0.91 \mathrm{~F} \mathrm{NaBr}$ solution. The usual quasi-reversible analysis of the polarographic wave was used (37) with the effective half-wave potential determined by the method of Koryta (38). The extrapolation to give the half-wave potential is illustrated in Figure 38.

The values of $(12 t / 7)^{\frac{1}{2}} \lambda$ are plotted as a function of potential in Figure 39. The minimum is close to the expected minimum required by the choice of half-wave potential, -0.501 v. vs. SCE. Similar plots were made for the same date analyzed using $-0.500 \mathrm{v}$. and $-0.502 \mathrm{v}$. vs. SCE for the effective half-wave potential. The fit in these cases was not as good. This gives us confidence in the cholce or reference potential.

\footnotetext{
From Figure 39 we obtain $\alpha=0.48$ and $\mathrm{k}_{\mathrm{h}}^{\circ}=1.82 \times 10^{-3} \mathrm{~cm} \cdot / \mathrm{sec}$. (referred to $\mathrm{E}=-0.500 \mathrm{v}$. vo. SCE) ,
}

Experimental details. The polarogram was obtained as described on page 100.

Chromic Bromide (K\&KLaboratories) was used as the source of $\mathrm{CrBr}^{2+}$. Solutions were $0.91 \mathrm{~F}$ in $\mathrm{NaBr}, 0.066 \mathrm{~F}$ in $\mathrm{HClO}_{4}$, and approximately $\mathrm{mF}$ in $\mathrm{CrBr}^{+}$.

4. Discussion.

The values obtained for the kinetic parameters are summarized in Table 12. The standard rate constants are calculated for 1, M bromide $\left(10^{-3}\right.$ moles $\left./ \mathrm{cm}^{3}\right)$. The standard potential obtained in Section 3 , 


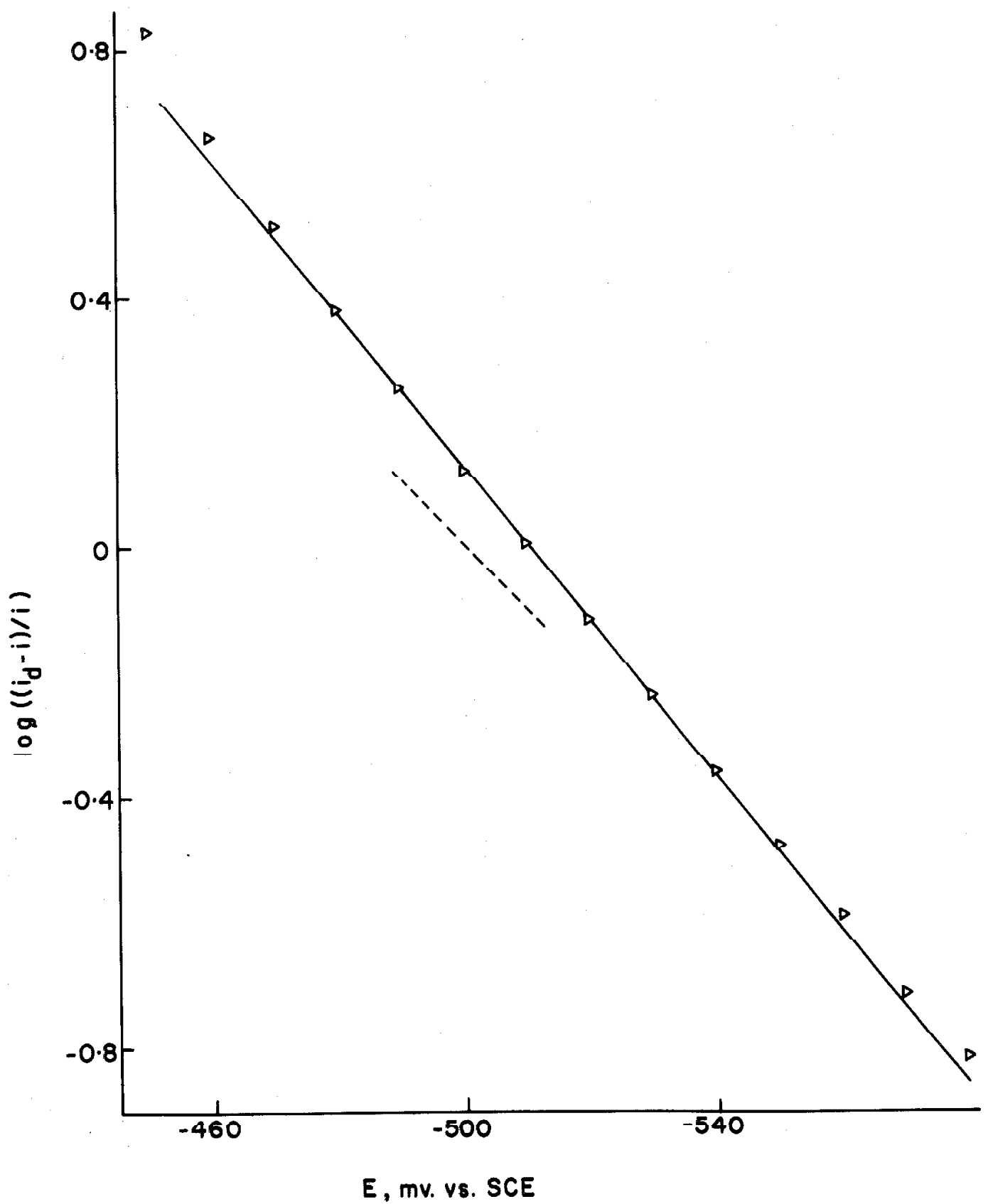

Figure 38. Nernst plot for the polarographic reduction of $\mathrm{CrBr}^{2+}$ in $0.91 \mathrm{~F} \mathrm{NaBr}, 0.066 \mathrm{~F} \mathrm{HClO}_{4}$ solution illustrating Koryta's method of determination of the reference potential. 


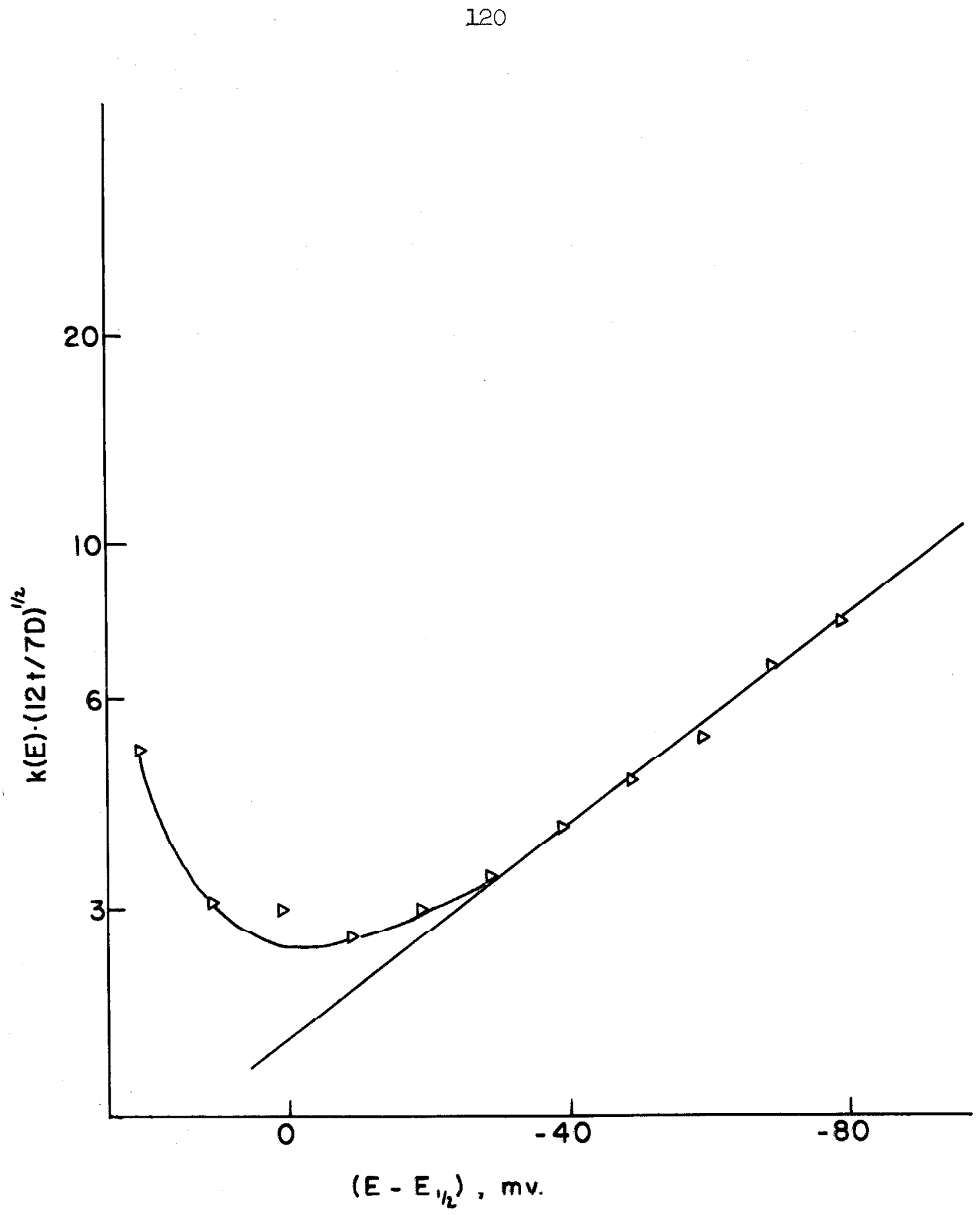

Figure 39. Semi-Iogarithmic plot of the potential dependence of the rate of reduction of $\mathrm{CrBr}^{+}$from polarographic measurements. $\mathrm{E}_{\frac{1}{2}}$ is the effective half-wave potential obtained from Figure 38 . 
$-0.501 \mathrm{v}$. vs. SCE, is shifted to $-0.499 \mathrm{v}$. vs. SCE in converting from 0.91 to $1 \mathrm{M}$ bromide. For convenience, the value of the standard potential has been arbitrarily chosen to be $-0.500 \mathrm{v}$. vs. SCE.

The values of the standard rate constants are in remarkably good agreement. The difference in $\alpha$ values, though large, is not especially surprising, because of the wide variation in conditions under which the data was obtained. This point is discussed in more detail below. The derived value of the standard rate constant for $\mathrm{Cr}$ (II) oxidation depends much more heavily on the transfer coefficient than does the value for $\mathrm{CrBr}{ }^{2+}$ reduction. The agreement of the standard rate constants suggests that the $\alpha$ value obtained from $\operatorname{Cr}$ (II) oxidation is at least a welldefined quantity, though it may be far from the "true" value because of doulle layer efrects.

TABIE 12

\begin{tabular}{|c|c|c|}
\hline$k_{h}^{0} x 10^{3}, \mathrm{~cm} . /$ see. & $\alpha$ & Reaction \\
\hline 1.82 & 0.21 & $\mathrm{Cr}^{2^{+}}+\mathrm{Br}^{-} \stackrel{-e^{-}}{\longrightarrow} \mathrm{CrBr}^{2^{+}}$ \\
\hline 1.88 & 0.48 & $\mathrm{CrBr}^{2^{+}} \stackrel{+e^{-}}{\longrightarrow} \mathrm{Cr}^{2^{+}}+\mathrm{Br}^{-}$ \\
\hline
\end{tabular}


IV. The Relation Bctwcon the Kinetic Parameters and Mechanism

In all of the rate determinations discussed ahove the effect of the $\psi$ potential on electrode kinetics has been ignored. This is an important effect, particularly in the oxidation of $\mathrm{Cr}^{2^{+}}$, where the reaction is strongly accelerated by negative $\psi$ potential and strongly decelerated by positive $\psi$ potential. Obtaining the true rates for the reactions investigated is a major project beyond the scope of this work. However, we can say a few things about the measured rate parameters. Much valuable progress has been made in development of theory to predict electrochemical standard rate constants and their relation to homogeneous rate constants, but work in this area has been confined to adiabatic reactions (39). Even the oxidation of $\mathrm{Cr}^{2+}$ to $\mathrm{Cr}^{3^{+}}$is non-adiabatic, because while $\mathrm{Cr}\left(\mathrm{H}_{2} \mathrm{O}\right)_{6} 3^{+}$is rigorously octahedral, $\mathrm{Cr}\left(\mathrm{H}_{2} \mathrm{O}\right)_{6}{ }^{2^{+}}$is highly distorted from octahedral symmetry, haying two short and four long metal-oxygen bonds (40). This means that bond deformation must accompany the electron-transfer process. However, the deviation of the values of the transfer coefficient from the adiabatic value of 0.5 (41) can be speculated upon.

In analysis of kinetic data the current or some related quantity is plotted semi-logarithmically against potential. The graph should give a straight line with the slope proportional to $-\alpha$ or to $1-\alpha$, depending on whether the reaction is a reduction or an oxidation. However, if the effect of the $\psi$ potential is taken into account, the slope must be decreased by the quantity 


$$
\left(\alpha_{n}-z\right) \frac{\mathfrak{J}}{\mathrm{RT}} \frac{\partial \psi}{\partial \mathrm{E}}
$$

independent of whether the reaction is an oxidation or a reduction (8). This correction is often not considered to be important because the semi-1ngarithmic plot is linear, but quite often dw/OF is constant or nearly so over a sufficiently wide potential range that the Ilnearity of the plot does not mean that neglecting the $\psi$ effect is justifled. For one-electron oxidations or reductions when the plot is Inear, we have

$$
\alpha_{\text {trme }}=\frac{\alpha_{\text {meas }}-z \frac{\partial \psi}{\partial E}}{1-\frac{\partial \psi}{\partial E}}
$$

where $\alpha_{\text {meas }}$ is the value of $\alpha$ one obtains from the slope of the line if the effect of double layer is ignored. Over the potential range of interest to us the variation of $\psi$ with potential is fairly small. We are helped in this respect by the fact that increasing the halide concentration, while shifting the flat portion of the curve to more cathodic potentials, also shifts the effective polarographic half-wave potenlial to more calhodic polentials, so that as one varies the halide concentration and studies the effect on the rate of oxidation of $\mathrm{Cr}$ (II), the effect of the double layer on the apparent value of $\alpha$ is remarkably constant. The actual amount of the correction on $\alpha$ may bo ao large ar 0.15. With this reservation in mind, let us examine the transfer coefficients listed in Table 13. 


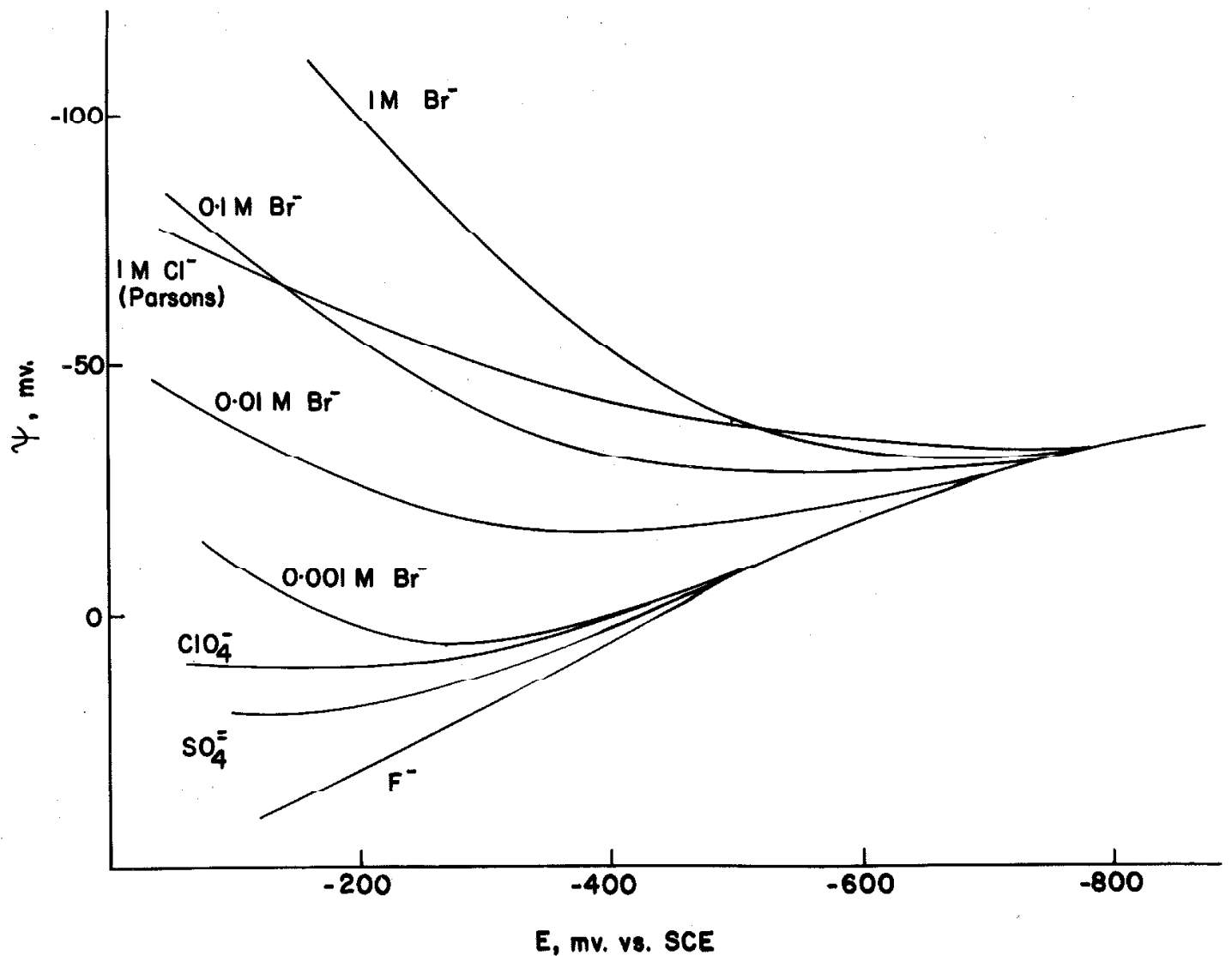

Figure 40 . The $\psi$ potential as a function of potential from the work of Gicrat (42). 
TABIF 13

\begin{tabular}{ccl}
\hline Couple & $\alpha$ & Process \\
\hline $\mathrm{Cr}(I I) / \mathrm{Cr}^{3+}$ & 0.63 & ox and red \\
$\mathrm{CrCl}^{2+}$ & 0.43 & ox \\
& 0.49 & red \\
$\mathrm{CrBr}^{2+}$ & 0.21 & ox \\
& 0.48 & red \\
\hline
\end{tabular}

The closeness of the $\alpha$ values for $\mathrm{CrX}^{\mathrm{e}^{+}}$reduction to 0.5 suggests that the electrode reaction is

$$
\operatorname{CrX}^{2^{+}}+e^{-} \longrightarrow \operatorname{CrX}^{+}
$$

followed by a fast dissociation step

$$
\mathrm{CrX}^{+} \longrightarrow \mathrm{Cr}^{2^{+}}+\mathrm{X}^{-}
$$

On the other hand, the low values of the transfer coefficients obtained for the oxidation of $\mathrm{Cr}$ (II) to $\mathrm{CrX}^{2^{+}}$support the view that intrusion of halide into the chromium coordination sphere forme the transition state for the electron transfer rather than constituting a fast prior reaction. 
1. J. Heyrovsky, Disc. Faraday Soc., 1, 212 (1947).

2. H. Taube and H. Myers, J. Am. Chem. Soc., 76, 2103 (1954).

3. H. Taube, "Mechanisms of Redox Reactions of Simple Chemistry" in Advances in Inorganic Chemistry and Radiochemistry, Vol. I, Academic Press, Inc., INew York, 1959.

4. R. I. Pecsok and J. J. Lingane, J. Am. Chem. Soc,, 72, 189 (1950).

5. W. Kemula and E. Rakowska, Roczniki Chemil, Ann. Soc. chim. Polonorum, 36, 203 (1962).

6. D. A. Alkens and J.W. Ross, Jr., J. Phys. Chem., 65, 1213 (1961).

7. R. T. Pecsok and .T. Rjerrmm, Acta. Chem. Scand, 11, 1418 (1957),

8. P. Delahay, Double Layer and Electrode Kinetics, Interscience Publishers, New York, 1965.

9. H. W. Stone and C. Beeson, Ind. Eng. Chem. Anal. Ed., 8, 188 (1936).

10. W. G. Davies and J. E. Prue, Trans. Faraday Soc., 51, 1045 (1955).

11. P. J. Elving and B. Zemel, J. Am. Chem. Soc., 79, 1281 (1957).

12. C. A. Bunton and G. Stedman, J. Chem. Soc., 2440 (1958).

13. F. A. Guthrie and E. I. King, Inorg. Chem., 3, 916 (1964).

14. T. W. Swaddle and E. I. King, Inorg. Chem., 4, 532 (1965).

15. E. L. King, J. Am. Chem. Soc., 80, 5011 (1958).

16. J. A. Laswicli and. R. A. Planc, J. Am. Chcm. Soc., 81, 3564 (1959).

17. W. P. Schaefer, Thesis, University of California at Los Angeles, 1961 .

18. A. Seidell, Solubilities of Inorganic and Metal Organic Compounds, Vol. 1. 3rd. Ed., D. Van Nostrand Co., Inc., 1955.

19. L. Meites, Polarographic Techniques, Interscience Publishers, New York, 1955. 
20. S. Thompson, C. S. J., Ph.D. Thesis, University of California at Berkeley, 1964. UCRL Report 11410.

21. P. Delahay, New Instrumental Methods in Electrochemistry, Interscience Publishers, New York, 1955.

22. W. M. Latimer, The Oxidation States of the Elements and Their Potentials in Aqueous Solutions, 2nd. Ed., Prentice-Hall, Inc., Englcwood Cliffe, N. J., 1952.

23. I. M. Kolthoff and J. J. Lingane, Polarography, 2nd. Ed., Vol. 2, p. 454. Interscience Publishers, New York, 1952.

24. J. D. Voorhies and N. H. Furman, Anal. Chem., 30, 1656 (1958).

25. M. OIsen. Unpublished results, C.I.T., 1963.

26. J. O'M. Bockris, M, A. V. Devanathan, and A. K. N. Reddy, Proc. Royal Soc., A, 279, 327 (1964).

27. N. Tanaka and R. Tamamushi, Electrochim. Acta, 9, 963 (1964).

28. J. H. Christie, R. A. Osteryoung, and F.C. Anson, J. Electroanal. Chem., in press.

29, J. H. Christie, J. Electroanal. Chem., in press.

30. G. Lauer, Thesis, C.I.T., 1966.

31. G. Lauer and R. A. Osteryoung, Anal. Chem., in press.

32. Reference 21, Chapter 2.

33. Ibid., pp. 76ff.

34. J. H. Christie, G. Lauer, and R. A. Osteryoung, J. Electroanal. Chem., I, 60 (1964).

35. D. A. Aikens and J. W. Ross, Jr., unpublished data, 1961. Private communication.

36. G. Mamantov and P. Delahay, J. Am. Chem. Soc., 76, 5323 (1954).

37. P. Delahay, J. Am. Chem. Soc., 75, 1430 (1953).

38. J. Koryta, Electrochim. Acta, 6, 67 (1962). 
39. R. A. Marcus, "Chemical and Electrochemical Electron Transfer Theory" in Ann. Rev. Phys. Chem., 15, 155 (1964); J. Phys. Chem., 67, 853 (1963).

40. L. E. Orgel, An Introduction Transition-Metal Chemistry: IIgand Field Theory, John Wliey and Sons, Tne., 1960.

41. R. R. Dogonadze and Yu. A. Chlzmadzhev, Doklady Acad. Nauk. SSSR, 145. 848 (1962); Proc. Acad. Sci. USSR, Phys. Chem. Sect. English Trans1. 145, 563 (1962).

42. I. Gierst, private communication to F, C. Anson. 


\title{
APPENDIX I
}

\section{CHRONOPOTENTIOMETRY AT EANGING MERCURY DROP EIECTRODES: \\ THE EHFECTS OF SPHERICAI, DIFFUSTON}

\begin{abstract}
Mercury pool electrodes, conventionally used in chronopotentiometry, have the disadvantage that the surface is not lruly renewalle. The hanglng mercury drop electrode provides an electrode surface which can be renewed in a reproducible way and is of constant area in contrast with the dropping mercury electrode.

The disadvantage of the hanging mercury arop electrode is that the solutions to the diffusion equation for common chronopotentiometric conditions are much more complicated for spherical diffusion than for linear diffusion. When the diffusion layer thickness is sufficiently small in comparison with the radius of the drop the physical situation is sufficiently close to semi-infinite linear diffusion that the simple linear solutions may be used. However, this usually demands transition times sufficiently short that switching problems vecome important and oscillographic recording is required.* The great advantages of avoiding instrumentation problems and being able to use more accurate and much more convenient pen and lnk recorders provide ample incentive to investigate the effects of spherical diffusion at longer times.
\end{abstract}

*Adequate switching is especially critical in chronopotentiometry with current reversal at short times. 


\section{Correction of the Forward Transition Time}

The solution of the diffusion equation for chronopotentiometry with spherical geometry which applies to work at hanging mercury drop electrodes was first obtained by Mamantov and Delahay (1) and is a relatively easily derived and well known result. It is given in Equation I along with the corresponding solution to the linear problem, Equation 2, the familiar Sand equation.

$$
\begin{gathered}
\frac{C^{0} n \tilde{S} A D}{i r_{0}}=1-\exp \left(\lambda^{2}\right) \operatorname{erfc}(\lambda) \\
1 T^{\frac{1}{2}}=\frac{\sqrt{\pi} n \cong A D^{\frac{\pi}{2}} C^{0}}{2}
\end{gathered}
$$

In Equation $1, \lambda=(D T)^{\frac{1}{2}} / r_{0}$, where $r_{0}$ is the radius of the drop. The other symbols have their usual meaning.

The qualitative effect of the change from linear to spherical diffusion is as one would predict, namely that all other things being equal, $T$ for Equation 1 is greater than $T$ for Equation 2.

If the right hand side of Equation 1 is expanded in a power series in $\lambda$, it is found that for oufficiently small values of $\lambda(\lambda \leqq 0.15)$ Equation 1 is well approximated by

$$
i T^{\frac{1}{2}} \Sigma=\frac{\sqrt{\pi} \mathrm{n} \cong A D^{\frac{1}{2}} \mathrm{C}}{2}
$$

where

$$
\Sigma=1-\frac{\pi^{\frac{1}{2}}}{2} \lambda+\frac{2 \lambda^{2}}{3}
$$


The data obtained under conditions where spherical diffusion is important can be "corrected for spherical diffusion" by multiplying the values of $i T^{\frac{1}{2}}$ calculated from the data by the factor $\Sigma$ to obtain the Sand value for the solution in question. To facilitate the routine application of this method calculated values of $\Sigma$ and the corresponding values of $\lambda$ are presented in Table I-I along with a working curve constructed from that table (Figure I-I).

It is instructive to see what the correction factor $\Sigma$ is under various experimental conäitions. First, for typical values $r_{0}=0.06 \mathrm{~cm}$, and $D^{\frac{1}{2}}=0.003 \mathrm{~cm} \cdot / \mathrm{sec}^{\frac{1}{2}}$, we find that $\lambda=0.15$ corresponds to a transition time of 9 sec., which is a longer time than is normally used on. hanging drop electrodes. Therefore, the working curve covers the region of interest. Second, let us consider the maximum time for which one should be able to avoid spherical diffusion effects. It is unreasonable to expect $i T^{\frac{1}{2}}$ values to be constant to better than $2 \%$. Therefore, selecting $98 \%$ as the minimum value of $\mathbb{Z}^{\mathrm{w}}$ with the above choices of $r_{0}$ and $D^{\frac{1}{2}}$, we find that $T$ must be less than or equal to $0.2 \mathrm{sec}$.

The upper limit for the application of the correction factor $\Sigma$ is a practical one, for at longer times density gradients and other stimring effects become important. The usefulness of the correction is shown by the fact that the approxtmale upper Itmil fur uncurrected lransition times is roughly the lower limit for routine recording.

Although this treatment of the spherical diffusion appears beyond reproach, it is common knowledge that no correction for spherical diffusion need be made for times less than about $3-5$ seconds. This is illustrated in Figures 10 and 15 above in which $i T^{\frac{1}{2}}$ data corrected for 
TABIE I-I

Correction to $1 T^{\frac{1}{2}}$ for Spherical Diffusion

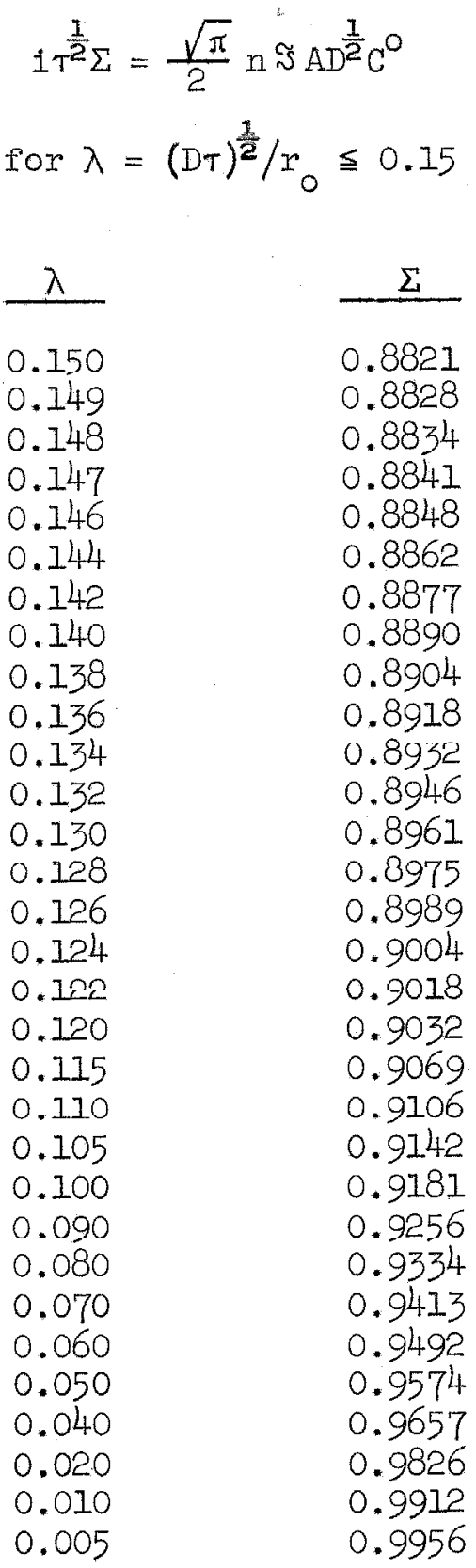




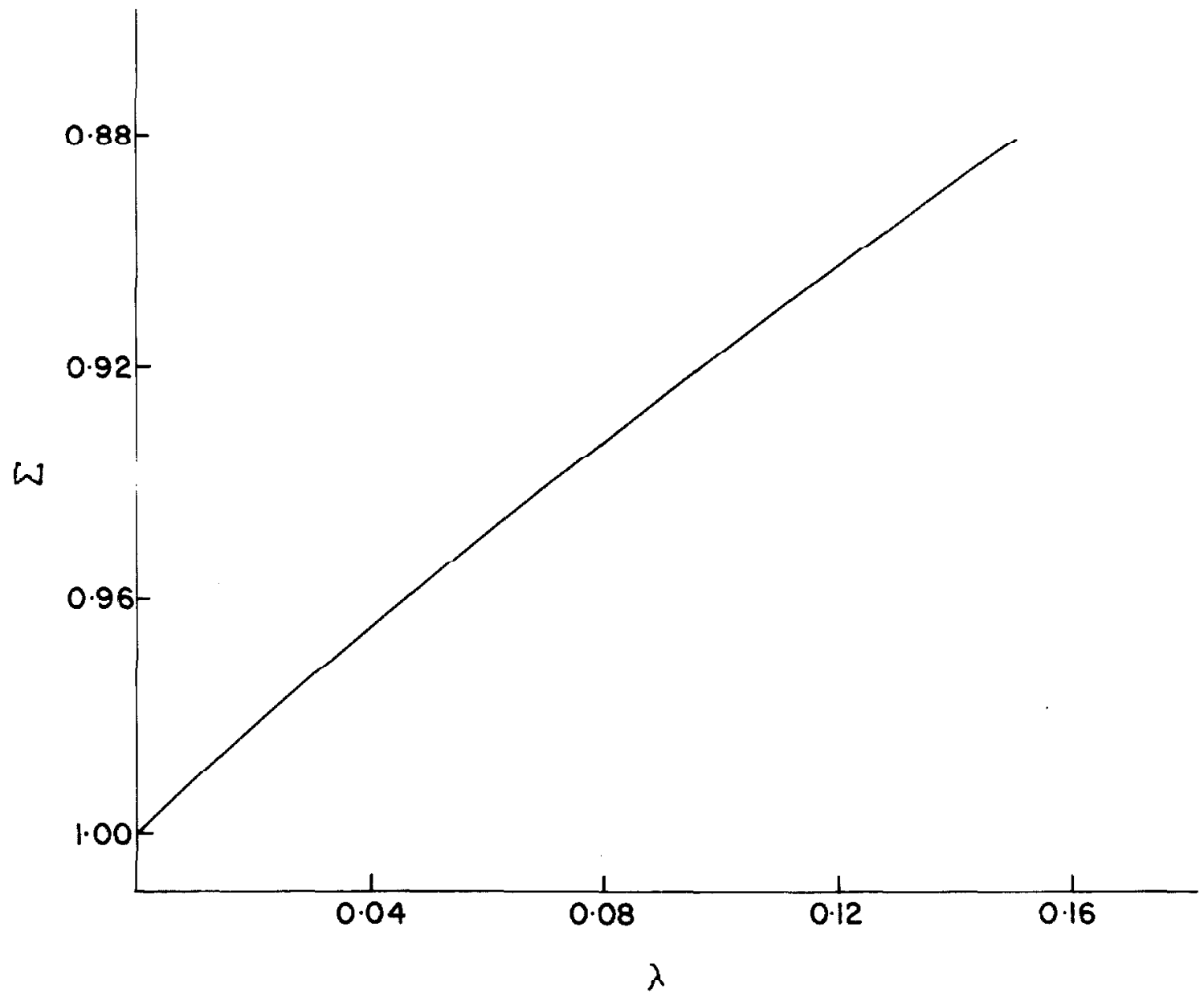

Figure $1-1$. The correction tactor tor spherical aitfulusion. $1 T^{\frac{1}{2}} \Sigma=$ $\pi^{\frac{1}{2}}-2 \Im D^{\frac{1}{2}} C^{0} / 2 ; \lambda=(D \tau)^{\frac{1}{2}} / r_{0}$. 
spherical diffusion shows a dip at times longer than about 1 sec. The uncorrected $i T^{\frac{1}{2}}$ values were nore nearly constant. The simple explanation for this is that the experimental conditions co not correspond to the conditions of spherical diffusion for which Equation 1 was obtained.

This point is illustrated in Figure I-2 which shows the typical design of a hanging mercury drop electrode of the Kemula or Shain type:

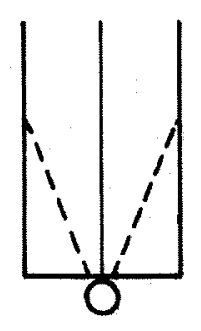

Figure I-2. Hanging mercury drop electrode.

The diffusion volume excluded by the glass capillary is sufficiently large that at intermediate times the increase in diffusion volume provided by the spherical geometry is compensated for by the excluded volume. This cancellation is fortultous anō of course lighly dependent on the exact geometry.

\section{Experimental Verlfication of the Spherical Correction}

The reduclion of Ca(II) In perchlorate solution was investigated on a hanging mercury drop electrode of the Kemula type in winch the capillary end was ground to a cone as illustrated by the dotted lines in Figure I-2 in order to minimize the excluded volume effect. The 
data and the calculated raw and corrected values of $1 T^{\frac{1}{2}}$ are presented in Table $I-2$.

TABIE I-P

\begin{tabular}{|c|c|c|c|c|c|}
\hline i, 11a. & T, sec. & $\lambda$ & $i T^{\frac{1}{2}}, \mu a \cdot \sec ^{\frac{1}{2}}$ & $1 T^{\frac{1}{2}} \Sigma$ & $\mu a \cdot \sec ^{\frac{1}{2}}$ \\
\hline 20.08 & 6.14 & 0.1069 & 49.8 & & 45.5 \\
\hline 25.55 & 3.684 & 0.0827 & 48.6 & & 45.2 \\
\hline 33.73 & 2.016 & 0.0618 & 48.3 & & 45.8 \\
\hline 40.28 & 1.286 & 0.0508 & 47.4 & & 45.4 \\
\hline 55.18 & 0.732 & 0.0369 & 47.2 & & 45.6 \\
\hline \multirow[t]{2}{*}{94.25} & 0.249 & 0.0249 & 47.0 & & 45.9 \\
\hline & & & & Av. & $45.6+0.2$ \\
\hline
\end{tabular}

The agreement between the measured value (the left hand side of Equation 3) and the calculated ralue (the right hand side of Equation 3) is convincing evidence that application of the spherical correction factor is a reliable procedure.

Additional confirmation is given by plotting $i T^{\frac{1}{2}}$ as a function of $\tau^{\frac{1}{2}}$. The $\tau=0$ intercept should give the corrected value of $i \tau^{\frac{1}{2}}$. This is shown in Figure I-3. The intercept is 45.7 .

Experimental procedure. Standard chronopotentiometric circuitry was used.

Chronopotentiometric waves at long times were recorded on a Moseley Autograph X-Y recorder; at short times they were recorded by 


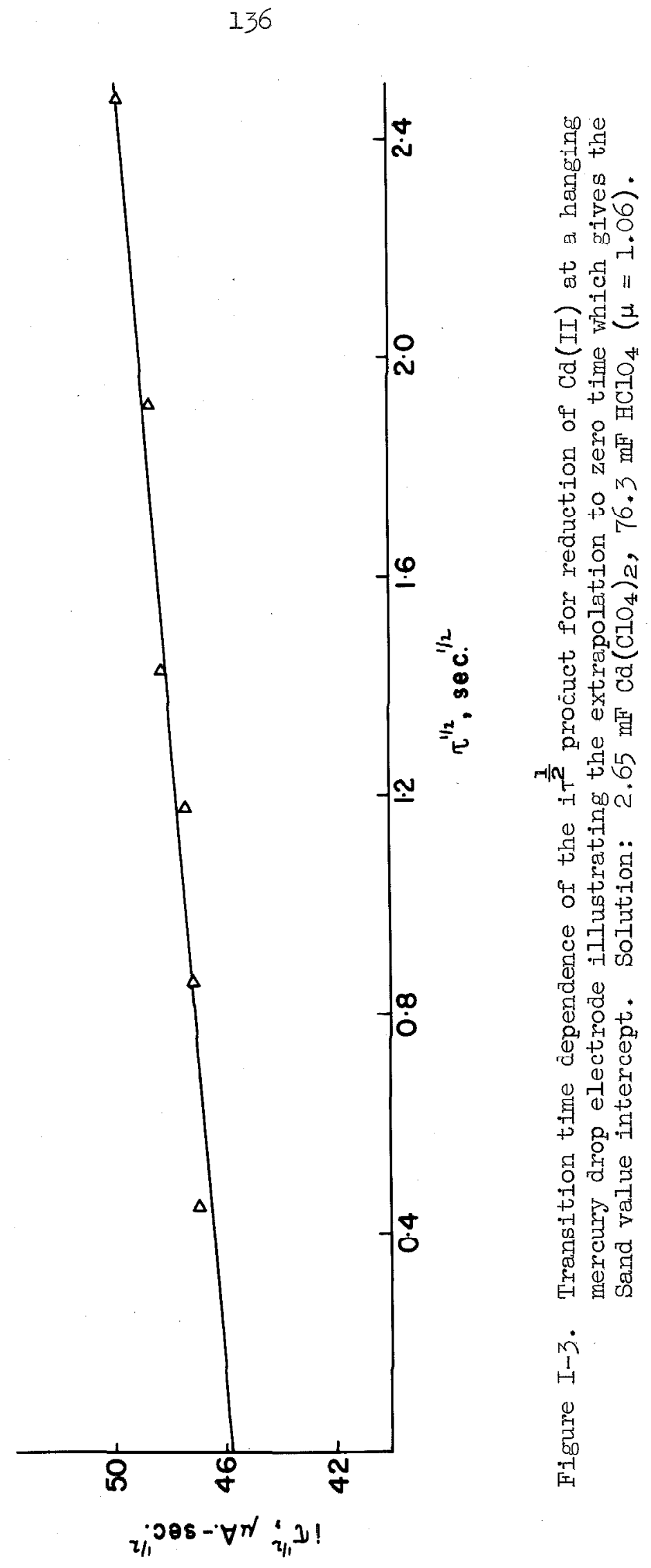


photographing the trace of a Tektronles Type 531A oscliloscope equipped WILi Type D Plug-1n Unit.

A solution approximately $0.2 \mathrm{~F}$ in $\mathrm{Cd}\left(\mathrm{ClO}_{4}\right)_{2}$ was prepared by adding less than a stoichiometric amount of $\mathrm{HClO}_{4}$ to $\mathrm{solid}^{\mathrm{CaCO}} 3$ and filtering off the excess salt. The solution was standardized by titration With EDTA solution standardized by titrating aliquots of a standard zinc solution made from zinc metal.

Sufficient $\mathrm{Cd}\left(\mathrm{ClO}_{4}\right)_{2}$ stock solution was mixed with $\mathrm{NaClO}_{4} / \mathrm{HClO}_{4}$ supporting electrolyte solution to give a solution for chronopotentiometric investigation with $2.65 \mathrm{mF} \mathrm{Cd}\left(\mathrm{ClO}_{4}\right)_{2}, 76.3 \mathrm{mF} \mathrm{HClO}_{4}(\mu=1.06)$. The indicator electrode was a Kemula-type mercury hanging drop electrode modified as described above with area $0.0409 \mathrm{~cm}^{2}$ and radius $0.0571 \mathrm{~cm}$. as determined from the weight of 10 drops.

\section{Conclusions}

Chronopotentiometry on hanging mereury drop electrodes at times where spherical diffusion effects are important can be accurately corrected by multiplying the values of $i T^{\frac{1}{2}}$ by the factor $\Sigma$ obtained from the working curve in Figure $I-1$. The value of $i T^{\frac{1}{2}} \Sigma$ is equal to the value of $1 r^{\frac{1}{2}}$ one would obtain for linear diffusion (the Sand value). In the region where the correction is most useful, significant departure from the conditions of spherical diffusion may be caused by the diffusion volume excluded by the support for the mercury drop. 


\section{Chronopotentiometry with Current Reversal:}

Correction of the Transition Time Ratio

Consider a solution containing bulk concentration of the oxidized species $O$ which can be electrochemically reduced to $R$ and subsequently reoxidized to 0 . Assume that the magnitude of the current is constant, but that its direction is changed at a time $t_{f}$ which is less than or equal to the forward transition time for 0 . The equation relating $t_{f}$, the forward time, and $T_{r}$, the reverse transition time, is obtained by solving the differential equation

$$
\frac{\partial C_{0}(r, t)}{\partial t}=D_{0}\left[\frac{\partial^{2} C_{0}(r, t)}{\partial r^{2}}+\frac{2}{r} \frac{\partial C_{0}(r, t)}{\partial r}\right]
$$

with the boundary and initial conditions

$$
\begin{gathered}
C_{O}(r, 0)=C_{O}(\infty, t)=C_{O}^{0} \\
C_{R}(r, 0)=C_{R}(\infty, t)=0 \\
\left(\left.\frac{\partial C_{0}(r, t)}{\partial r}\right|_{r=r_{0}}=\frac{i}{n \Im A D}\right. \\
D_{O}\left(\left.\frac{\partial C_{0}(r, t)}{\partial r}\right|_{r=r_{0}}+D_{R}\left(\left.\frac{\partial C_{R}(r, t)}{\partial r}\right|_{r=r_{0}}=0\right.\right.
\end{gathered}
$$

The subscript $O$ refers to the oxidized species, 0 , the subscript $R$ to the reduced species, $R$, and $r_{0}$ is the radius of the electrode. After the change of variable

$$
U(r, t)=r\left[c^{0}-C_{0}(r, t)\right]
$$


a solution is readily obtained using standard Laplace transform method.s. The result is ${ }^{*}$

$$
0=1+\text { experfe } a \lambda-2 \text { experfc } \lambda
$$

whero

$$
\lambda-\frac{D^{\frac{1}{2}}}{r_{0}} T^{\frac{1}{2}} ; a-\left(1+\frac{t_{f}}{T_{r}}\right)^{\frac{1}{2}}
$$

This solution has in common with the familiar solution to the corresponding problem with linear diffusion:

$$
\frac{t_{P}}{\tau_{x}}=3
$$

the important feature that the result is independent of $\mathrm{C}^{\circ}, i$, and $\mathrm{A}$. Figure I-4 shows the variation of transition time ratio with forward time according to Equation $8 . \mathrm{D}^{\frac{1}{2}} / \mathrm{r}_{0}$ is typically 0.05 . Figure I-5 gives the correction to the measured ratio $t_{f} / \tau_{r}$ which must be applied to obtain the value for linear diffusion. The curve was obtained from Equation 8 by calculating a for vartous values of $\lambda$ and using the rolation $\rho=3 /\left(a^{2}-1\right)$. A similar curve for $\rho$ as a function of $t_{f}^{\frac{1}{2}}$ is shown in Figure I-6.

If the simple model assumed by Equation 8 is obeyed, $\rho\left(t_{f} / \tau_{r}\right)=$ 3.00. If chronopotentiometry with current reversal is done on second time scales the application of the correction factor $\rho$ to the measured transition time ratios should provide a convenient check for any unusual behavior of the system.

*This result has also been obtained by Murray and Reilly (2). 


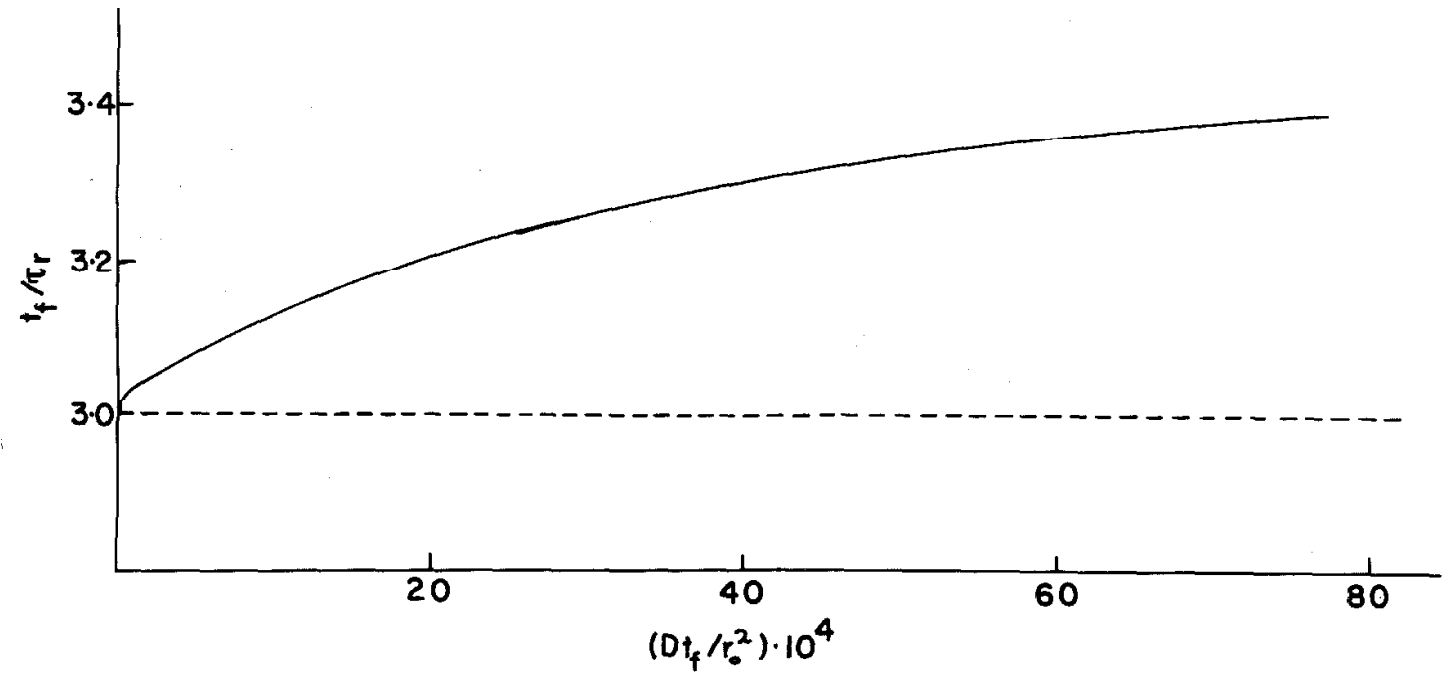

Figure I-4. Variation of the transition time ratio with forward time for spherical diffusion. Calculated from Equation 8. 
141

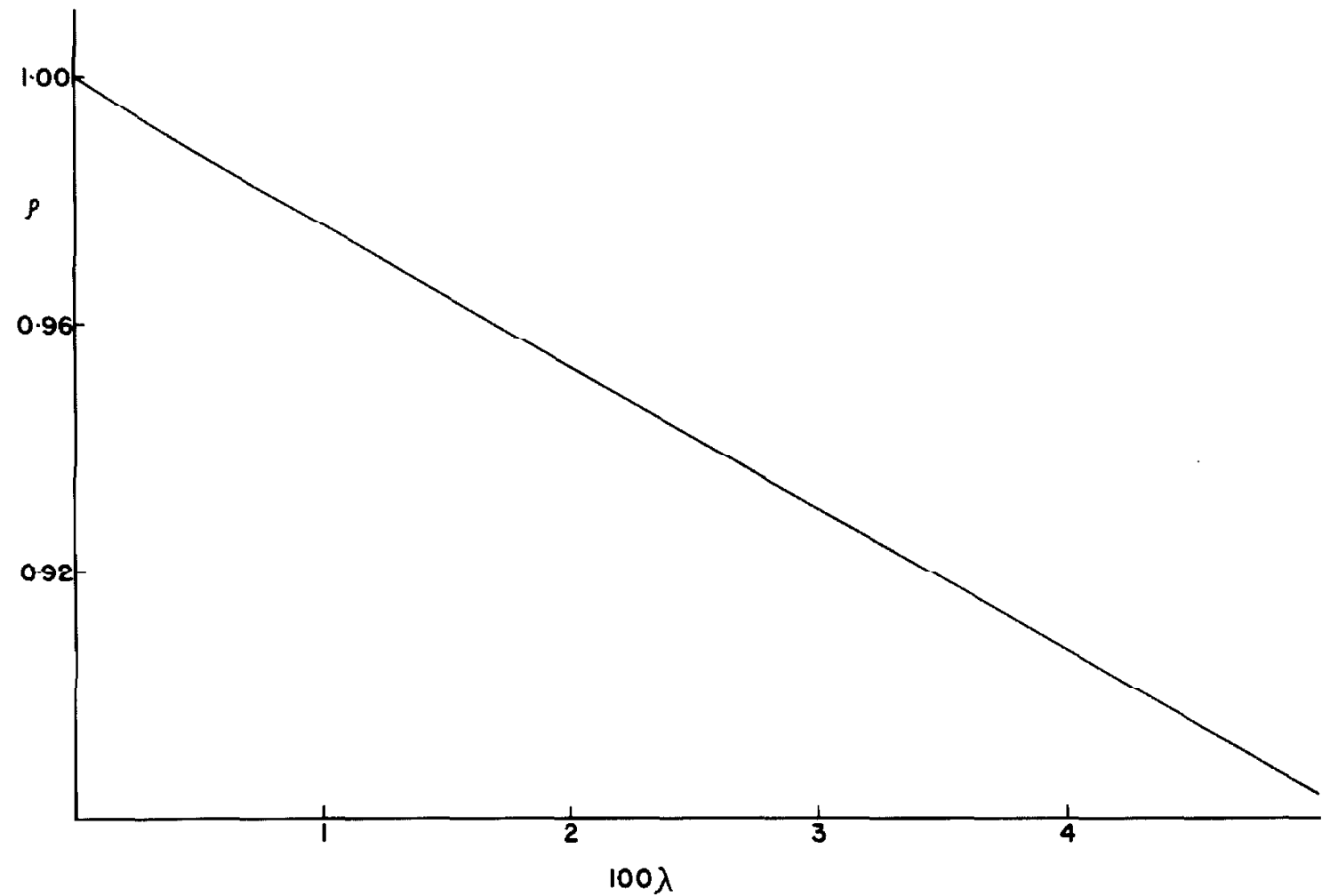

Figure $i-5$. Working curve for the correction factor for transition time ratios. Calculated from Equation 8. 


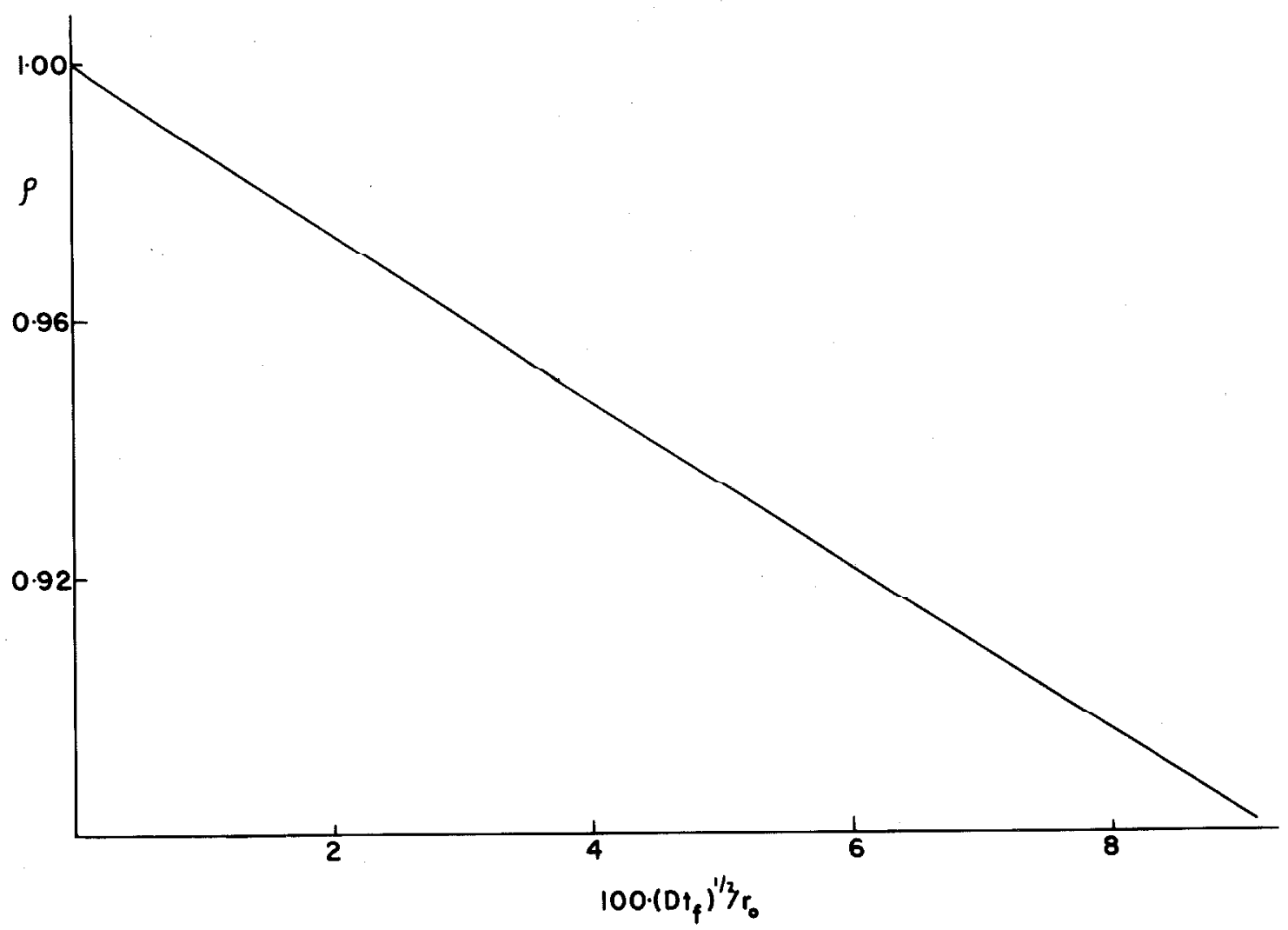

Figure I-6. Working curve for the correction factor for transition time ratios. Calculated from Equation 8. 
Experimental Investigation of the Spherical Correction

The relevance of this treatment to experiment was tested by examining the reverse current chronopotentiometric behavior of $\mathrm{Fe}$ (II) in pyrophosphate solution at $\mathrm{pH} 2$. It is known that under these conditions $\mathrm{Fe}$ (II) conforms to the simple behavior assumed by Equation 8 (3). A typical chronopotentiogram shown in Figure I-7 illustrates the features which make this system ideal. The large potential difference between Fe(III) oxidation and background gives an exceptionally well defined transition time, and the near reversibility of the couple minimizes the effect of double layer charging.

The results presented in Figure I-8 show that the deviation from linear behavior caused by spherical diffusion is rather small. Some data are presented in a slightly different way in Figure I-9. This shows the surprising result that the effect of spherical diffusion is highly current density dependent. Equation 8 not only predicts no cur rent density dependence but also predicts that all the points in Figure I-9 must lie below the dotted line. Figures I-10 and I-II show the der pendence of the transition time ratio, the usual parameter of interest, on $t_{f}$ and $i t_{f}$, respectively. These figures make it clear that abnormally low values of the transition time ratio accompanied by severe irreproduc1bility are characteristic of low current densities. The same general characteristics have been observed by Gross (4). We suggest that the abnormally long reverse transition times are due to materlal formed. during the forward time that is trapped between the mercury drop and the base of the capillary. 


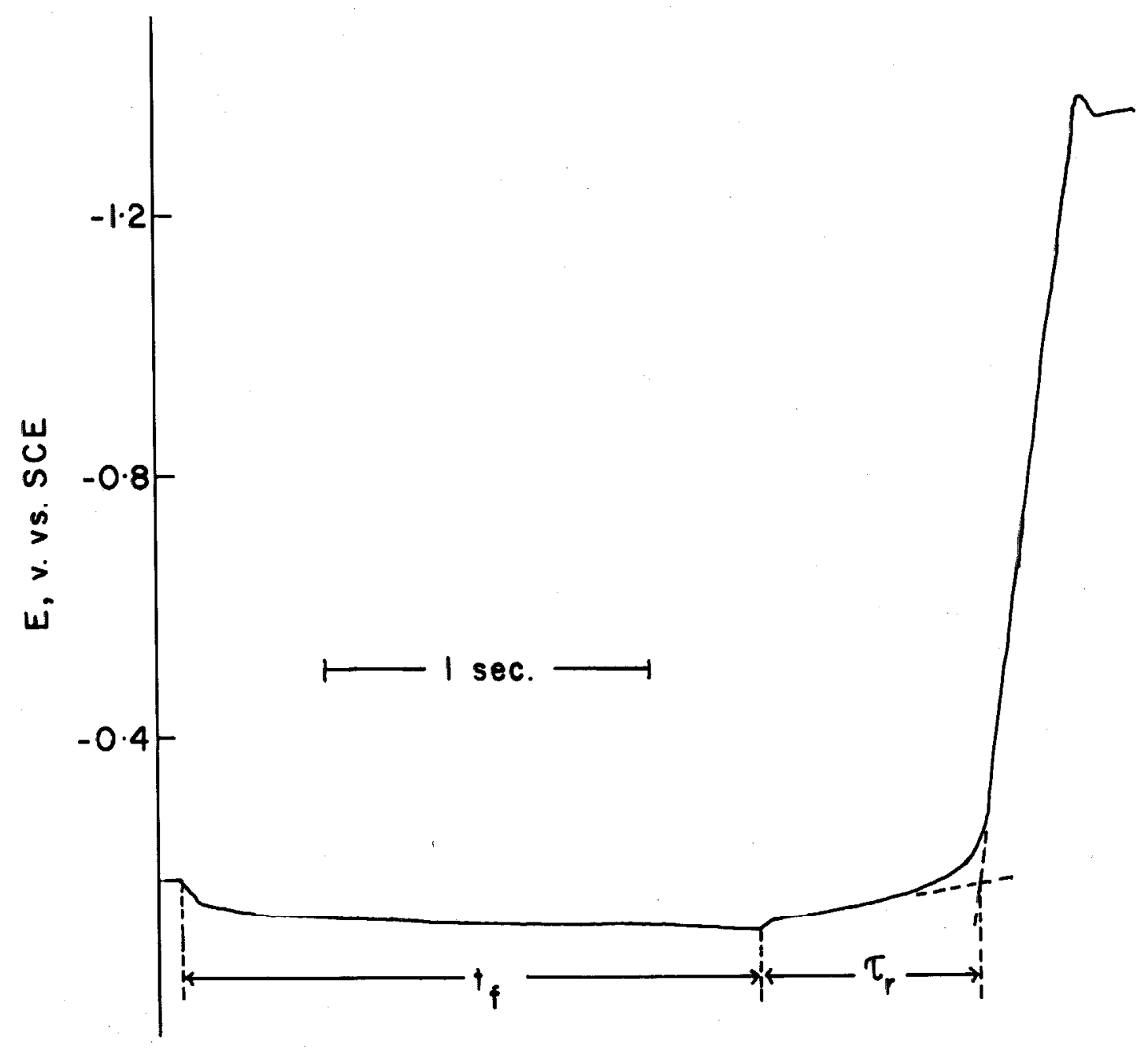

Figure I-7. Chronopotentiometric wave with current reversal for $30 \mathrm{mF} \mathrm{FeSO}_{4}$ in $0.5 \mathrm{~F} \mathrm{Ma}_{4} \mathrm{PeO}_{2}$, at $\mathrm{pH} 2$. 


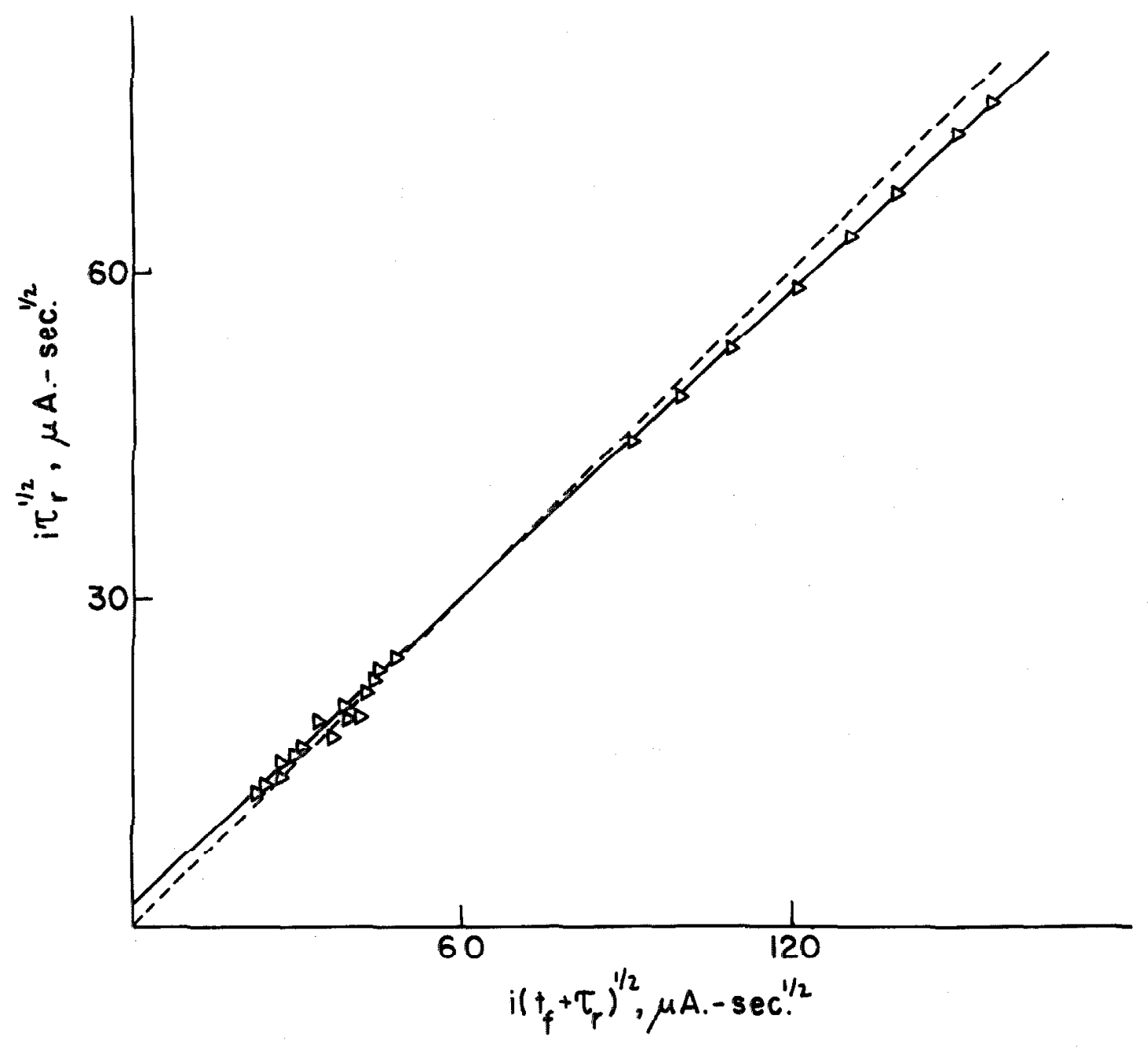

Figure I-8. The effect of spherical diffusion on transition time ratios. The dotted Iine shows the theoretical behavior for linear diffusion. The points were obtained as illustrated in Figure I-7. 


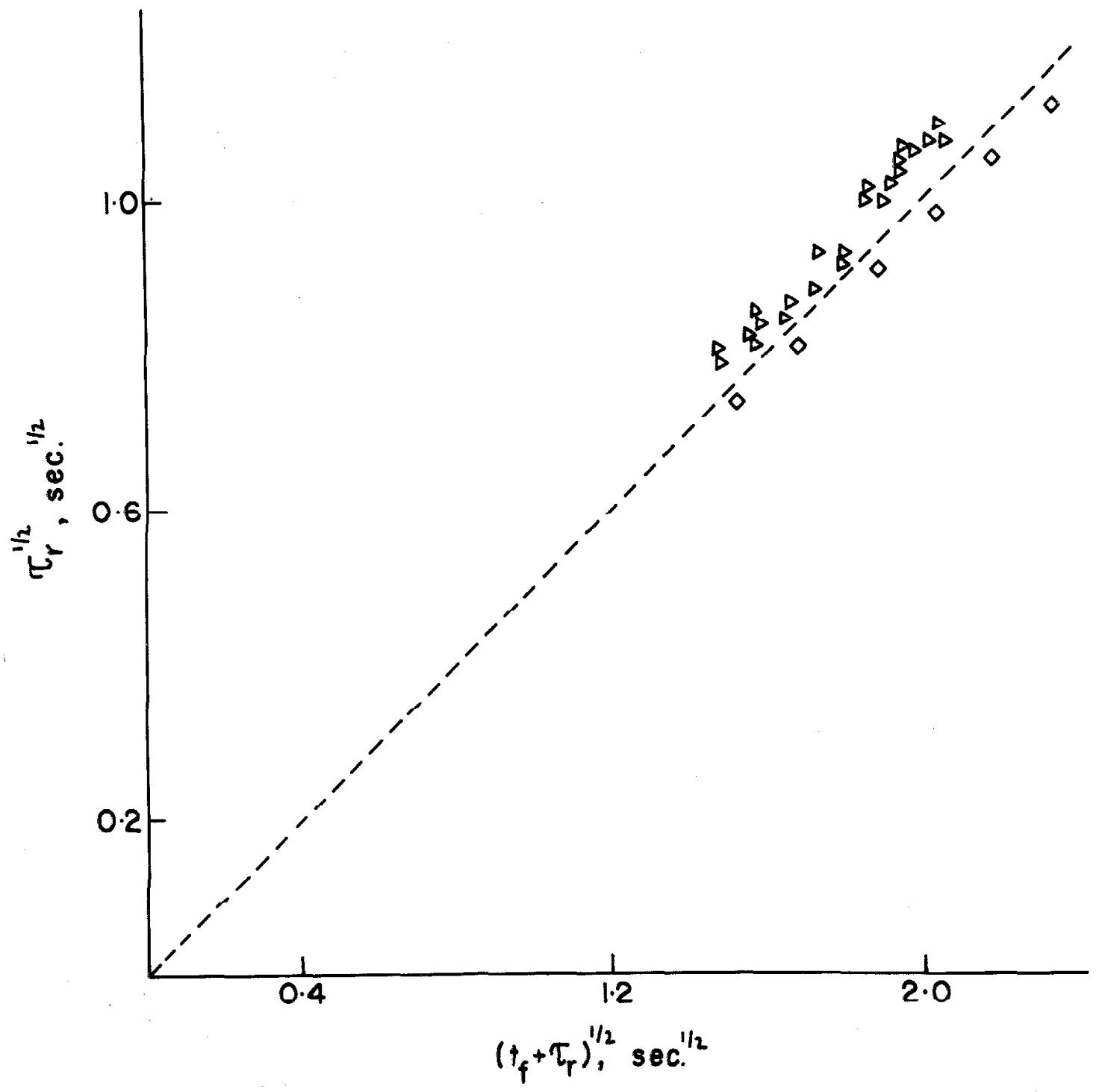

Figure I-9. IIlustration on the pronounced current density dependence of the data shown in Figure I-8. The dotted line shows the theoretical behavior for linear diffusion. The points above the line were obtained at a current density of $367 \mu \mathrm{A} . / \mathrm{cm} .^{2}$, those below the line at $1468 \mu \mathrm{A} . / \mathrm{cm} .{ }^{2}$ 


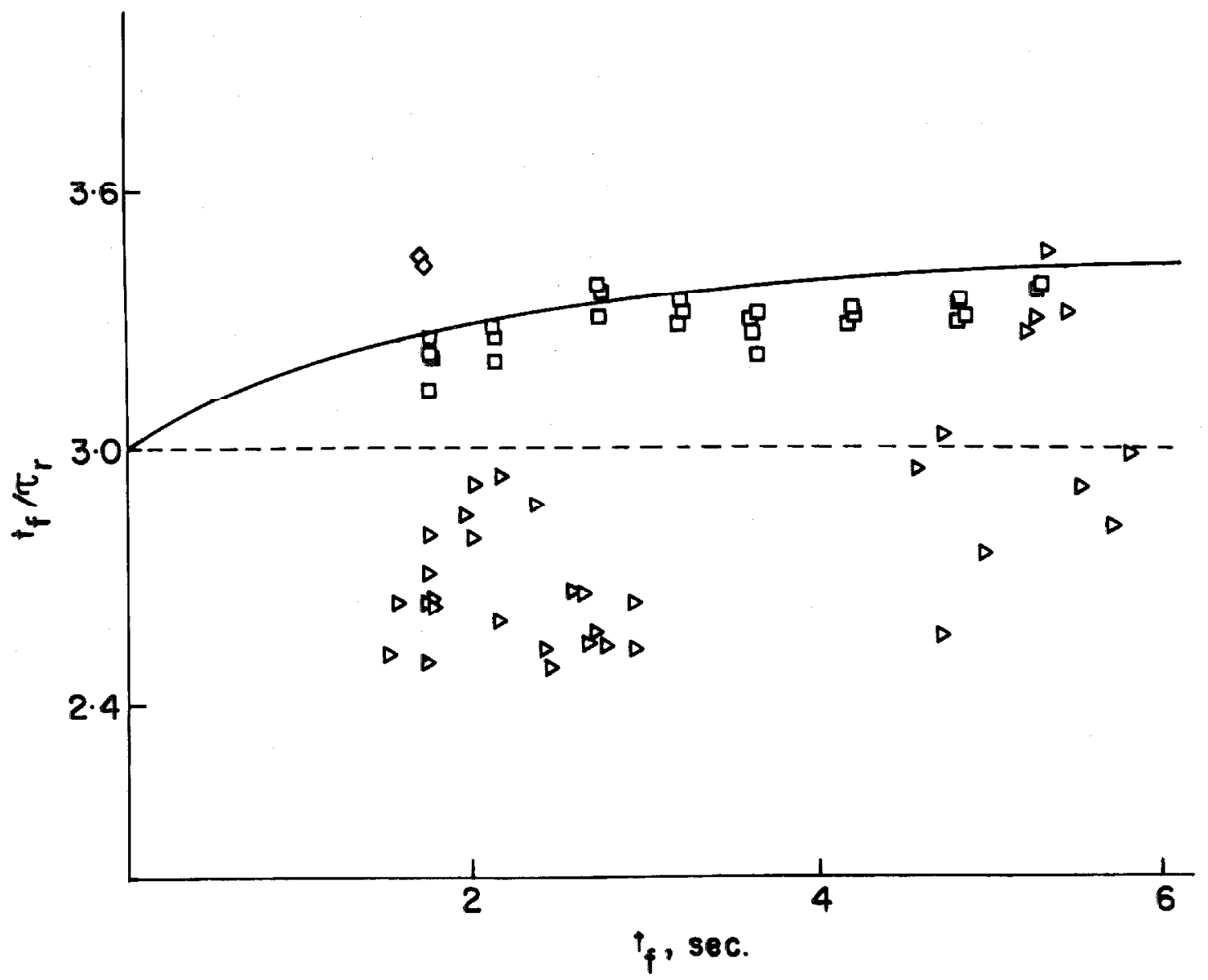

Figure I-10. Illustration of the pronounced deviation of the data of Figure I-8 from the predicted behavior for spherical diffusion, the solid line. The dotted line shows the predicted behavior for linear diffusion. $D, 367 \mu \mathrm{A} . / \mathrm{cm} .^{2}$;

$\square, 1467 \mu \mathrm{A} . / \mathrm{cm}^{2} ; 0,2440 \mu \mathrm{A} . / \mathrm{cm} .^{2}$ 


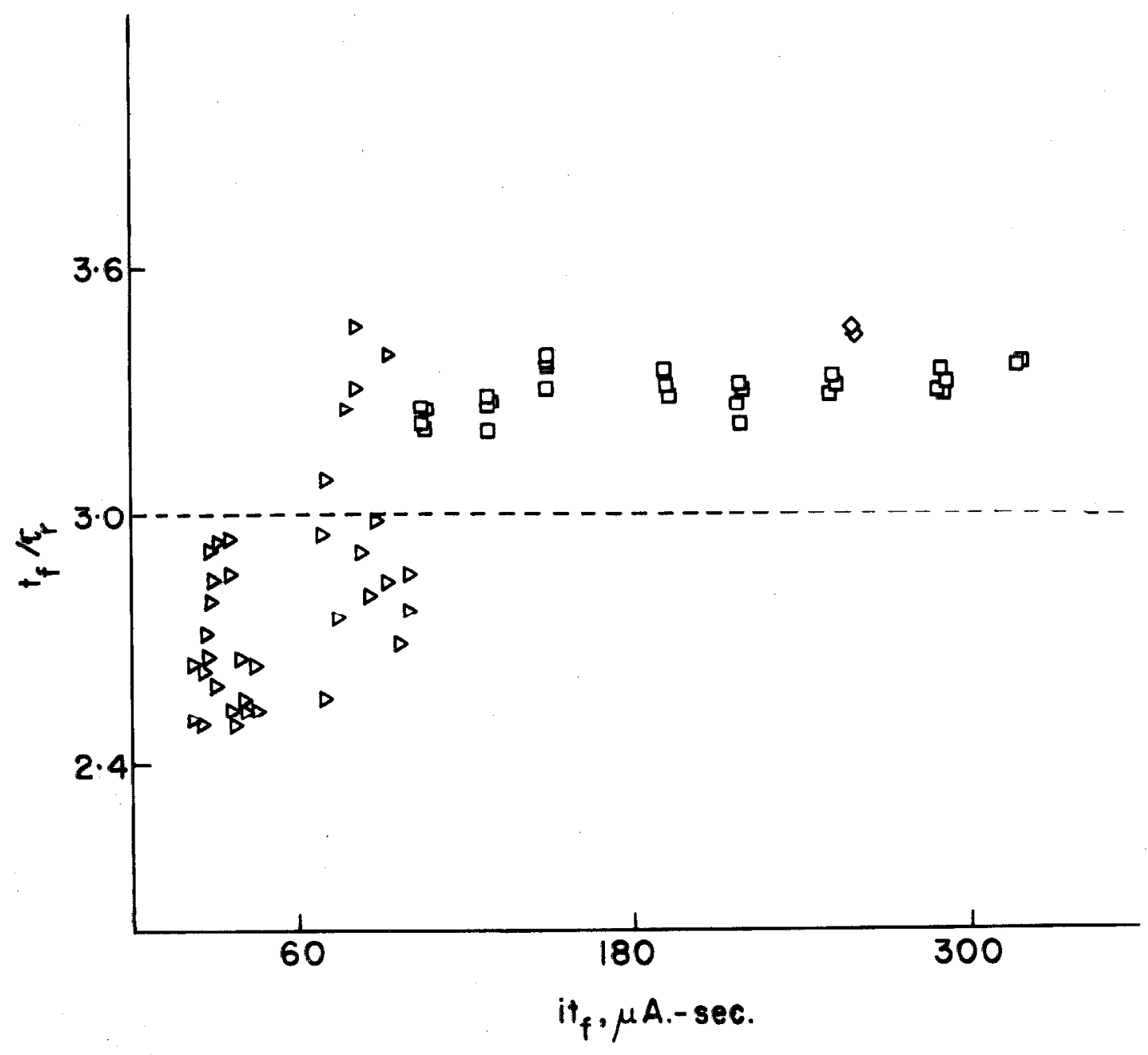

Figure I-11. The dependence of the deviation of the data of Figure I-8 from ideal behavior on it $_{f}$, the number of microcoulombs of material formed during the forward time. $D, 367 \mu \mathrm{A} . / \mathrm{cm}$; $\square, 1467 \mu \mathrm{A} . / \mathrm{cm} .^{2} ; \diamond, 2440 \mu \mathrm{A} . / \mathrm{cm}^{2}$ 
The most important feature of these data is their mimecry of product adsorption hehavior at low current densities. At very low current densities the amount of material trapped is comparable to the total amount formed. Figure 20 illustrates the similarity of the results to those obtained with product adsorption. The "amount adsorbed" for Fe(II) In pyrophosphate at pH 2 from Figure 20 is about $150 \mu \mathrm{C} . / \mathrm{cm} .^{2}$ There is ample evidence (3) that there is no product adsorption in this system.

Experimental procedures. 'l'he equipment has been described above (page 135).

Solutions of $\mathrm{Fe}(\mathrm{II})$ were prepared by dissolving the appropriate quantity of $\mathrm{FeSO} \mathrm{S}_{\frac{4}{4}} \cdot 7 \mathrm{H}_{2} \mathrm{O}$ in a supporting clcctrolytc solution prepared by adjusting the $\mathrm{pH}$ of $0.5 \mathrm{~F} \mathrm{Na}_{4} \mathrm{P}_{2} \mathrm{O}_{7}$ solution to $\mathrm{pH} 2$ with $18 \mathrm{~F} \mathrm{H}_{2} \mathrm{SO}_{4}$. The final solutions were $30 \mathrm{mF}$ in $\mathrm{Fe}(\mathrm{II})$.

The cathodic background wave for the small amount of Fe(III) present was measured at intervals during each experiment using a very low current density. This cathodic background wave was used to correct the measured reverse transition time by subtracting from it the appropriate value of the transition time for the measured bulk concentration of He $(111)$. In no case was this correction more than $3 \%$ of the reverse transition time. It was always less than $1 \%$ for current densities greater than $100 \mu \mathrm{a} / \mathrm{cm} .^{2}$

\section{Conclusions}

He who approaches reverse current chronopotentiometry at spherical electrodes with a spherical correction factor and a prayer needs the prayer. 
APPEIVIX II

PARAITIL REACTIONS

Considor tho elcetrochemical reactione

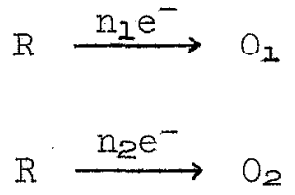

In which reactions ( $1 \mathrm{a}$ ) and ( $1 \mathrm{~b}$ ) are characterized by the parameters $\mathrm{E}_{i}^{0}, \alpha_{i}, \mathrm{k}_{i}$, and $\mathrm{D}_{i}, 1=1,2$. We wish to find the current and the charge which would flow in a potential step expertment of the follawing type. The solution initially contains only $R$ and the initial potential, $E_{0}$, is adjusted so that no current flows due to the oxidation of $R$. At time $t=0$ the potential is stepped to a value $E$ at which $R$ is oxidized to $\mathrm{O}_{1}$ and $\mathrm{O}_{2} \cdot \mathrm{O}_{1}$ and $\mathrm{O}_{2}$ are not in chemical equilibrium with each other.*

The eurrent flowing for each reaction is given by (I)

$$
\frac{I_{1}}{n_{i} \widetilde{s}}=D_{i}\left(\frac{\partial C_{1}}{\partial x}\right)_{X=0}=-\left[C_{R}(0, t) \kappa_{i f}-C_{i}(0, t) \kappa_{i b}\right], i=1,2
$$

where

$$
\begin{aligned}
& \kappa_{i f}=k_{i} \exp \left[\left(1-\alpha_{i}\right) \frac{n_{i} \Im}{R T}\left(E-E_{i}^{0}\right)\right] \\
& \kappa_{i h}=k_{i} \exp \left[-\alpha_{i} \frac{n_{i} \Im}{R T}\left(E-E_{i}^{0}\right)\right]
\end{aligned}
$$
of C.I.T.

*The solution to this problem was suggested by Joseph H. Christie 
and the other symbols have their usual meaning.

The solution to the problem is obtained by solving the ditfusion equation:

$$
\frac{\partial C}{\partial t}=D \frac{\partial^{2} C}{\partial x^{2}}
$$

with the initial conditions

$$
C_{R}(x, 0)=C_{R}^{0} ; \quad C_{i}(x, 0)=0, \quad i=1,2
$$

and the boundary conditions

$$
\begin{aligned}
& C_{R}(\infty, t)=C_{R}^{0} ; \quad C_{i}(\infty, t)=0, \quad i=1,2 \\
& -D_{R}\left(\frac{\partial C_{R}}{\partial x}\right)_{X=0}=D_{I}\left(\frac{\partial C_{I}}{\partial x}\right)_{X=0}+D_{Z}\left(\frac{\partial C_{2}}{\partial x}\right)_{X=0}
\end{aligned}
$$

The solutions to Equation 4 in Laplace transform space are

$$
\begin{aligned}
& \bar{C}_{i}(x, s)=\xi_{i} \exp \left(-s^{\frac{1}{2}} x / D_{i}^{\frac{1}{2}}\right), i=1,2 \\
& \bar{C}_{R}(x, s)=\frac{C_{R}}{s}+\xi_{R} \exp \left(-s^{\frac{1}{2}} x / D_{R}^{\frac{1}{2}}\right)
\end{aligned}
$$

where all conditions except (6b) have been applied.

Transforming pquation 2 and combining with the derivatives of Equation 7, we find

$$
\frac{\bar{I}_{i}}{n_{i} \tilde{S}}=-D_{i}^{\frac{1}{2}} S^{\frac{1}{2}} \xi_{i}, i=1,2
$$

Combining the transform of Equation $6 \mathrm{~b}$ with Equation 8 and solving for the constants of integration, $\xi_{i}, i=1,2$, we obtain 


$$
\begin{aligned}
& 152 \\
& \frac{\mathrm{C}_{\mathrm{R}}^{\circ}}{\mathrm{s}}\left[\kappa_{2 f} \mathrm{D}^{\frac{1}{2}} \mathrm{~s}^{\frac{1}{2}}+\kappa_{1 b} k_{2 f}\right]
\end{aligned}
$$

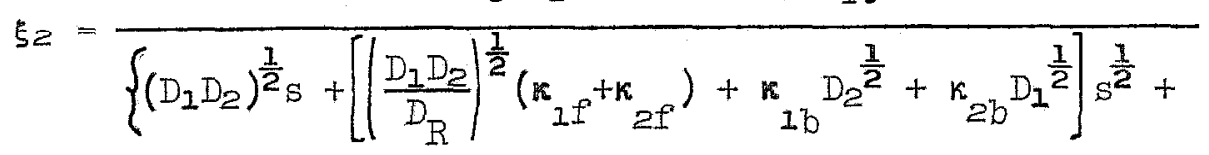

$$
\begin{aligned}
& \left.\kappa_{1 f^{k}}\left(\frac{D_{1}}{D_{R}}\right)^{\frac{1}{2}}+\kappa_{1 b} \kappa_{2 f}\left(\frac{D_{2}}{D_{R}}\right)^{\frac{1}{2}}+\kappa_{1 b} \kappa_{2 b}\right\}
\end{aligned}
$$

A similar equation is obtained for $\xi_{1}$ by permuting all of the numerical subscripts in Equation 9.

The current is obtained by finding the inverse transform for Equation 8. Equation 9 can be written in the torm

$$
\xi_{2}=\frac{\lambda p+\mu}{(p+\gamma)(p+\beta)}
$$

where $p=s^{\frac{1}{2}}$. From this form we find the inverse transform (2) and also tho curront:

$$
\begin{aligned}
\frac{-I_{i}}{n_{i} \tilde{S}} & =\frac{D_{i}^{\frac{1}{2}} C_{R}^{\circ}}{\gamma-\beta}\left\{\left(\gamma \lambda_{i}-\mu_{i}\right) \exp \left(\gamma^{2} t\right) \operatorname{erfc}\left(\gamma t^{\frac{1}{2}}\right)\right. \\
& \left.-\left(\beta \lambda_{i}-\mu_{i}\right) \exp \left(\beta^{2} t\right) \operatorname{erfc}\left(\beta t^{\frac{1}{2}}\right)\right\}, i=1,2 .
\end{aligned}
$$

and by integration, the charge

$$
\begin{aligned}
\frac{-Q_{i}}{n_{i} U^{\dddot{S}}} & -\frac{D_{i}^{\frac{1}{2}} C_{R}^{0}}{\gamma-\beta}\left\{\gamma ^ { - 2 } ( \gamma \lambda _ { i } - \mu _ { i } ) \left(\frac{2 \gamma t^{\frac{1}{2}}}{\pi^{\frac{1}{2}}}\right.\right. \\
& \left.-1+\exp \left(\gamma^{2} t\right) \operatorname{erfc}\left(\gamma t^{\frac{1}{2}}\right)\right)-\beta^{-2}\left(\beta \lambda_{1}-\mu_{1}\right) \cdot \\
& \left.\left(\frac{2 \beta t^{\frac{1}{2}}}{\pi^{\frac{1}{2}}}-1+\exp \left(\beta^{2} t\right) \operatorname{erfc}\left(\beta^{\frac{1}{2}}\right)\right)\right\}, 1=1,2
\end{aligned}
$$


where

$$
\begin{aligned}
& \lambda_{i}=k_{i f} / D_{i}^{\frac{1}{2}}, i=1,2 \\
& \mu_{i}=\frac{k_{i f}{ }^{k} b_{b}}{\left(D_{i} D_{j}\right)^{\frac{1}{2}}}, i=1,2 ; j=1,2 \text {, not } i \\
& \gamma=\frac{1}{2}\left(e-\sqrt{e^{2}-4 f}\right), \beta=\frac{1}{2}\left(e+\sqrt{e^{2}-4 f}\right) \\
& e=\left(\kappa_{1 f}+\kappa_{2 f}\right) / D_{R}^{\frac{1}{2}}+\kappa_{1 b} / D_{1}^{\frac{1}{2}}+\kappa_{2 b} / D_{2}^{\frac{1}{2}}
\end{aligned}
$$

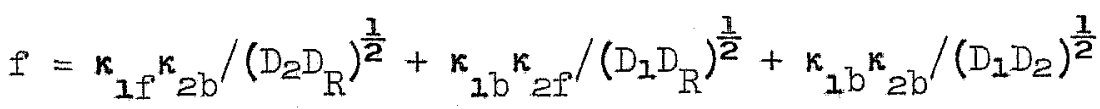

The solution for the charge, Equation 12, is sufficiently complicated that the qualitative results are obscured by the algebra. In particular, the parameters $\gamma$ and $\beta$ contain all of the rate parameters for both reaction paths, which means that one cannot single out terms corresponding to a single path.

When the arguments of the error function complement are sufficiently small, an expansion of these functions shows that when $\beta t^{\frac{1}{2}} \leqq$ 0.01 , then the charge going to each reaction is proportional to the rate for that reaction, so that

$$
\frac{Q_{1}}{Q_{1}+Q_{2}}=\frac{\kappa_{1 f}}{\kappa_{1 f}+\kappa_{2 f}} \quad \text { whenever } \beta t^{\frac{1}{2}} \leqq 0.01
$$

Intuitively this means that if the reactions are sufficiently slow, then the backward reactions have no effect and the amount of current going to each reaction is affected only by the competition between the two reaction paths. 


\section{4}

If $\gamma$ is sufficiently small that a small argument expansion may be used for the error function complement of $\gamma t^{\frac{1}{2}}$ but at the same time $\beta$ Is sufficiently large that a large argument expansion may be used for the error function complement of $\beta t^{\frac{\pi}{2}}$, it can be shown that the same relationship holds for the product ratios:

$$
\frac{Q_{1}}{Q_{1}+Q_{2}}=\frac{\kappa_{1 f}}{\kappa_{1 f^{+\kappa} 2 f}} \text { whenever } \quad \beta t^{\frac{1}{2}}>5, \beta \gg t^{\frac{1}{2}}, E-E_{1}^{0} \geqslant 0.2 \mathrm{~V} \text {. }
$$

Here the physical condition is that the reaction is quasi-meversible, but the potential is far enough from the nearest standard potential that the back reactions need not be considered. Of course under these conditions

$$
Q_{1}+Q_{12} \cong \frac{2 \mathrm{n} \cong \mathrm{D}^{\frac{1}{2}} \mathrm{AC}_{\mathrm{R}}{ }^{\mathrm{O}^{\frac{1}{2}}}}{\sqrt{\pi}} \text { if } \mathrm{n}_{1}=\mathrm{n}_{2}=\mathrm{n}
$$

The relation

$$
\frac{Q_{1}}{Q_{1}+Q_{2}}=\frac{\kappa_{1 f}}{\kappa_{1 f}+\kappa_{2 f}}
$$

also holds under a wide variety of conditions excluded in Equations 14 and 15. This is readily demonstrated by calculating the values of $Q_{1}$ and $Q_{2}$ directly and comparing the value of $Q_{1} /\left(Q_{I}+Q_{2}\right)$ with the calculated rate ratio, $k_{1 f} /\left(\kappa_{1 f}+\kappa_{2 f}\right)$. However, it is not possible to obtain a simple algebraic condition to insure that the relationship holds as is the case for Equations 14 and 15 .

The results of calculation of the ratios directly from the equation suggest that if the standard rate constants do not differ by more than a factor of about 5 and if the product $\left(1-\alpha_{i}\right)\left(\mathbb{E}_{-} \mathrm{E}_{i}{ }^{0}\right) \mathrm{n}_{i}$ is greater than about $0.100 \mathrm{v}$. , then Equation 17 should hold. However, 
for cases in which the conditions of neither Equation 14 nor Equation 15 apply, the safest approach is to calculate the charge ratios directly from Equation 12. 
APPENDIX III

REVERSE CURRENT CHRONOPOTENTIONETRY:

REVERSAI AFTER THE TRANGITION TIMP

Consider roveroc current chronopotentiometry in a colution containing bulk concentrations $\mathrm{C}_{1}{ }^{\circ}$ and $\mathrm{C}_{2}{ }^{\circ}$ of the species $\mathrm{O}_{1}$ and $\mathrm{O}_{2}$, respectively, with the reactions:

$$
\mathrm{O}_{1}+\mathrm{n}_{1} \mathrm{e} \rightarrow \mathrm{R}_{1} ; \quad \mathrm{O}_{2}+\mathrm{n}_{2} \mathrm{e} \longrightarrow \mathrm{R}_{2}
$$

Suppose that $\mathrm{O}_{2}$ is reduced at more cathodic potentials than is $\mathrm{O}_{1}$, and that the couple $\mathrm{O}_{2} / \mathrm{R}_{2}$ is sufficiently irreversible that $\mathrm{R}_{2}$ is oxidized at more anodic potentials than is $R_{1}$. If one were to reverse the current on the wave for $\mathrm{O}_{2}$ reduction, the expected qualitative potentialtime behavior is as illustrated in Figure III-1.

This situation is easily obtainable in practice, for instance, with many choicca for $\mathrm{O}_{\perp}$ on mercury clcetrodec where $\mathrm{O}_{2}$ is $\mathrm{H}^{+}$or $\mathrm{H}_{2} \mathrm{O}$ and $\mathrm{R}_{2}$ is $\mathrm{H}_{2}$.

The solution to this problem which expresses the relationship of the reverse time, $\tau_{3}$, to the forward times, $\tau_{1}$ and $t_{2}$, is obtained by solving the diffusion equation for semi-infinite linear diffusion for the concentration of $R_{\mathcal{I}}$ as a function of $x$, the distance from the electrode, and $t$, the time from $\tau_{1}$, and applying the condition that ( 1 )

$$
C_{R_{1}}\left(x=0, t=T_{3}\right)=0
$$

In the following derivation all diffusion coefficients are assumed to be equal and $C_{R_{I}}(x, t) \equiv C(x, t)$. Also, $n_{I}=n_{2}$, The problem, then, is 


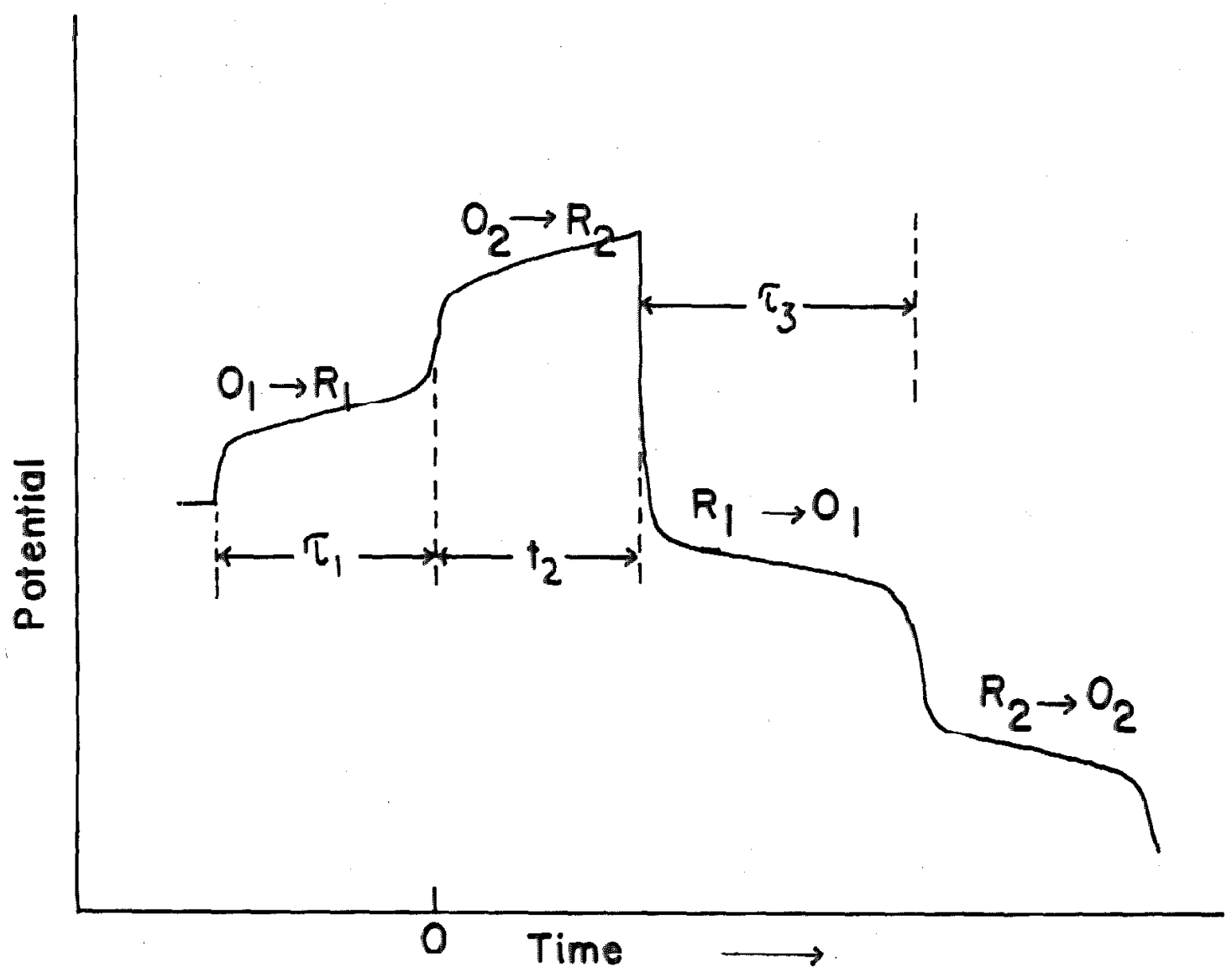

Figure III-I. Qualitative behavior for reverse current chronopotentiometry with reversal after the transition time, Case in which the product of the second reduction is electroinactive at potentials where the product of the first is reoxidized. 
simply to solve the differential equation

$$
\frac{\partial c(x, l)}{\partial t}=D \frac{\partial c c\left(x_{1} t\right)}{\partial x^{2}}
$$

subject to the initial condition

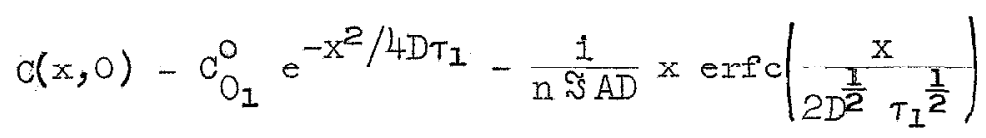

and the boundary conditione (1)

$$
\begin{aligned}
& c(\infty, t)=0 \\
& \left.\frac{\partial C(x, t)}{\partial x}\right]_{X=0}= \begin{cases}-\frac{i}{n \cong A D}\left[\frac{1}{2}+\frac{1}{\pi} \sin ^{-1}\left(\frac{\tau_{1}-t}{\tau_{1}+t}\right)\right] ; & 0 \leqq t \leqq t_{2} \\
+\frac{i}{n \cong A D} & ; t_{2} \leqq t\end{cases}
\end{aligned}
$$

The Laplace transform of Equation 2 is

$$
C(x, 0)+s \bar{C}(x, s)=D \frac{\partial^{2} \bar{c}(x, s)}{\partial x^{2}}
$$

where $\mathrm{s}$ is the transform variable. The solution to this equation is obtained using the method of variation of parameters assuming a solution of the form $v(x) \exp \left(-s^{\frac{1}{2}} x / D^{\frac{1}{2}}\right)$. The general solution to the complete equation is

$$
\begin{aligned}
& \bar{C}(x, s)=\beta e^{-s^{\frac{1}{2}} x / D^{\frac{1}{2}}}+\xi e^{s^{\frac{1}{2}} x / D^{\frac{1}{2}}} \\
& -\frac{i}{n \cong A D} \frac{x}{S} \operatorname{erfc}\left(\frac{x}{2 D^{\frac{1}{2}} \tau_{1} \frac{I}{2}}\right)+\frac{2 i \tau_{1}^{\frac{1}{2}}}{n \cong A D^{\frac{1}{2} \pi^{\frac{1}{2}} S}} e^{-x^{2} / 4 D \tau_{1}} \\
& +\frac{1}{2 n \Im A D^{\frac{1}{2}} S^{\frac{3}{2}}} e^{S \tau_{1}}\left[e^{-S^{\frac{1}{2}} x / D^{\frac{1}{2}}} \operatorname{erf}\left(\frac{x}{2 D^{\frac{1}{2}} \tau \tau_{1}^{\frac{1}{2}}}-S^{\frac{1}{2}} \tau_{1}^{\frac{1}{2}}\right)-e^{S^{\frac{1}{2}} x / D^{\frac{1}{2}}} \operatorname{erf}\left(\frac{x}{2 D^{\frac{1}{2}} \tau I^{\frac{1}{2}}}+S^{\frac{1}{2}} \tau_{1}^{\frac{1}{2}}\right)\right]
\end{aligned}
$$


The transformed boundary conditions are

$$
\begin{gathered}
\bar{C}(\infty, s)=0 \\
\frac{n \tilde{I} A D}{i}\left|\frac{\partial \bar{C}(x, s)}{\partial x}\right|_{x=0}=\frac{3}{2 s} e^{-s t_{2}}-\frac{1}{s}+\frac{e^{-s t_{2}}}{s \pi} \sin ^{-1}\left(\frac{\tau_{1}-t_{2}}{\tau_{1}+t_{2}}\right) \\
+\frac{\sqrt{2} t_{2}^{\frac{1}{2}} \tau_{1} \frac{1}{2}}{s} e^{-s t_{2} / 2} \sum_{k=1}^{n} \frac{1}{n} \frac{e^{-s t_{2} x_{k} / 2\left(1-x_{k}\right)^{\frac{1}{2}}}}{\left(2 \tau_{1}+t_{2}+t_{2} x_{k}\right)} \\
x_{1 k}=\cos (\pi(2 k-1) / 2 n)
\end{gathered}
$$

where

The sum in Equation 7o arises from a quadrature approximation (2) of the integral

$$
\int_{0}^{t} \frac{e^{-s t}}{t^{\frac{1}{2}}\left(\tau_{1}+t\right)} d t
$$

which is a form of Smith's integral (3).

$$
\text { Appropriate combination of } 6,7 \mathrm{a} \text {, and } 7 \mathrm{~b} \text { gives the solution in }
$$
transform space evaluated at $\mathrm{x}=0$

$$
\begin{aligned}
& \bar{C}(0, s)=\frac{-i}{n \cong A D^{\frac{1}{2}} s^{\frac{3}{2}}}\left[\left(\frac{3}{2}+\frac{1}{\pi} \sin ^{-1}\left(\frac{\tau_{1}-t_{2}}{\tau_{1}+t_{2}}\right)\right) e^{-s t_{2}}\right. \\
& +\sqrt{2} t_{2}^{\frac{1}{2}} \tau_{1}^{\frac{1}{2}} \sum_{k=1}^{n} \frac{1}{n} \frac{e^{-s t_{2}\left(1+x_{k}\right) / 2}\left(1-x_{k}\right)^{\frac{1}{2}}}{\left(2 \tau_{1}+t_{2}+t_{2} x_{k}\right)} \\
& \left.-e^{S T_{1}} \operatorname{erfc}\left(s^{\frac{1}{2}} \tau_{1}^{\frac{1}{2}}\right)-\frac{2 S^{\frac{1}{2}} \tau_{1}^{\frac{1}{2}}}{\pi^{\frac{1}{2}}}\right]
\end{aligned}
$$


The inverse transform of this expression involves the integral

$$
\int_{0}^{t_{2}} \frac{(t-\alpha)^{\frac{1}{2}} d \alpha}{\left(\alpha+\tau_{1}\right) \alpha^{\frac{1}{2}}}
$$

which ic also evaluated by quadrature approximation (P). Application of the condition $\mathrm{C}\left(0, \mathrm{t}_{2}+\tau_{3}\right)=0$ to the transformed equation gives the final solution

$$
\begin{aligned}
& \left(\frac{T_{3}}{\tau_{1}}\right)^{\frac{\pi}{2}}=\frac{1+\frac{1}{n} \sum_{i=1}^{n} \frac{\left(1-y_{1}\right)}{\left[11 y_{i} \mid \frac{2 \tau_{1}}{t_{2}+\tau_{3}}\right]}-\frac{1}{m} \sum_{j=1}^{m} \frac{\left(1-x_{j}\right)^{\frac{1}{2}}\left(\frac{2 \tau_{3}}{\tau_{2}}+1-x_{j}\right)^{\frac{1}{2}}}{\left[\frac{2 \tau_{1}}{t_{2}}+1+r_{j}\right]}}{\frac{3}{2}+\frac{1}{\pi} \sin ^{-1}\left(\frac{\tau_{1}-t_{2}}{\tau_{1}+t_{2}}\right)} \\
& y_{i}=\cos \frac{\pi}{2}\left(\frac{2 i-1}{n}\right) ; x_{j}=\cos \frac{\pi}{2}\left(\frac{2 j-1}{m}\right)
\end{aligned}
$$

The choice $n=m=5$ gives sufficient accuracy for calculation. No algebraic simplification is gained by choosing $\mathrm{n}=\mathrm{m}$ and combining the two sums.

As $t_{2}$ approaches infinity the two sums in the numerator of the right hand side of Equation 12 approach each other and the denominator approaches unity. Therefore

$$
\lim _{t_{2} \rightarrow \infty}\left(T_{3} / \tau_{1}\right)=1
$$

This simply means that an infinite amount of $R_{1}$ would be generated during time $t_{2}$, a trivial limiting case. 
If $t_{2}$ is small, Equation 12 can be approximated by

$$
2\left(\frac{\tau_{3}}{\tau_{1}}\right)^{\frac{1}{2}}=1+\frac{1}{n} \sum_{ \pm=1}^{n} \frac{\left(1-y_{1}\right)}{\left.\mid \frac{2 \tau_{1}}{\tau_{3}}+1+y_{1}\right)}
$$

If we let $\tau_{3} / \tau_{1}=1 / 3$ in the right hand side of Equation 15 we can easily calculate the value of $\tau_{3} / \tau_{1}$ using

$$
2\left(\frac{\tau_{3}}{\tau_{1}}\right)^{\frac{1}{2}}=1+\frac{1}{n} \sum_{1=1}^{n} \frac{\left(1-y_{1}\right)}{\left(7+y_{1}\right)}
$$

From Equation 16 for $n \geqq 2$ we obtain $T_{3} / \tau_{1}=0.333$, the value preaicted by the simple theory for the case of reversal before the trancition time. 
1. G. Mamantov and P. Delahay, J. Am. Chem. Soc., 76, 5323 (1954).

2. R. W. Murray anā S. N. Reilley, J. ElectroanaI. Chem., 3, 182 (1962).

3. J. N. Foster, Thesis, C.I.T., 1965.

4. D. J. Gross, Thesis, University of North Carolina, 1965.

\section{APPENDIX II}

1. P. Delahay, New Instrumental Methods in Electrochemistry, Interscience Publishers, Inc., New York, 1954, Chapter 4.

2. Tables of Integral Transforms, Vol. 1. Bateman Manuscript Project, A. Erdélyi, Ed. McGraw-Hill Book Co., Inc., New York, 1954.

APPENDIX III

1. P. Delahay, New Instrumental Methods in Electrochemistry, Interscience Punilshers, Tnc., New York, 1954, Chapter 8.

2. National Bureau of Standards Applied Mathematics Serles 55. Superintendent of Documents, U.S. Government Printing Office, Washington, D.C., 20402, Section 25.4.38.

3. R. C. T. Smith, Australian J. Ihys., 6, 127 (1953). 